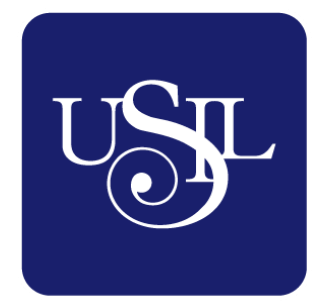

UNIVERSIDAD

SAN IGNACIO

DE LOYOLA

ESCUELA DE POSTGRADO

Maestría en Educación con mención en Docencia en Educación Superior

\title{
ESTRATEGIA METODOLÓGICA PARA MEJORAR LA AUTOPERCEPCIÓN DE LOS ESTUDIANTES EN LA FACULTAD DE PSICOLOGÍA DE UNA UNIVERSIDAD PRIVADA DE LIMA
}

Tesis para optar el grado de Maestro en Educación con mención en Docencia en Educación Superior

LEONARDO PERCY HUERTAS MANTILLA

\section{Asesor:}

Félix Fernando Goñi Cruz

Lima - Perú 



\section{Dedicatoria}

Dedico con afecto este trabajo a la Universidad Ricardo Palma por abrirme las puertas y permitirme recopilar la información requerida, así como al esmero que la Universidad San Ignacio de Loyola viene realizando por brindar todas las facilidades, como las asesorías sostenidas, para obtener con éxito el grado académico.

Finalmente, a Dios y a mis familiares por su aliento y apoyo. 


\section{Agradecimiento}

Agradecer con un sentimiento del ser a todo aquello que hizo posible la elaboración de la presente investigación, con la debida reciprocidad generada por el arduo trabajo de un colectivo, resumido y sistematizado a un conjunto de datos plasmados en este texto científico.

Así empiezo agradeciendo a la Dra. Montero por brindarme la facilidad de llegar a sus estudiantes para la muestra y aceptar desarrollar la entrevista, a la Dra. María del Carmen Espinoza y al Dr. Reyes Carlos; por colaborar con la entrevista de la autopercepción y la autorregulación y a todos los participantes que conformaron de manera voluntaria la muestra del presente estudio y a quienes influyeron e hicieron posible el presente trabajo.

En esta misma senda, agradezco a Dios por permitir las circunstancias necesarias para la culminación de este proyecto, así como a mis seres queridos por creer en la consecución de este estudio y apoyo brindado. 


\section{Índice}

Dedicatoria

Agradecimiento

Índice

Índice de tablas

Índice de figuras

Introducción 1

Planteamiento del problema de la investigación $\quad 2$

Formulación del problema 3

Objetivos de investigación $\quad 4$

Categorías y subcategorías apriorísticas $\quad 4$

$\begin{array}{ll}\text { Justificación de la investigación } & 7\end{array}$

Metodología de la investigación $\quad 8$

Tipo y diseño de investigación 9

Población, muestra, muestreo: unidad de análisis 9

$\begin{array}{ll}\text { Métodos de investigación } & 10\end{array}$

Técnicas e instrumentos para el trabajo de campo 12

$\begin{array}{ll}\text { Marco teórico } & 14\end{array}$

Un acercamiento a las teorías que sustentan la autopercepción 17

Fundamento teóricos de la estrategia metodológica 22

$\begin{array}{ll}\text { Trabajo de campo } & 31\end{array}$

$\begin{array}{ll}\text { Características del campo de estudio } & 31\end{array}$

Análisis, interpretación y discusión de los hallazgos por técnicas e instrumentos 31

Análisis, interpretación, triangulación y discusión de las categorías emergentes $\quad 36$

Categorías influyentes en el problema 42

Conclusiones aproximativas de los análisis realizados $\quad 43$

Modelación y validación de la propuesta $\quad 44$

$\begin{array}{ll}\text { Propósito de la investigación } & 44\end{array}$

Fundamentación teórica y científica $\quad 44$

Diseño gráfico funcional de la propuesta 53

Implementación de la propuesta $\quad 55$

$\begin{array}{ll}\text { Validación de la propuesta } & 65\end{array}$

Conclusiones aproximativas de los análisis y resultados de la propuesta y su validación teórica/práctica $\quad 68$

$\begin{array}{ll}\text { Conclusiones } & 69\end{array}$ 
Recomendaciones

Referencias

72

Anexos 


\section{Índice de tablas}

Tabla 1. Resultados de la validación de instrumentos por juicio de expertos

Tabla 2. Organización de contenidos y actividades del diseño de la estrategia metodológica

Tabla 3. Especialistas de la validación

Tabla 4. Validez interna por juicio de expertos

Tabla 5. Validez externa por juicio de expertos.

Tabla 6. Escala de Valoración.

Tabla 7. Valoración interna y externa por criterio de jueces 


\section{Índice de figuras}

Figura 1. Presentación de las categorías apriorísticas y las emergentes.

Figura 2. Modelado iconográfico de la estrategia metodológica. 


\section{Resumen}

La investigación consistió en diseñar una estrategia metodológica para mejorar la autopercepción de los estudiantes de octavo semestre de psicología en una universidad privada de Lima. La metodología de estudio fue cualitativa con paradigma socio crítico e interpretativo, mientras que el tipo es aplicada educacional, cuyo diseño fue no experimental de corte transversal descriptivo. La muestra estuvo conformada por 28 estudiantes de ambos sexos y con una edad que oscila desde los 20 a 25 años pertenecientes a la asignatura de Diagnóstico Psicológico y tres docentes que laboran por más de 15 años. El muestreo fue de tipo no probabilístico e intencional. Las técnicas empleadas fueron la observación, la encuesta y la entrevista con sus respectivos instrumentos de guía de observación, cuestionario de encuesta y guía de entrevista. En el marco teórico, se recurrió a las teorías de William James, la Vygotskiana, el enfoque fenomenológico, el cognitivista, el interaccionismo simbólico, el sociocognitivista, el constructivista, el operante y el volitivo. Los resultados principales del trabajo de campo fueron dificultad para discernir entre las identificaciones personales y académicas, enorme cantidad de alumnos por clase para poder realizar una retroalimentación individual de los juicios valorativos y empleo por conveniencia de las relaciones interpersonales. Las conclusiones fueron que se sistematizaron las teorías, los modelos y los enfoques de las categorías apriorísticas, se diseñó la estrategia metodológica, se validó la propuesta con la escala de valoración de muy bueno mediante la validación de tres especialistas por criterio de jueces.

Palabras claves: Estrategia metodológica, Autopercepción y Autorregulación. 


\begin{abstract}
The present investigation consisted of designing a methodological strategy to improve the self-perception of the students of the eighth semester of psychology in a private university of Lima. The study methodology was qualitative with a socio-critical and interpretive paradigm, while the type is applied educational, whose design was non-experimental of descriptive cross-section. The sample consisted of 28 students of both sexes and with an age ranging from 20 to 25 years belonging to the Psychological Diagnosis subject and three teachers who work for more than 15 years. The sampling was non-probabilistic and intentional. The techniques used were observation, survey and interview with their respective instruments of observation guide, survey questionnaire and interview guide. In the theoretical framework, the theories of William James, the Vygotsky, the phenomenological approach, the cognitivist, the symbolic interactionism, the sociocognitivist, the constructivist, the operant and the volitional were used. The main results of the field work were difficulty in discerning between the personal and academic identifications, huge number of students per class to be able to make an individual feedback of the judgments and employment for the convenience of interpersonal relationships. The conclusions were that theories, models and approaches of the aprioristic categories were systematized, the methodological strategy was designed, the proposal was validated with the rating scale of very good through the validation of three specialists by judge criteria.
\end{abstract}

Key terms: Methodological strategy, Self-perception and Self-regulation. 


\section{Introducción}

La presente investigación sobre educación superior abordó una estrategia metodológica en aras de la autopercepción en estudiantes de octavo semestre de psicología de una universidad privada de Lima en el proceso de enseñanza-aprendizaje. Resaltando el componente práctico operativo de la estrategia metodológica a través de su fundamento teórico con la autorregulación, entendiéndola como una dimensión empírica y concreta del ser, mientras que la autopercepción se la entiende como una captación abstracta y teórica.

Respecto a la metodología, el enfoque de investigación fue el cualitativo y cuantitativo de tipo aplicado educacional con diseño no experimental transversal y descriptivo, cuyo paradigma fue el socio crítico e interpretativo. Dentro de los métodos teóricos utilizados, están el histórico-lógico, el análisis-síntesis, la inducción y deducción, de lo abstracto a lo concreto, la modelación, y de los métodos empíricos, están la observación pedagógica, el de encuesta, el de entrevista, los estadísticos descriptivos, la codificación y la categorización. Y de estos, se utilizaron las técnicas de observación, de encuesta y de entrevista, con sus debidos instrumentos como la guía de observación, el cuestionario de encuesta y la guía de entrevista semiestructurada.

En el marco teórico, se presentó la relación dialéctica entre la autopercepción y la estrategia metodológica, cuya fundamentación se basó en la autorregulación, sustentándola en la información recopilada de los estudiantes de octavo semestre de psicología y de los docentes de octavo semestre de psicología, además de un rico cuerpo teórico de diversos enfoques que aportaron significativamente a ambas categorías, como la teoría de William James, la Vygotskiana, el enfoque fenomenológico, el cognitivista, el interaccionismo simbólico, el sociocognitivista, el constructivista, el operante y el volitivo. Asimismo, de la teoría recopilada se desprendieron las subcategorías; las de la autopercepción son: el sí mismo material, el sí mismo personal, el sí mismo adaptativo, el sí mismo social y el sí mismo-no sí mismo, mientras que las de la estrategia metodológica son: estrategia de planificación, estrategia de ejecución y estrategia de autorreflexión.

Referido al trabajo de campo, se describió el proceso de recopilación de datos a través de las técnicas de observación, encuesta y entrevista con sus respectivos instrumentos; guía de observación, cuestionario de encuesta y guía de entrevista. De estos, se analizaron, interpretaron y discutieron los hallazgos según los resultados de la entrevista a docentes, análisis de la observación a clase de docentes y resultados de la encuesta aplicada a los estudiantes, además de la triangulación de las categorías emergentes, obteniéndose de este proceso las categorías emergentes e influyentes en el problema de estudio, las cuales fueron los juicios valorativos del ser de los estudiantes, las relaciones interpersonales del ser de los estudiantes y las identificaciones del ser de los estudiantes. Cada una con sus problemáticas respectivamente; falta de tiempo para realizar una 
retroalimentación individualizada de los juicios valorativos de los educandos sobre sí mismos y la materia mediada en sesión, vínculos interpersonales con tendencia a la práctica de conductas inmorales, como el plagio colaborativo e identificaciones personales no diferenciadas con las académicas.

Por otro lado, en la modelación y validación de la propuesta, se presentaron el propósito de la investigación, la justificación, el esquema teórico funcional, la descripción de la propuesta con sus fundamentaciones socioeducativa, pedagógica, psicológica y curricular, aparte de la implementación de la propuesta con su organización de las actividades. Luego, se tiene la validación de la propuesta bajo la óptica de tres especialistas a través del juicio de expertos, quienes validaron mediante una ficha de valoración interna y externa de 10 criterios, obteniendo una valoración escalar de muy buena.

Finalmente, se dan cinco conclusiones en base a la formulación del problema con las preguntas científicas y sus respectivas cinco recomendaciones.

\section{Planteamiento del problema de la investigación}

La autopercepción es uno de los fenómenos psicológicos de mayor impacto en la personalidad, y por extensión, en el ámbito académico. Pues al respecto, González \& Tourón (1992), refirieron que su importancia radica en el hecho de su influencia en la autorregulación del aprendizaje, por ende, del rendimiento académico. Así, se aprecia la relación que hay entre la autopercepción y el campo de la educación. Premisa que González-Pienda, Nuñez, González-Pumariega \& García (1997); Núñez y GonzálezPumariega (1996); Nuñez et al (1998), reafirmaron al postular que el ser, núcleo de la autopercepción, destaca un papel central en el aprendizaje autorregulado. De esto, se señala como la autopercepción presenta una conexión simbiótica con la autorregulación en el proceso de enseñanza aprendizaje.

El ser es uno de los cuatro pilares de la educación, según el informe de la Organización de las Naciones Unidas para la Educación, la Ciencia y la Cultura de la comisión internacional sobre la educación para el siglo XXI, presidida por Jacques Delors en 1996, quien alegó que, en el campo de la educación, aprender a ser contribuye al desarrollo global de cada persona.

El desarrollo del ser humano, que va del nacimiento al fin de la vida, es un proceso dialéctico que comienza por el conocimiento de sí mismo y se abre después de las relaciones con los demás. En este sentido, la educación es ante todo un viaje interior, cuyas etapas corresponden a las de la maduración constante de la personalidad (Delors, 1996, p. 106). 
Asimismo, Delors concluyó que un proceso fundamental de los cuatro pilares de la educación es el aprender a ser ya que recoge elementos del aprender a conocer, aprender a hacer y aprender a vivir juntos, en suma, el ser es el tetrasustentador de los cuatro pilares.

Habiendo revisado grosso modo el contexto de la autopercepción, autorregulación y su simbiosis en el proceso enseñanza aprendizaje, el Informe de la Comisión Internacional para el Desarrollo de la Educación, presidido por Paredes (1972), arguyó qué podría pasar si es que no desarrollamos el aprender a ser, cuya esencia es el ser,

Es por tanto preciso que este pueda resistir el riesgo de alienación de su personalidad, que va implícito en las formas obsesivas de la propaganda y de la publicidad, en el conformismo de los comportamientos que pueden serle impuestos desde el exterior, en detrimento de sus necesidades auténticas y de su identidad intelectual y afectiva (p. 31).

Es por esto la importancia de desarrollar el ser, cuya experiencia desembocará en la autopercepción del sujeto en sus diferentes facetas como la individual, social y material, básicamente. Más aún en estudiantes de octavo semestre de psicología, quienes atraviesan el puente entre sus estudios de pregrado con el preprofesional, por tanto, su objeto laboral consistirá en la interacción dinámica con diversos seres en su cotidianeidad laboral a lo largo de sus vidas. Finalmente, Delors (1996), refirió lo que pasaría si es que se cultiva el aprender a ser, "para que florezca mejor la propia personalidad y se esté en condiciones de obrar con creciente capacidad de autonomía, de juicio y de responsabilidad personal" ( $p$. 107).

Frente a la problemática descrita en párrafos anteriores, es de interés proponer una estrategia metodológica basada en la autorregulación que intente mejorar la autopercepción de los estudiantes de octavo semestre en una facultad de psicología.

\section{Formulación del problema}

¿Cómo mejorar la autopercepción de los estudiantes de la asignatura de Diagnóstico Psicológico de octavo semestre de psicología en una universidad privada de Lima?

\section{Preguntas científicas.}

¿Cuál es el estado actual de la autopercepción de los estudiantes de la asignatura de Diagnóstico Psicológico de octavo semestre de psicología?

¿Cuáles son los fundamentos de la estrategia metodológica para la mejora de la autopercepción de los estudiantes de la asignatura de Diagnóstico Psicológico de octavo semestre de psicología? 
¿Qué criterios teóricos y metodológicos se debe tener en cuenta en la modelación de la estrategia metodológica para la mejora de la autopercepción de los estudiantes de la asignatura de Diagnóstico Psicológico de octavo semestre de psicología?

¿Cómo validar la estrategia metodológica para mejorar la autopercepción de los estudiantes de la asignatura de Diagnóstico Psicológico de octavo semestre de psicología?

\section{Objetivos de investigación \\ Objetivo principal.}

Modelar una estrategia metodológica para mejorar la autopercepción de los estudiantes de la asignatura de Diagnóstico Psicológico de octavo semestre de psicología en una universidad privada de Lima.

\section{Objetivos específicos o tareas de investigación.}

Para dar respuesta a los problemas específicos se formula los siguientes objetivos:

Diagnosticar el estado actual de la autopercepción de los estudiantes de la asignatura de Diagnóstico Psicológico de octavo semestre de psicología.

Fundamentar teóricamente la estrategia metodológica para la mejora de la autopercepción de los estudiantes de la asignatura de Diagnóstico Psicológico de octavo semestre de psicología.

Determinar los criterios teóricos y metodológicos a tener en cuenta en la modelación de la estrategia metodológica para la mejora de la autopercepción de los estudiantes de la asignatura de Diagnóstico Psicológico de octavo semestre de psicología.

Validar la estrategia metodológica a través del juicio de expertos para su factibilidad e implementación de su uso para mejorar la autopercepción de los estudiantes de la asignatura de Diagnóstico Psicológico de octavo semestre de psicología.

\section{Categorías y subcategorías apriorísticas \\ Autopercepción.}

La autopercepción se entiende según Sendín (2007), como un conjunto de constructos, valoraciones y actitudes hacia sí mismo en las áreas material, personal, adaptativa, social e identificativa con el otro que cada individuo ha ido construyendo sobre su ser para conseguir un autoconocimiento de sí de acuerdo a la realidad.

En la definición de Sendín, se puede apreciar el componente cognitivo de la autopercepción al mencionar el conjunto de constructos, también el componente afectivo al postular valorativos, además del componente motor al mencionar actitudes. Por esto, la definición de Sendín es una de las más completas respecto a la categoría de la autopercepción ya que incluye todos los componentes de la psique humana. 


\section{Subcategorías.}

Sí mismo material.

Dimensión que hace referencia a todos aquellos enunciados en los cuales el educando identifica su cuerpo y posesiones (L'Ecuyer, 1985). De esta se desprenden dos indicadores:

El sí mismo somático; son todos aquellos enunciados en los cuales el educando identifica su cuerpo como suyo (L'Ecuyer, 1985).

El sí mismo posesivo; son todos aquellos enunciados en los cuales el educando identifica a los objetos y personas como suyos (L'Ecuyer, 1985).

\section{Sí mismo personal.}

Dimensión que alude a todas aquellas formulaciones que hace el educando de sus características psíquicas (L'Ecuyer, 1985). De igual modo, se divide en dos indicadores:

La imagen de sí mismo; son todas aquellas descripciones que el educando hace de su experiencia de sí mismo (L'Ecuyer, 1985).

La identidad de sí mismo; son todas aquellas elaboraciones en las cuales el educando proyecta consciencia de su existir y ser (L’Ecuyer, 1985).

\section{Sí mismo adaptativo.}

Dimensión que engloba todas aquellas reacciones por parte del educando como producto de sus percepciones (L'Ecuyer, 1985). De la misma manera, de esta emergen dos indicadores:

El valor de sí mismo; son todos aquellos juicios negativos o positivos del educando hacia sí mismo (L’Ecuyer, 1985).

Las actividades del sí mismo; son todas aquellas acciones y reacciones por parte del educando frente a las percepciones de sí mismo ante la realidad (L’Ecuyer, 1985).

\section{Sí mismo social.}

Dimensión que indica todas aquellas interacciones entre el sí mismo del educando con los otros (L'Ecuyer, 1985). Siguiendo la misma senda, también se derivan dos indicadores:

Las preocupaciones y actitudes sociales; alude a todas aquellas participaciones del educando en actividades junto a los otros (L'Ecuyer, 1985).

La referencia al sexo; implica todos aquellos enunciados por parte del educando que integran el componente sexual (L'Ecuyer, 1985).

\section{Sí mismo-No sí mismo.}

Dimensión en la cual el educando se identifica por contraste interpersonal (L'Ecuyer, 1985). En el mismo curso, de esta emergen dos indicadores: 
La referencia al prójimo; enmarca todos aquellos enunciados en los cuales el educando no se proyecta a sí mismo, si no que a los otros (L'Ecuyer, 1985).

La opinión del prójimo sobre sí mismo; encierra aquellos enunciados en los cuales el educando alude a sí mismo por medio de los juicios de otros (L’Ecuyer, 1985).

\section{Estrategia metodológica.}

Este conjunto de estrategias y técnicas didácticas son mediadas a través de actividades y recursos de enseñanza - aprendizaje sustentadas teóricamente en base a la autorregulación, cuya definición es dada por Zimmerman (2000), como un proceso formado por pensamientos, emociones y acciones autogeneradas que están organizadas en fases de planificación, ejecución y autorreflexión para alcanzar las metas propuestas. Este postulado es completo en lo que refiere a estrategia metodológica para el ser, ya que incluye el componente cognitivo al mencionar pensamientos autogenerados, el componente afectivo al mencionar emociones y al componente motor al mencionar acciones de los educandos en el proceso de enseñanza aprendizaje para una autopercepción integral y real.

\section{Subcategorías.}

Fase de planificación.

Fase inicial en la cual el educando se enfrenta a la tarea analizándola, valorando su capacidad para realizarla con éxito, estableciendo metas y planificándolas (Panadero \& Alonso-Tapia, 2014a). En esta etapa emergen dos subfases:

Análisis de la tarea; el educando analiza la tarea en fragmentos más pequeños y donde, a partir del conocimiento previo, se establece una estrategia personal para su ejecución (Panadero \& Alonso-Tapia, 2014a).

Creencias automotivadoras; estas están compuestas por la interacción de las metas, intereses, valores y creencias personales del educando que inician y mantienen el nivel y tipo de motivación para la ejecución de una actividad (Panadero \& Alonso-Tapia, 2014a).

\section{Fase de ejecución.}

Fase intermedia en la cual el educando desempeña la actividad en sí (Panadero \& AlonsoTapia, 2014a). E igual a la anterior, se desprenden dos subfases:

Autoobservación; el educando controla el desarrollo de la actividad con el objetivo de modular la calidad de lo que está ejecutando para hacerlo bien, o de no ser así, cambiar su comportamiento (Panadero \& Alonso-Tapia, 2014a).

Autocontrol; el educando mantiene el interés y la concentración apoyándose del uso de estrategias personales durante la actividad (Panadero \& Alonso-Tapia, 2014a). 
Fase de autorreflexión.

Fase final cuya característica es que el educando valore su desempeño y trate de explicarse el porqué de sus resultados conseguidos (Panadero \& Alonso-Tapia, 2014a). También aquí emergen dos subfases:

Autojuicio; el educando realiza un proceso de juzgamiento de su desempeño realizado a través de las atribuciones causales y autoevaluación (Panadero \& Alonso-Tapia, 2014a).

Autorreacción; el educando atribuye fracaso o éxito a las causas de su desempeño, generando esto emociones negativas o positivas y expectativas respecto a su actividad futura (Panadero \& Alonso-Tapia, 2014a).

\section{Justificación de la investigación}

\section{Teórica.}

La justificación teórica se sustentó en el hecho de que enriquecerá el campo teórico del ser desde la relación dialéctica entre la estrategia metodológica basada en la autorregulación y la autopercepción en aras del proceso de enseñanza-aprendizaje. Esto debido a que los antecedentes teóricos que incluyen ambas categorías son escasos. Por esto, el presente trabajo comprobó cómo diferentes categorías de un mismo fenómeno, el ser, son factibles para mejorar una realidad educativa desde sus dos vertientes antagónicas; la autopercepción y la autorregulación. Para esto, las categorías aprioristas se fundamentaron desde los aportes de James (1890), González y Tourón (1992), Cooley (1902), Mead (1934), Combs, (1981), Rogers (1973), Epstein (1973), Bandura (1977), Panadero y AlonsoTapia (2014), Maslow (1943), Zimmerman (2001) y Piaget (1952), quienes coincidieron en que no hay autopercepción sin autorregulación y viceversa en el proceso de enseñanzaaprendizaje.

\section{Metodológica.}

La justificación metodológica deviene de la propuesta de estrategia metodológica a la práctica psicopedagógica en los alumnos de octavo semestre de psicología para enriquecer el repertorio de autopercepciones que, mediado por docentes capacitados, tendrá como bondad un reforzamiento en el área del saber ser. Además, esta se sostuvo en el valor de los métodos teóricos empleados; el histórico-lógico, análisis-síntesis, inducción y deducción, de lo abstracto a lo concreto, de modelación y matemáticos y estadísticos. También, se sustenta en las técnicas de observación, encuesta y entrevista con sus respectivos instrumentos como la guía de observación, guía de entrevista y cuestionario de encuesta. 


\section{Práctica.}

La justificación pragmática se fundamentó en que los estudiantes enriquecerán su modus operandi de autorregularse una vez constatada a través de la experiencia de su autopercepción tal como se encuentra, sin modificar, distorsionar ni negar lo que hallen en sí mismos, por el contrario, con aceptación incondicional para la mejora continua de sus autopercepciones. Además, de que este producto de estrategia metodológica se convierte en una herramienta psicopedagógica para el docente para que pueda incrementar las competencias del ser en sus educandos.

\section{Metodología de la investigación}

La presente investigación se enmarcó dentro del paradigma socio crítico, porque de acuerdo con Schuster, Puente, Andrada y Maiza (2013), le agrega la autorreflexión crítica a los procesos del conocimiento, con el objetivo de mejorar la estructura de las relaciones interpersonales describiéndolas y comprendiéndolas, en comparación al interpretativo, ya que según Hernández, Fernández y Baptista (2014), esta última "se centra en el entendimiento del significado de las acciones de los seres vivos, sobre todo de los humanos y sus instituciones, buscando interpretar lo que van captando activamente" (p. 9). Asimismo, es naturalista, ya que "estudia los fenómenos y seres vivos en sus contextos o ambientes naturales y en su cotidianidad" (Hernández, Fernández y Baptista, 2014, p. 9).

Luego, presenta un enfoque cualitativo que en palabras de Hernández, Fernández y Baptista (2014), significa que "se enfoca en comprender los fenómenos, explorándolos desde la perspectiva de los participantes en un ambiente natural y en relación con su contexto" (p. 358). Por esto, se seleccionó este enfoque ya que examina la autorregulación de los estudiantes en su autopercepción por lo general al tener contacto experiencial con su ser.

\section{La investigación cualitativa en el contexto educativo.}

Aplicando el entender de Restrepo (2002), respecto a la investigación en educación, se comprende que la aborda con el objetivo de aclarar su objeto, así deslinda dos concepciones específicas; investigación sobre educación e investigación educativa, de las cuales la primera se relaciona con este estudio, por provenir de una ciencia afín a la pedagogía con el objetivo de enriquecer la investigación aplicada educacional. Entonces, se entiende que las categorías de estrategia metodológica basada en la autorregulación en aras de la autopercepción, provienen de la investigación psicológica aplicada al contexto de educación superior.

Asimismo, Mosteiro y Porto (2017), aluden a la investigación educativa como el conjunto de métodos, en este caso el cualitativo, procedimientos, como el aplicado 
educacional y técnicas, como las de observación, encuesta y entrevista, utilizadas para conseguir una comprensión científica de los fenómenos educativos, además de solucionar las problemáticas educativas, como lo es la elaboración de una estrategia metodológica para mejorar la autopercepción de estudiantes de octavo semestre de psicología.

Por esto, en el marco del origen y evolución de la investigación en educación, esta se inició en un ámbito experimental junto a corrientes pragmatistas, positivistas y afines, para devenirse en un ámbito de educación superior con metodología cualitativa de tipo aplicado.

\section{Tipo y diseño de investigación}

El tipo de investigación fue aplicada educacional porque,

Son experiencias de investigación con propósitos de resolver o mejorar una situación específica o particular para comprobar un método o modelo mediante la aplicación innovadora y creativa de una propuesta de intervención, en este caso de índole orientadora en un grupo, persona, institución o empresa que lo requiera (Vargas, 2009, p. 162).

Esta propuesta de Vargas (2009), se adaptó ya que se utilizó una estrategia metodológica para mejorar la autopercepción de estudiantes de octavo semestre de psicología, apreciándose así el carácter aplicativo de una estrategia para mejorar una situación específica en un grupo de personas en el proceso de enseñanza aprendizaje.

Asimismo, el diseño que se acomodó según Hernández, Fernández y Baptista (2014), fue el diseño transversal descriptivo, porque se indagó la incidencia de las categorías estrategia metodológica y autopercepción en los estudiantes con el objetivo de describirlas.

\section{Población, muestra, muestreo: unidad de análisis}

\section{Población.}

La población es entendida por Lepkowski (2008), como el total de casos que guardan relación por una serie de especificaciones. De esta forma, la población estuvo compuesta por todos los estudiantes de la asignatura de Diagnóstico Psicológico de octavo semestre de psicología y por todos los docentes que enseñan en octavo semestre de la URP. La cantidad de la población de estudiantes fue de 35, mientras que el de profesores fue de seis.

\section{Muestra y muestreo.}

La muestra es "un subgrupo de la población de interés sobre el cual se recolectarán datos, y que tiene que definirse y delimitarse de antemano con precisión, además de que debe ser 
representativo de la población" (Hernández, Fernández \& Baptista, 2014, p. 173). De acuerdo a este aporte, la muestra estuvo estimada en 28 estudiantes de ambos sexos y con una edad que oscila desde los 20 a 25 años pertenecientes a la asignatura de Diagnóstico Psicológico y tres docentes que laboran por más de 15 años en dicha institución.

La selección fue a través del tipo de muestreo no probabilístico, porque no se conoce la probabilidad de cada uno de los elementos de la población de poder ser seleccionado, e intencional, debido a que el investigador buscó que la muestra sea representativa de acuerdo a una intención particular de quien selecciona la muestra, por lo tanto, la evaluación de la representatividad es subjetiva (Sánchez y Reyes, 2015).

\section{Unidad de análisis.}

Esta incluye a los estudiantes y docentes de octavo semestre y la bibliografía especializada.

\section{Métodos de investigación}

Métodos teóricos.

Método histórico-lógico.

De acuerdo con Sánchez \& Reyes (2015), el método histórico es el "conocimiento de las distintas etapas de los objetos en su sucesión cronológica, para conocer la evolución y desarrollo del objeto o fenómeno de investigación se hace necesario revelar su historia" ( $p$. 59). Por tanto, se empleó este método con el fin de recolectar sistemáticamente los antecedentes históricos de las categorías de autopercepción y estrategia metodológica basada en la autorregulación en el proceso de enseñanza-aprendizaje desde fuentes primarias y científicas, comprendiéndose a través del análisis histórico, las relaciones de las categorías de estudio en su proceso evolutivo en el contexto universitario.

\section{Método de análisis-síntesis.}

Este método de carácter dialéctico es entendido por Cerezal \& Fiallo (2002), en el contexto de las categorías de autopercepción y estrategia metodológica basada en la autorregulación, desde el método de análisis como los factores por separado de cada categoría, su descomposición e influencia en las experiencias de los estudiantes, mientras que, desde el método de síntesis, como el descubrimiento de la integración de sus relaciones e interrelaciones entre las subcategorías e indicadores. La manifestación de este método se apreció en el proceso que se situó a la hora de sistematizar los documentos y los hallazgos del trabajo de campo en el momento de extraer las categorías emergentes. 


\section{Método de inducción y deducción.}

El método inductivo en palabras de Sánchez \& Reyes (2015), "parte de planteamientos derivados de la experiencia concreta de casos particulares sobre los cuales se elabora un juicio particular y se eleva a conocimientos generales" (p. 58). Mientras que, en el método deductivo, Sánchez \& Reyes (2015), afirmaron que "es una demostración o inferencia de una aseveración particular, singular (consecuencia), a partir de una o varias aseveraciones generales, universales (premisas) aplicando a leyes de la lógica" (p. 58). Adaptando este método, se establecieron las inferencias y deducciones lógicas en la sistematización de las categorías, subcategorías e indicadores del marco teórico apriorístico y emergente, del proceso de triangulación y el cuerpo metodológico.

\section{Método de lo abstracto a lo concreto.}

Cerezal \& Fiallo (2002), argumentaron que la primera etapa de conocimiento autoperceptivo relacionado a la estrategia metodológica basada en la autorregulación es el concreto y sensible, etapa que los estudiantes ya tienen incorporado gracias al ensayo y error de su desarrollo psicoevolutivo, y que por este han venido representándolo en conocimiento abstracto de sí mismos a través de los procesos lógicos racionales del pensamiento. De esta forma, lo concreto que se recopiló del trabajo de campo se abstrae en un modelo de estrategia metodológica en aras de la autopercepción.

\section{Método de modelación.}

Sánchez \& Reyes (2015), definieron el método de la modelación como la creación de "estructuras abstractas con vistas a explicar la realidad. Aquí el modelo es sustituto del objeto real de investigación" (p. 60). Conforme a esto, el presente estudio sustituyó los datos de la autopercepción de los estudiantes de psicología arrojados por el trabajo de campo para proveer un modelo plasmado en una estrategia metodológica basada en la autorregulación.

\section{Métodos empíricos.}

Los criterios de los métodos empíricos que se aplicaron de acuerdo con Cerezal \& Fiallo (2002), son el de observación pedagógica, entendida como método que los maestros utilizan para observar empírica e intuitivamente fenómenos educativos, como la autopercepción y autorregulación de la estrategia metodológica de los estudiantes en el proceso de enseñanza-aprendizaje según los indicadores de la guía de observación.

El de encuesta que según Cerezal \& Fiallo (2002), la definieron como la aplicación de un cuestionario cuyo fin es conocer las valoraciones y opiniones de algún fenómeno educativo, como lo fue el cuestionario de encuesta dirigido a los estudiantes de octavo 
semestre de psicología para recopilar información sobre la autopercepción y la autorregulación de la estrategia metodológica en el proceso de enseñanza-aprendizaje.

Igualmente, el de entrevista que conforme a Cerezal \& Fiallo (2002), la identificaron como "un método complementario de nivel empírico que consiste en una conversación profesional de carácter planificado entre el entrevistador y el o los entrevistados" (p. 109). La cual se aplicó en una conversación profesional semiestructurada con los maestros de octavo semestre de psicología respecto a las categorías de estudio.

\section{Métodos matemáticos y estadísticos.}

Dentro de los métodos matemáticos y estadísticos que arribaron al presente estudio, están los estadísticos descriptivos que según Cerezal \& Fiallo (2002), son "la media, moda y mediana como medidas de tendencia central" (p. 149), ya que permitieron conocer la agrupación de los datos que tomaron en lo concerniente a un valor situado en el medio, promedio y centro. Asimismo, estos métodos se aplicaron a través del programa SPSS en su versión número 25.

Por otro lado, también se utilizaron la codificación que según Cerezal \& Fiallo (2002), es la atribución de un símbolo o número a cada una de las respuestas recopiladas de las categorías de autopercepción y estrategia metodológica basada en la autorregulación, y la categorización de las preguntas abiertas que consiste en agrupar las respuestas de los estudiantes y maestros en tendencias, aspectos negativos o positivos, etc., estos métodos últimos fueron procesados en el programa Atlas. Ti.

\section{Técnicas e instrumentos para el trabajo de campo}

Las técnicas, conforme con Valderrama (2013), son procedimientos cuyo seguir sistemático se da con la intención de aproximarse a los hechos per se y poder acceder a lo que estos contienen, apoyándose de instrumentos para empaquetar las diversas formas de información.

Las técnicas utilizadas fueron la observación, la encuesta y la entrevista, mediante los instrumentos de guía de observación; cuya realización se dio en base a 16 indicadores a examinar en varias sesiones de clases con el propósito de constatar el estado actual de la autopercepción y autorregulación de la estrategia metodológica de los estudiantes y su influencia con el rol del maestro durante el proceso de enseñanza-aprendizaje. E cuestionario de encuesta; cuya administración fue explícitamente dirigida a los estudiantes a través de 16 reactivos con opciones de respuesta en escala Likert. Y la guía de entrevista; cuya aplicación se dio a tres docentes en el contexto universitario a través de 12 preguntas con opción a profundizar en cada cuestión en caso sea necesario respecto a la manera 
cómo perciben la autopercepción y la autorregulación de la estrategia metodológica en sus educandos.

\section{Validación de los instrumentos.}

Los instrumentos de recolección de datos empleados tuvieron rigor científico por juicio de expertos; dos temáticos y dos metodólogos. A cada experto se le entregó una carpeta cuyo contenido abarcaba la ficha de validación, los instrumentos y la matriz de categoría.

Al plazo de un tiempo, los expertos validaron a través de criterio de jueces; la pertinencia, la relevancia y la construcción gramatical de cada uno de los ítems de cada instrumento; arrojando los siguientes resultados que se muestran en la tabla uno.

Tabla 1.

Resultados de la validación de instrumentos por juicio de expertos

\begin{tabular}{lcccc}
\hline \multirow{2}{*}{ Expertos } & Especialidad & \multicolumn{3}{c}{ Instrumentos } \\
\cline { 3 - 5 } & & $\begin{array}{c}\text { Entrevista a } \\
\text { docentes }\end{array}$ & $\begin{array}{c}\text { Cuestionari } \\
\text { o a } \\
\text { estudiantes }\end{array}$ & $\begin{array}{c}\text { Guía de } \\
\text { observació } \\
\mathrm{n}\end{array}$ \\
\hline Dra. Montero Doig, Ana & Temática & Aplicable & Aplicable & Aplicable \\
Dra. Espinoza Reyes, María & Metodóloga & Aplicable & Aplicable & Aplicable \\
Dr. Montes de Oca, Jesús & Temático & Aplicable & Aplicable & Aplicable \\
Dr. Muñoz Salazar, José & Metodólogo & Aplicable & Aplicable & Aplicable \\
\hline Funyyy
\end{tabular}

Fuente: Elaboración propia (2019)

Como se aprecia, los cuatro expertos concordaron en que los instrumentos son aplicables, no obstante, sugirieron algunas observaciones cuyas correcciones se enmendaron en lo inmediato para su pronta aplicación y procesamiento. 


\section{Capítulo I \\ Marco teórico}

Es menester iniciar esclareciendo algunas de las características que generan confusión, ambigüedad e imprecisión conceptual y terminológica respecto a la autopercepción. Así, este galimatías tiene su reflejo en los diversos términos que aluden a una misma realidad, entre ellos se tienen: autoconcepto, autopercepción, autoestima, concepto de sí mismo, concepto del yo, autoesquema, autoconsistencia, autoimagen, representación de sí, conciencia de sí mismo, autorregulación, autovalía, autodirección, autorreación, autocontrol, autoaceptación, autoeficacia, autoobservación, autoevaluación, autocoaching y todos aquellos constructos que tienen como denominador común al ser (González y Tourón, 1992).

Al respecto, Contreras (2010), mencionó que el término ser tiene una traducción al español que es la más usual y aceptada, esta es autoconcepto. Asimismo, las frecuencias de los términos van a variar de acuerdo al origen de investigación, de esta forma, L'Ecuyer (1985), refirió que los términos autoconcepto y autoestima son los más utilizados en la literatura americana, mientras que conciencia de sí y representación de sí son los más frecuentes en la literatura europea.

De esta manera, se aprecia que los términos dependen del lugar de investigación y que aluden al mismo fenómeno. Sin embargo, para estos fines se refirió al ser con el término de autopercepción. Esto debido a que el presente estudio al ser de corte aplicado educacional, propicia la posibilidad de experimentar un contacto directo con sus sí mismos.

\section{Antecedentes de la investigación \\ Antecedentes internacionales.}

Gonzálvez, Inglés, Vicent, Lagos-San Martín, Sanmartín y García (2016), realizaron un análisis comparativo entre ansiedad escolar y los 11 puntajes de las dimensiones del autoconcepto en una muestra de 1414 estudiantes de educación media en chile con edades que oscilan desde los 13 a 18 años. El enfoque de investigación empleado fue el cuantitativo con diseño descriptivo comparativo. Los instrumentos fueron el Inventario de Ansiedad Escolar y el Self-Description Questionnaire 11-Short Form. Entre los hallazgos, encontraron que los adolescentes con el autoconcepto bajo presentaron resultados estadísticamente significativos más altos en ansiedad escolar a sus coetáneos que arrojaron alto autoconcepto y baja ansiedad escolar.

Penado y Rodicio (2017), investigaron el análisis del autoconcepto en víctimas de violencia de género en 266 adolescentes de edades que oscilan los 14 a 19 años que 
cursaban el bachillerato y secundaria obligatoria. Su enfoque de investigación fue el cuantitativo y empleó el diseño descriptivo correlacional. Sus instrumentos fueron el Cuestionario de autoconcepto AFS y la subescala de violencia sufrida del Conflict in Adolescent Dating Relationships Inventory. Entre sus resultados, se constataron un nivel menor de autoestima entre las víctimas de violencia de género, relación significativa del autoconcepto entre género y edad, además que los participantes con mayor edad, demuestran mayor violencia de género.

Ramos, Rodríguez y Antonio (2017), desarrollaron un análisis entre la relación del bienestar subjetivo y el autoconcepto, en la cual participaron 1250 estudiantes adolescentes de nivel secundario obligatorio por muestreo aleatorio. Utilizaron los instrumentos de Cuestionario de Autoconcepto Dimensional, la Escala de Satisfacción con la Vida y la Escala de Balance Afectivo. El enfoque de investigación fue cuantitativo y el diseño que empleó fue el descriptivo correlacional. Entre sus hallazgos, arrojaron que los estudiantes con autoconcepto alto tienen puntuaciones estadísticamente significativas más altas que sus coetáneos con autoconcepto bajo en la variable de afecto positivo y satisfacción con la vida, mientras que puntuaciones más bajas en afecto negativo. Estos hallazgos son iguales para la muestra en función del nivel educativo y sexo.

Goñi (2009), realizó una tesis cuyo objetivo fue proponer un modelo del autoconcepto personal integrado por las siguientes dimensiones: la percepción de la autorrealización, la percepción de la autonomía propia, el autoconcepto emocional y el autoconcepto moral. La muestra estuvo compuesta por 1135 individuos con una edad que oscila desde los 15 hasta los 65 años. Los instrumentos aplicados fueron el Satisfaction with life scale, Escala de bienestar psicológico y El trait meta mood scale-24 en aras de corroborar la validez de criterio del instrumento que creó, el Cuestionario de Autoconcepto Personal, instrumento que cuenta con confiabilidad de alpha de Cronbach de .834, además de demostrar que el autoconcepto personal varía en función del sexo y la edad, obteniendo los varones mejores resultados en las tres dimensiones a excepción de autoconcepto moral, pero todo esto es hasta la edad de 34 años donde los resultados se invierten.

Morales (2017), realizó un análisis entre las relaciones de habilidades sociales, inteligencia emocional, autoconcepto y estrategias de afrontamiento en una muestra compuesta por 154 estudiantes adolescentes de secundaria obligatoria. Su enfoque de investigación fue cuantitativo y empleó un diseño descriptivo correlacional. Utilizó como instrumentos el Cuestionario sobre habilidades sociales, Escala multidimensional de autoconcepto, Escala de afrontamiento y el Trait Meta-Mood Scale. Entre sus hallazgos encontró que los estudiantes con mayores estrategias de afrontamiento presentan mayor puntuación en habilidades sociales, inteligencia emocional y autoconcepto. 


\section{Antecedentes nacionales.}

Castro (2013), realizó una investigación cuyo objetivo fue describir la relación existente entre claridad del autoconcepto con compromiso vocacional y autoestima con exploración vocacional en una muestra de 182 alumnos de un colegio particular de Lima que cursaban el cuarto y quinto de secundaria con edades que oscilan los 14 a 18 años. Su enfoque de investigación fue el cuantitativo con un tipo de investigación sustantiva y de diseño no experimental, transversal correlacional. Los instrumentos que utilizó fueron la Escala de Claridad del Autoconcepto, la Escala de Autoestima de Rosernberg, la Escala de Identidad Vocacional y el Cuestionario de Desarrollo de Carrera. Entre sus hallazgos, encontró que hay relación estadísticamente significativa entre claridad del autoconcepto, controlando autoestima, con compromiso y autoestima, controlando claridad del autoconcepto, con exploración en el marco de la identidad vocacional.

Salazar (2016), ejecutó una investigación con el objetivo exploratorio de relacionar la claridad del autoconcepto, la calidad de la relación de pareja y la autoestima en una muestra de 61 parejas de orientación heterosexual con una edad que oscila los 20 a 62 años y un mínimo de tres meses de relación. Su enfoque de investigación fue el cuantitativo de tipo sustantivo y con diseño no experimental, transversal correlacional. Como instrumentos utilizó la Escala de Autoestima de Rosenberg, la Escala de Claridad del Autoconcepto Campbell y el Modelo de Inversión de Rusbult. Con esto, obtuvo como conclusiones que hay relación estadísticamente significativa entre claridad del autoconcepto y autoestima en ambos miembros; masculinos y femeninas. Además, que también hay relación entre claridad del autoconcepto con la subescala de compromiso en los varones y claridad del autoconcepto con la subescala de satisfacción en las mujeres.

Conde (2015), investigó la relación entre la claridad del autoconcepto y la inclusión del otro en el ser en una muestra de 84 adultos de Lima Metropolitana con una edad que oscila los 25 a 55 años y una media de 15 años de relación en promedio. Su enfoque de investigación fue el cuantitativo de tipo sustantivo y con diseño no experimental, transversal correlacional. Utilizó como instrumento un cuestionario de autorreporte hallando de este modo que los varones tienen una relación estadísticamente significativa en su claridad del autoconcepto con la inclusión del otro en el ser, además de que discutió este hallazgo desde la teoría de la autoconstrucción de Markus y Kitayama, así como sus diferencias de género.

Contreras (2010), realizó una investigación con el objetivo de relacionar el autoconcepto y el rendimiento académico en la asignatura de matemáticas en educandos de cuarto y quinto de secundaria en un colegio estatal de Ventanilla. Su enfoque de 
investigación fue cuantitativo con un tipo de investigación sustantiva y de diseño no experimental, transversal correlacional. Su población consideró a todos los alumnos de cuarto y quinto de secundaria con una muestra total de 150 educandos entre mujeres y varones. Sus instrumentos fueron una ficha bibliográfica, hemerográfica y de contenido, así como un cuestionario sobre el autoconcepto del discente como aprendiz de matemáticas. Las conclusiones a las cuales llegó son la existencia de relación estadísticamente significativa entre el rendimiento académico y el autoconcepto como aprendiz de matemáticas.

Reyes (2003), realizó una investigación con el objetivo de conocer la relación entre el autoconcepto, los rasgos de personalidad, el rendimiento académico, la ansiedad ante los exámenes y la asertividad en alumnos de psicología que cursaban el primer año en la Universidad Nacional Mayor de San Marcos. Su enfoque de investigación fue el cuantitativo, el tipo de investigación fue sustantiva con diseño no experimental, transversal correlacional. En lo que refiere a la población, estuvo integrada por todos los estudiantes de primer año con una muestra de 62 universitarios de ambos sexos. Los instrumentos que empleó fueron el Cuestionario de Personalidad 16 PF de Cattell, el Inventario de Autoevaluación de la Ansiedad sobre Exámenes, el Autoinforme de Conducta Asertiva y la Escala de Autoconcepto Forma A. En sus conclusiones, halló que existe relación estadísticamente significativa entre el autoconcepto familiar, académico y el rendimiento académico del alumno, infiriendo mediante la ecuación de análisis de regresión múltiple que un alto autoconcepto académico es predictor de un alto rendimiento académico en los estudiantes.

\section{Un acercamiento a las teorías que sustentan la autopercepción}

La autopercepción de acuerdo con Satici \& Deniz (2019), ha sido derivada del autoconcepto, cuyo diseño ha sido definido por las experiencias y evaluaciones del individuo hacia sí mismo en adición a la retroalimentación de los otros y el ambiente. Asimismo, diversos autores concuerdan que la autopercepción es el conjunto de impresiones dinámicas y parcialmente estables que el sujeto ha ido construyendo sobre sí mismo (Fenning \& May, 2013; Barros \& Duarte, 2016) y tiene un componente cognitivo, afectivo y físico que es influido constantemente por el ambiente donde el sujeto se desenvuelve (Abu, Abdelfattah, Alshumrani, Abduljabbar \& Marsh, 2013; Lachowicz \& Sniecinska, 2011; Fareo, 2011; Robertson, 2013).

Las teorías citadas fueron aquellas que constituyeron los cimientos más significativos en la investigación de la autopercepción. Por ende, en concreto, son las teorías de W. James, Interaccionismo Simbólico, Fenomenológica y Cognitivista (González y Tourón, 1992). 


\section{La teoría de William James.}

El precursor y pionero de las investigaciones de la autopercepción fue el filósofo estadounidense William James (1842-1910), quien en su obra titulada Principios de Psicología, dedicó un capítulo de suma relevancia a la "Consciencia de sí mismo". En esta obra, James (1890), expresó que se pueden diferenciar dos dimensiones del ser o yo total; el Yo o sí mismo como conocedor y el Mí o sí mismo como conocido. Al respecto, González y Tourón (1992), afirmaron que "cada uno de estos aspectos no pueden existir sin el otro, ya que el proceso de autoconsciencia es imposible sin ambos elementos" (p. 36).

Asimismo, James (1890), le dedicó particular atención al Mí, quien lo consideró el objeto de estudio de la psicología. De este modo, argumentó que el Mí está compuesto por tres aspectos multidimensionales; los componentes del primer aspecto dimensional son el Mí material que alude al cuerpo del individuo, posesiones materiales y personales con las cuales se identifica como parte de su sí mismo. Mientras que el segundo factor del primer aspecto dimensional, es el Mí social que hace referencia al reconocimiento del individuo por parte de los otros, así como la manera de intentar agradar a los otros en el contexto social. Y el Mí espiritual que atañe al conglomerado de estados de conciencia que el sujeto experimenta a lo largo de su vida producto del contacto con su sí mismo y todo lo relacionado al mundo intrapsíquico; el segundo aspecto dimensional es autoapreciación y autodecepción que da como resultado la formación de la autoestima, y; el tercer aspecto dimensional es cuidado y conservación del yo, ya que la motivación conductual del ser humano tiene como fin cuidar, conservar y trabajar los diversos Mí.

Respecto al modelo de James, L'Ecuyer (1978), afirmó que este resulta hoy en día perfectamente contemporáneo, ya que los autores actuales no han hecho nada más que desarrollar a profundidad y en esencia su modelo y corroborar empíricamente sus intuiciones.

\section{El enfoque del interaccionismo simbólico.}

El concepto de Interaccionismo Simbólico surge en 1937 acuñado por Blumer, quien hace referencia al corpus de conocimientos que fueron originados por los filósofos pragmatistas, como James, para devenirse en una psicología social de rasgos sociológicos con Mead (House, 1977). Los máximos representantes de esta corriente son Cooley y Mead.

\section{La teoría de Cooley.}

Cooley (1902), trabajó el autoconcepto con mucho énfasis luego del legado de W. James, planteando su teoría del yo reflejo a través de la metáfora del looking-glass self, postulado medular que sustentó el conglomerado teórico del interaccionismo simbólico. 
Esta metáfora del autoconcepto aborda que la autopercepción de uno es el mero reflejo que las personas tienen del sujeto, en otros términos, uno forma su autoconcepto en la medida como los demás lo perciben. Además, al igual que James, Cooley consideró los afectos acerca de sí mismo como parte del looking-glass self mediante la necesidad de autoaprecio que fundamenta como requisito para la autovaloración. En este sentido, la autopercepción del sujeto no solo es la percepción que los demás tienen del sujeto, sino que también es influida por el aprecio que tiene el sujeto perceptor por los otros significativos.

\section{La teoría de Mead.}

Mead (1934), se caracterizó por ampliar y profundizar el legado de Cooley respecto a la formación del autoconcepto. Así, se enfocó en la interrogante de cómo el ser humano puede tener noción de sí mismo, y arguyó que este proceso es posible a través del taking the role of other, afirmando que el individuo al adoptar las actitudes que los otros significativos tienen hacia uno mismo, permite que la persona tenga consciencia de sí, ya que estas actitudes organizadas de otros forman el Mí, y al cobrar consciencia de este Mí, da forma al Yo.

Por otro lado, un postulado adicional es el otro generalizado, haciendo referencia con este término a que, en el proceso psicoevolutivo del ser, el individuo no solo internaliza las actitudes de sus seres cercanos, sino que también, a manera de impresión general, del grupo social en su totalidad, que vendría a ser la simbolización de la sociedad en uno.

\section{El enfoque de la fenomenología.}

Este enfoque postuló que el ser no es determinado por los factores ambientales que condicionan la conducta, ni por las fuerzas inconscientes que determinan el comportamiento humano, sino que es el mero fruto de la interpretación subjetiva que hace el individuo de la realidad (González y Tourón, 1992). Además, da mucho énfasis a la percepción del sí mismo, por tanto, por ser núcleo de su materia de estudio, es considerado el enfoque por excelencia que ha influido considerablemente en el estudio del ser. Los máximos representantes de esta vertiente que trabajaron este constructo son Combs y Rogers.

\section{Teoría de Combs.}

González y Tourón (1992) afirmaron ya que "el autoconcepto es el centro de la teorización de Combs por el papel que, según él, ejerce en la determinación de la conducta" (p. 54). Así, Combs, Blume, Newman \& Wass (1979), haciendo referencia a la autopercepción, mencionaron que está sujeta a la manera de cómo la persona se ve a sí misma, cómo ve las situaciones en las cuales está inmerso y de la dinámica de ambas interrelaciones. 
Combs (1981), postuló que el sujeto tiene un campo fenoménico que está compuesto por tres factores: (a) Percepciones totales del individuo; en este campo se alude a todas las percepciones del individuo, (b) Percepciones diferenciadas del sí mismo; aquí incorpora dentro del total de percepciones a aquellas en las cuales el individuo se distingue a sí mismo, sin considerar valor alguno, y (c) Autoconcepto; este factor refiere solo a las percepciones medulares del autoconcepto del individuo en sí, descartando aquellas que son periféricas.

Otro aporte de Combs (Combs, Avila \& Purkey, 1978), es el efecto circular del autoconcepto, aludiendo con este término a que el autoconcepto del sujeto actúa como filtro selectivo de toda percepción que tenga, tendiendo a seleccionar los datos que refuercen las convicciones ya preexistentes de su ser, las cuales, tal cual efecto de copo de nieve en caída, se mantienen y refuerzan. Este efecto en espiral genera que el autoconcepto del sujeto tienda a desarrollarse en la continuidad del tiempo por la vía por donde ha sido, es y será formado.

\section{Teoría de Rogers.}

Carl Rogers abordó el autoconcepto como una parte de su teoría de la personalidad a través de 19 postulados en sus trabajos denominados por él Psicoterapia centrada en el cliente (1951) y formalizada posteriormente en El proceso de convertirse en persona (1961), y de los cuales varios hacen alusión al autoconcepto. Esta psicoterapia basada en el ser, se resume en la cita que Rogers (1973), tomó de Lao-Tsé:

Si me abstengo de entrometerme, los demás cuidan de sí mismos. Si me abstengo de ordenar a los demás, ellos se gobiernan a sí mismos. Si me abstengo de predicar, los demás avanzan por sí solos. Si me abstengo de imponer mi voluntad, los demás se convierten en ellos mismos (p. 13).

Así, él se refirió al autoconcepto con el constructo de yo fenoménico para hacer referencia a que el hombre vive inmerso en un mundo de experiencias subjetivas fluctuantes en las cuales es el centro y a estas experiencias que forman el mundo y realidad subjetiva de la persona lo denomina campo fenoménico. De esta manera, afirma que el estilo conductual del individuo depende del campo fenoménico, es decir, todo lo que haya en su mundo subjetivo sirve como marco referencial conductual y que muy poco tiene que ver la realidad objetiva o condiciones externas.

Por otro lado, otro aporte importante que Rogers señaló sobre el autoconcepto es que las experiencias de vida del individuo pueden ser autopercibidas como verdaderas si es que mantiene alguna relación positiva con la estructura del autoconcepto, pero también pueden ser experiencias ignoradas si es que no poseen relación alguna con dicha estructura, además, pueden ser autopercibidas como falsas o distorsionadas si la 
experiencia es incompatible con el autoconcepto, lo cual levantaría los mecanismos de defensa predilectos de la persona. De esto, infirió al igual que la teoría de la autoconsistencia de Lecky (1945), que el individuo se ve impulsado en la medida de lo posible a salvaguardar su configuración del sí mismo frente a aquellas experiencias que son incongruentes con su autoconcepto, ya que, de no ser así, podrían generar sentimientos negativos hacia uno mismo, pero, por el contrario, tiende a preservar aquellas que son coherentes.

\section{El enfoque de la cognición.}

Este enfoque declaró al autoconcepto como un agente mediador del procesamiento de la información y su mayor aporte fue el hecho "de que los individuos son sujetos activos, reflexivos, constructivos y planificadores" (González y Tourón, 1992, p. 70).

Hallazgo que permitió dilucidar el carácter dinámico del autoconcepto en la determinación de la conducta humana, así como su rol activo en su formación, y no pasivo como ya habían señalado los teóricos del interaccionismo simbólico.

\section{La teoría de Epstein.}

Seymour Epstein, al observar el estado científico del autoconcepto, y luego de revisar sus antecedentes, sustentó que el autoconcepto es una teoría científica, y como todo instrumento conceptual, su valor radica en el de un constructo explicativo de la personalidad. Así, proclamó que "el autoconcepto es una teoría del sí mismo" (Epstein, 1973, p. 407).

Más tarde, aportó que, si el autoconcepto es una teoría del sí mismo, es para realizar un propósito, como "el de asimilar los datos de la experiencia de una manera que sea efectiva, facilitar el mantenimiento de la autoestima y optimizar el balance dolor/placer que experimenta la persona a lo largo del curso de la vida" (Epstein, 1973, p. 407).

Asimismo, Epstein (1973), al ser de corriente cognitivista e interesado en el estudio de la personalidad, estuvo muy influido por George Kelly (1955), y su teoría de los constructos personales. Afirmando, de este modo, que el individuo como producto de su experiencia consigo mismo, tiende a generar sistemas conceptuales de sí mismo con los cuales maneja la realidad interna y externa, y le hace frente.

\section{La teoría de Bandura.}

Es con la teoría de Bandura que se concibe el inicio entre la relación dialéctica del autoconcepto y la autorregulación, pues es en el marco de su teoría del aprendizaje social donde postuló la autoeficacia percibida, a la cual le atribuyó tres dimensiones, siendo una de ellas la autorregulación de la conducta. Es conocido que por autoeficacia se entiende a 
la certeza que presenta el individuo por realizar una actividad con éxito (Bandura, 1977). Además, aclaró que esta se forma como "el resultado de diversas fuentes de información transmitidas por experiencia directa y mediada" (Bandura, 1977, p. 203).

Asimismo, González y Tourón (1992), acotaron que "las expectativas de autoeficacia, a las que se refiere Bandura, no son rasgos globales de la personalidad ni tampoco autoconceptos generales. Son, más bien, autoconcepciones específicas, que se elaboran a partir de la experiencia en distintas actividades" (p. 76). Y con esta acotación, se resalta el componente motivacional y conductual que conlleva la autoeficacia y su aplicación al campo educativo, puesto que, a mayor expectativa de autoeficacia, mayor motivación conductual.

\section{Fundamentos teóricos de la estrategia metodológica}

Campusano y Díaz (2017), establecieron que la estrategia metodológica es un "conjunto integrado y coherente de estrategias y técnicas didácticas, actividades y recursos de enseñanza - aprendizaje" (p. 1), que han de estar preparadas según el nivel formativo de los estudiantes, el nivel de regulación de la complejidad, el nivel de vinculación con el contexto laboral y el nivel de favorecimiento a la autonomía en su aprendizaje, además de que el nivel de mediación del docente ha de ser mínimo.

Esto se relaciona con lo expresado por Quintero (2011), quien afirmó que las estrategias metodológicas son una serie de procedimientos, técnicas y métodos en función a una secuencia organizada y sistematizada para la mediación del conocimiento por parte del docente y la construcción de la misma por parte del educando.

De este modo, la estrategia metodológica se la entiende no solo orientada hacia el proceso de enseñanza aprendizaje como se viene abordando, sino, orientada desde la institución que la ejerce. Al respecto, Moya (2017), afirma que cualquier institución en aras de la consecución de sus objetivos y la cumplimentación de estas a través de metas, es necesario que recurra a una estrategia metodológica, cuya elaboración ha de considerar la gestión de recursos internos, externos y del ambiente.

Por otro lado, Moya (2017), también aborda las estrategias docentes como práctica pedagógica perteneciente a una estrategia metodológica. Así, la define como el conglomerado dinámico entre docente, currículo, proceso formativo y alumnos. Además, considera que esta está influenciada por un modelo de aprendizaje y un enfoque, de preferencia, uno integrado y holista. $Y$ entre sus características, se tiene el aprendizaje activo, la conexión entre lo cognitivo, afectivo y motor, la contextualización del proceso, el binomio de trabajo individual y colectivo y la relación maestro a alumno y alumno a alumno.

Asimismo, estas estrategias metodológicas docentes tienen su importancia puesto que están en función al contenido específico a mediar en el proceso de enseñanza 
aprendizaje según el currículo a prescribir y porque permite describir, comprender e interpretar su proceso. A esto, Moya (2017), enfatiza la pericia del docente ya que, gracias a su habilidad, se podrá discernir cuál estrategia es conveniente, en qué momento y cómo administrarla.

Finalmente, el diseño de la estrategia metodológica a emplearse tiene sus fundamentos en la teoría de la autorregulación, cuyo origen deviene, a manera de categoría emergente, del ser. Asimismo, Panadero \& Alonso-Tapia (2014b), mencionaron que hay diversas teorías que explican cómo funciona, así como diversos modelos; el de Zimmerman (2000; Zimmerman \& Campillo, 2003; Zimmerman \& Moylan, 2009), el de Winne (1997), el de Boekaerts \& Niemivirta (2000), entre otros.

Panadero \& Alonso-Tapia (2014a), señalaron un denominador común de la autorregulación: "todas las teorías coinciden en que la autorregulación es una capacidad compuesta de diferentes procesos, ciclo que se retroalimenta a partir de la experiencia y la activación de las estrategias de aprendizaje" (p. 450). No obstante, también refirieron que a pesar de que todas tienen un punto en común, también presentan diferencias marcadas entre ellos. Por esto, se consideran los enfoques teóricos que Zimmerman (2001), logró distinguir por sus aportes de cada una de ellas a la competencia autorregulatoria.

Los criterios que Panadero \& Alonso-Tapia (2014b), utilizaron para considerar un aporte, fueron aquellos que deberían explicar cómo es que un educando adquiere esta competencia. Para ello, se basaron en cinco procesos fundamentales;

1) ¿Cuál es el origen de la motivación para autorregularse?, 2) ¿cómo se toma conciencia de la autorregulación?, 3) ¿cuáles son los procesos autorregulatorios fundamentales?, 4) ¿cómo influye el entorno social y físico en la autorregulación? Y, por último, 5) ¿cómo se adquiere la capacidad autorregulatoria? (p. 11).

Las teorías que en la actualidad explicaron cómo es que un educando adquiere esta competencia según sus cinco procesos fundamentales, emergieron desde el enfoque operante.

\section{El enfoque del conductismo operante.}

Homme (1965), especificó en su artículo titulado "Control of coverants, the operants of the mind", el componente operacional de la autorregulación respetando sus principios empíricos y leyes científicas que la rigen. Así, de acuerdo al primer proceso fundamental de cómo explica esta la motivación para autorregularse, la sustentó como un factor que depende de la anticipación del sujeto a las recompensas, así como de su valor y proximidad. Postulado que Panadero \& Alonso-Tapia (2014b), corroboraron, pero criticaron al afirmar que "esta teoría señala la importancia de los incentivos, pero no explica cuáles conviene utilizar ni 
cómo incrementar las expectativas de conseguirlos para que el esfuerzo autorregulador se mantenga hasta su consecución" (p. 12). Crítica que pone de manifiesto la carencia del conductismo operante respecto a la motivación conductual sostenida y generalizada de la autorregulación.

Para el segundo proceso fundamental de la competencia autorregulatoria, según Mace, Belfiore y Hutchinson (2001), señalaron respecto a la consciencia por parte del individuo al organizar y dirigir su conducta, que tomar consciencia es un tema ignorado por los operantes.

Mientras que en el tercer proceso fundamental que apela a los procesos autorregulatorios fundamentales, de acuerdo con Kanfer (1977), hay cuatro procesos autorregulatorios principales: autoinstrucciones, automonitorización, autoevaluación y autorrefuerzo. Procesos que no consideran lo socioemocional de la autorregulación.

Por otro lado, en el cuarto proceso referido al papel que el entorno físico y social juegan en la manera cómo el educando autorregula, Mace et al., (2001) y Zimmerman, (2001), afirmaron que la autorregulación es producida por el efecto que existe entre la interacción del sujeto con su entorno.

Finalmente, en el quinto proceso, cuya característica menciona cómo el educando adquiere la capacidad de autorregular su aprendizaje, la explicó como explicaría la adquisición de cualquier aprendizaje; obedece a las mismas leyes operantes del aprendizaje.

La crítica es que el condicionamiento operante restó y obvió la debida importancia de los procesos de información y la subjetividad que conlleva la autorregulación.

\section{El enfoque de la fenomenología.}

Maslow (1943), con su teoría de la motivación humana en la cual describió las necesidades fundamentales y la autorregulación como mecanismo para llegar a la autorrealización, y Marsh \& Shavelson (1985), quienes le atribuyeron el carácter multidimensional y estructural al autoconcepto, aportaron con su implicancia a la autorregulación educativa.

Entonces, según el primer proceso de cómo la teoría fenomenológica explicó la motivación para autorregularse, Panadero \& Alonso-Tapia (2014b), sustentaron que "la motivación para regular el propio comportamiento se genera por la necesidad de autoactualización, esto es, por la necesidad que tiene la persona de sentirse competente" ( $p$. 12), con lo cual, McCombs (2001), está de acuerdo al indicar que la motivación para autorregular surge como producto de la discrepancia entre donde el individuo está, es decir, el yo real y adonde quiere llegar, el yo ideal. Estos enunciados dejaron en vacío los reforzadores positivos por los cuales el sujeto regula y dirige su conducta que el operante sí enfatizó. 
En el segundo proceso se tiene el cómo la teoría fenomenológica entendió la manera en la que el individuo toma consciencia de la organización y dirección de su actuar, que McCombs (2001), indicó que es como una actividad mental adherida al mundo subjetivo del sujeto, ya que existe la posibilidad de que la persona sea consciente de sus experiencias, facilitando de esta manera la concepción del autoconcepto.

Continuando, la teoría fenomenológica tiene como principios el engrandecimiento de la autoestima y el mantenimiento y preservación de la identidad, no aportando un sistema de procesos autorregulatorios para la consecución de estos. Por ende, se observa que carece de un rasgo operativo, reemplazándolo por un rol descriptivo y explicativo de la autorregulación.

Por otro lado, en el proceso de la afectación que tiene el ambiente físico y social sobre el educando, McCombs (2001), apuntó que la teoría fenomenológica no hace hincapié en la relación entre autorregulación y entorno, a comparación del enfoque sociocognitivo.

En la misma senda, la adquisición de la capacidad de autorregular el aprendizaje por parte del educando se da en la medida que se comprende a sí mismo. En términos de Panadero \& Alonso-Tapia (2014b), "al entender mejor su papel en su propio aprendizaje y al tener conciencia de su auto-valía el alumno quiere mantenerla y para ello trata de regular el modo en que realiza las actividades de las que aquella depende" (p. 18). Esto no deja explicito qué otros factores intervienen para facilitar y desarrollar el entendimiento del sí mismo, dejando en evidencia su componente concreto y general.

\section{El enfoque de la cognición.}

Esta contribución se ha dado a través del papel que tiene en el procesamiento de la información y su estudio mediante la actividad mental. Además, esta es debida a JohnsonLaird (1988), por haber recopilado las investigaciones de los cognitivistas, aplicadas a la autorregulación. Así, en el primer proceso de la motivación para autorregularse, JohnsonLaird sintetizó que la motivación tiene poca relevancia en la autorregulación del comportamiento. Aporte que Panadero \& Alonso-Tapia (2014b), reforzaron al resaltar que "la modificación y ajuste de la actividad se producen de manera automática en función de la información a la que el sujeto presta atención en cada momento" (p. 13).

Por otro lado, respecto al proceso que aborda la incógnita del factor consciencia en la manera cómo el individuo llega a dirigir y organizar su conducta, Winne $(2001,2011)$, afirmó que la actividad cognitiva necesaria para conseguir la consciencia se da a través de la automonitorización, pues permite modular la acción en aras de lograr las metas propuestas. 
Mientras que, para resaltar los procesos autorregulatorios, el modelo de Winne y Hadwin (1998), enfatizó actividades mentales que se caracterizan por un ciclo recursivo de procesos cognitivos complejos de planificación, control y monitorización, descuidando de este modo el componente volitivo motivacional, pero enfatizando la secuencia cognitiva.

Pasando al cuarto proceso, el entorno físico y social juega roles autorregulatorios en el educando que de acuerdo con Winne $(2001,2011)$, se da a través de la interacción con otras personas, ya que el otro puede llevar al sujeto a regular información en la medida que uno influye al otro. No obstante, no prepondera el entorno físico y social como la sociocognitiva.

Y en el proceso de adquisición de la competencia autorregulatoria por parte del educando en su aprendizaje, Zimmerman (2001), expuso que esta es adquirida cuando el discente desarrolla la madurez de su sistema cognitivo, hecho que ocurre cuando se automatizan procesos y se liberan recursos cognitivos para otras tareas. Nuevamente, no explica el acontecimiento de automatizar procesos a autorregular procesos, solo el cuándo se da la adquisición, es decir, cómo un proceso automatizado se convierte en autorregulado.

\section{El enfoque de la sociocognición.}

Bandura (1986, 1997), aportó a la autorregulación desde sus postulados de metas personales, expectativas de autoeficacia y expectativas de resultado, cuya ejecución por parte del discente implica el uso de la competencia autorregulatoria. Iniciando los procesos, la teoría sociocognitiva entiende la motivación del educando por autorregularse en las situaciones donde presenta interés por conseguir un objetivo específico. Sin embargo, Panadero \& Alonso-Tapia (2014b), resaltaron que "el problema es que no siempre estas metas son positivas para el aprendizaje" (p. 13). Y así es, guiar el objetivo que el discente presenta en consecución de su aprendizaje es el factor necesario para una autorregulación adaptativa.

En el segundo proceso de la toma de consciencia de la dirección y organización conductual por parte del educando, Panadero \& Alonso-Tapia (2013), indicaron que la autorreflexión, fase tercera de la propuesta por Zimmerman, es la que permite reflexionar respecto a lo realizado y su consecuencia respectiva comparando su desempeño con lo planificado en mente. Así, la toma de consciencia es primaria para la sociocognición.

Continuando con los procesos fundamentales de la competencia autorregulatoria de acuerdo a la teoría sociocognitiva, esta parte desde Zimmerman (2001), quien la dejó perpetuada en su último modelo (Panadero \& Alonso-Tapia, 2014a), cuya indicación presentó las tres fases cíclicas de la autorregulación; planificación, ejecución y 
autorreflexión. Un modelo integrador que incluyó aportes de la teoría operante, cognitiva, fenomenológica y los procesos de la teoría volitiva de Zimmerman \& Moylan (2009).

En esta misma senda, el cuarto proceso que alude al rol que tiene el ambiente físico y social en la competencia autorregulatoria, la teoría sociocognitiva argumentó a través de los trabajos de Bandura $(1986,1997)$, que sí cumple los dos niveles de influencia del entorno; generando la primera que el sujeto se sintonice con su entorno físico de modo tal que este lo obliga a autorregular su conducta al ser un factor material y perenne de su ecosistema, mientras que en el segundo nivel; los otros y otros significativos mediante el aprendizaje vicario y el modelado, influyen en la formación de la autorregulación.

Por último, el quinto proceso referido a la adquisición de la competencia autorregulatoria del aprendizaje por parte del educando es sustentado a través de un modelo propuesto por Zimmerman \& Kitsantas (2005), cuya formación incluye las fases de observación, emulación, automatización y autorregulación. Fases que identifican instantes en las cuales se aprende la autorregulación a través de sus procesos cognitivos y modelos sociales, resaltando así que "este modelo resulta muy completo en la explicación de los procesos internos y sociales que influyen en la adquisición de la autorregulación" (Panadero \& Alonso-Tapia, 2014b, p. 18). En suma, este enfoque destaca más la competencia autorregulatoria por sus aportes científicos desde sus cinco procesos fundamentales.

\section{El enfoque de la volición.}

Kuhl (1984, 1987, 2000), enfatizó la voluntad en el acto autorregulatorio. Así, en el primer proceso, abordó la motivación en el curso de la autorregulación como un factor que según Corno (2001), es mantener la atención durante la actividad autorregulatoria. No obstante, esta teoría no menciona cómo inicia la motivación puesto que solo enfatiza su inicio durante esta, en consecuencia, Panadero \& Alonso-Tapia (2014b) acotaron que "la explicación de la motivación para autorregularse que ofrece esta teoría se centra en el mantenimiento de la acción para alcanzar una meta determinada mientras se ejecuta la tarea" (p. 13), es decir, ocurre antes al proceso volitivo, ya que hay una motivación inicial (Wolters, 2003).

Pasando al proceso de cómo explica la teoría volitiva la toma de consciencia por parte del discente en la dirección y organización de su comportamiento, Kuhl (1984, 2000), postuló la importancia de que el educando permanezca en una postura de orientación a la acción en su aprendizaje, ya que así se torna consciente en su proactividad, por ende, actor principal de su aprendizaje, además de conseguir sus objetivos trazados. La teoría volitiva no deja en claro cómo se llega a ella para autorregular, sin embargo, su aporte es sustancial puesto que en el estado a la acción se regula conscientemente el comportamiento en aras de una meta. 
Mientras que, en los procesos fundamentales de la autorregulación, la teoría volitiva sostuvo que estos son estrategias que controlan los procesos cognitivos, emocionales y motivacionales, como autoinstrucciones, control de la atención, movilización de emociones, etc., estas han sido bien respaldadas por los resultados empíricos de Corno (2001). Empero, estos procesos no enfatizan el inicio de la autorregulación como los sociocognitivistas.

Continuando con el cuarto proceso, la teoría volitiva explicó el rol que el ambiente físico y social juegan en la competencia autorregulatoria a través de los aportes de Corno (2001), quien demostró que el educando al ser activo en su aprendizaje, modula sus comportamientos afectando al entorno, como la toma de recursos educativos en aras de sus metas. Sin embargo, deja de lado al entorno social como factor mediador autorregulatorio.

Por último, la teoría volitiva aportó respecto a la adquisición de la competencia autorregulatoria del educando en su aprendizaje que este la adquiere cuando adquiere las estrategias volitivas necesarias para poder controlar su comportamiento, es decir, sus cogniciones, emociones, motivaciones y el ambiente físico en donde realiza la acción (Corno, 2001). Hallazgo cierto hasta que Panadero y Alonso-Tapia (2014b), criticaron que esta teoría "no aclara cómo fomentar la adquisición de estrategias que permiten ese control" (p. 18).

\section{La teoría Vygotskiana.}

Vygotsky $(1962,1978)$, atribuyó poca relevancia a la autorregulación, a excepción de que esta emerge en el individuo a manera de deseo por mejorar su autocontrol en sus relaciones con la sociedad y el entorno. De este modo, en lo que concierne al proceso del origen de la motivación por la autorregulación, McCaslin y Hickey (2001), propusieron en base a la teoría de la autoeficacia de Bandura (1997), y a la teoría de la atribución de Weiner (1986), un modelo de corregulación donde se consideró la motivación por la autorregulación, explicando que cuando la persona internaliza el desarrollo de su identidad por medio de los estándares socioculturales, genera "que el individuo quiere sentirse competente en los contextos sociales en los que interactúa, siendo a su vez en estos contextos en los que se desarrolla la identidad del sujeto" (Panadero \& Alonso-Tapia, 2014b, p. 13). Ahora, no siempre el factor sociocultural es la fuente primaria de autorregulación como se ha señalado.

Por el lado del segundo proceso de cómo el educando toma consciencia de la dirección y organización de su conducta, la teoría Vygotskiana propuso que esta se da cuando el significado de las palabras es interiorizado por el sujeto (Hadwin, Järvelä y Miller, 2011), una vez que son interiorizados los significados que vienen del entorno sociocultural, 
el sujeto adquiere la capacidad de dirigirlas hacia sí mismo con propósitos de autorregularse.

En la propuesta Vygotskiana de cuáles son los procesos autorregulatorios, en el modelo de corregulación de Hadwin et al. (2011), propusieron que es el habla privada, ya que esta es la fuente del proceso de autoinstrucciones, proceso vital para autorregular el organismo a nivel cognitivo, emocional, motivacional y comportamental.

En el cuarto proceso que alude al rol que el entorno físico y social tienen en la autorregulación del educando, la teoría Vygotskiana desarrolló con especial énfasis el nivel social, es decir, la influencia determinante que tienen los agentes sociales mayores a los menores a través de la mediación social que genera que estos últimos desarrollen el habla privada, por ende, el desarrollo de la autorregulación, sin esclarecer el rol del entorno físico.

En el último proceso autorregulatorio, la teoría Vygotskiana propuso que el discente adquiere la capacidad autorregulatoria para modular su aprendizaje por medio del habla privada que va interiorizando a través de la mediación social (McCaslin \& Murdock, 1991), de este modo, el habla privada induce a que el educando autorregule sus emociones, motivaciones, cogniciones y conductas.

\section{El enfoque del constructivismo.}

Piaget (1926, 1932, 1952), aportó a través de sus postulados de esquema mental, asimilación, acomodación, equilibrio y adaptación, ocasionando que el educando al ejecutarlos, regule su comportamiento en aras de la adaptación ante el desequilibrio que el entorno le propone.

Entonces, el constructivismo aborda la incógnita de cómo el educando se motiva por la autorregulación mediante Paris, Byrnes y Paris (2001), al afirmar que existe una tendencia intrínseca por equilibrar el organismo ante el conflicto cognitivo provocado por el proceso de asimilación y acomodación, además de que el educando tiene un deseo instintivo de encontrar solución a las inquietudes que se le plantea. Al respecto, Panadero \& Alonso-Tapia (2014b), comentaron que "aunque es cierto que de forma natural se busca respuesta a las preguntas, no siempre que se regula el aprendizaje se intenta dar respuesta a una duda" (p. 13).

Por otro lado, el constructivismo explicó que el educando adquiere consciencia de la dirección y organización de su comportamiento según va escalando en los estadios de desarrollo cognitivo de Piaget $(1926,1932,1952)$, es decir, cuando se llega a las operaciones formales se puede autorregular a plenitud, solo que no esclarecieron cómo autorregularse en los estadios previos donde la consciencia es escasa, pero sí se puede llegar a autorregular. 
En los procesos autorregulatorios, Paris et al. (2001), sustentaron cuatro factores para que un educando autorregule su aprendizaje; las estrategias, las tareas académicas, el control y la agencialidad y la autocompetencia. De esta manera, "las estrategias de los teóricos constructivistas son las usadas por la teoría sociocognitiva y la volitiva, pero en estas teorías se encuentran mejor explicadas" (Panadero \& Alonso-Tapia, 2014b, p. 16).

En el cuarto proceso, la teoría constructivista desarrolló que el entorno físico y social juegan un rol en la autorregulación del educando a través de la mediación social (Paris \& Paris, 2001), es decir, la autorregulación se estimula cuando el educando tiene dudas generadas a raíz del conflicto social que le genera interactuar con otros, lo cual lo lleva a querer resolverlas. Considerando esto, no aborda cómo afecta el entorno físico.

En el proceso autorregulatorio, el constructivismo aportó que el educando adquiere la competencia autorregulatoria de su aprendizaje por medio de reflexiones cognitivas; como la comprensión adecuada de su inventario de estrategias, entendimiento de las tareas académicas, estimación del control que puede tener sobre una tarea y entendimiento del rol que tiene el esfuerzo y la habilidad en los resultados académicos (Paris \& Newman, 1990). 


\section{Capítulo II \\ Trabajo de campo}

\section{Características del campo de estudio}

En el presente capítulo se describen los hallazgos y resultados obtenidos al aplicar las diferentes técnicas; observación, encuesta y entrevista, y sus respectivos instrumentos; guía de observación, cuestionario de encuesta y guía de entrevista, a docentes de octavo semestre de psicología y estudiantes de octavo semestre del curso Diagnóstico Psicológico en la URP.

Las guías de observación se realizaron durante seis sesiones en dos asignaturas que pertenecen a la malla curricular de octavo semestre la cual estaban cursando los participantes y con el fin de observar los diversos indicadores de la autopercepción y autorregulación en el proceso de enseñanza-aprendizaje de los educandos. Asimismo, el cuestionario a los estudiantes se dio con el fin de constatar la autorregulación y autopercepción que ellos tienen de sí mismos a través de 16 ítems con cinco alternativas de respuestas tipo escala Likert. Luego, la entrevista semiestructurada a los docentes fue realizada con el objetivo de conocer la preparación profesional que poseen los docentes sobre la autopercepción y autorregulación de los educandos a través de doce preguntas semiabiertas.

\section{Análisis, interpretación y discusión de los hallazgos por técnicas e instrumentos Resultados de la entrevista a docentes.}

Los docentes entrevistados fueron tres; dos profesoras y un profesor. Las entrevistas fueron basadas en 12 preguntas semiestructuradas elaboradas en base a los indicadores de las subcategorías apriorísticas de la autopercepción y autorregulación, además del uso frecuente de preguntas a manera de retroalimentación conforme se iban desarrollando estas.

En la primera pregunta referida a cómo el docente utiliza las posesiones de los educandos en el proceso de enseñanza-aprendizaje, se encontró como denominador común que dos de ellos apelan a las posesiones físicas de corte académica, mientras que una enfatiza la importancia de anclar su atención a sus sensaciones corporales para estar en la realidad y no divagar en los estados subjetivos propios de la mecanicidad humana. Luego, un docente demanda la importancia de no solo enfatizar en las posesiones físicas de los educandos para adaptarse, sino, de desarrollar consciencia que son sujetos de aprendizaje y no solo objetos como él ha observado a lo largo de su praxis. 
Es importante señalar que estas dos tópicas que surgieron durante la entrevista, conectan con un solo factor de la dimensión material del ser propuesta por James (1890), pues el enfatizar los objetos académicos tanto como el objeto corpóreo de los educandos solo alude a un enfoque tubular de las posesiones objetales de los educandos, ya que como se mencionó, también están los objetos socioafectivos del proceso de enseñanzaaprendizaje (L'Ecuyer, 1985), como las interacciones que se generan entre compañeros de clase.

En otra pregunta respecto a cómo los docentes abordan la identidad de los educandos en el proceso de enseñanza aprendizaje, se encontró que un entrevistado lo hace enfatizando a la autoafirmación de su identidad contrastándolos con autoevaluaciones, autodiagnósticos y autoconocimiento para desarrollar su identidad personal, mientras que una entrevistada opta por estimularla a través de ejemplos de su vida cotidiana contrastándolos con la sesión a trabajar y exhortándolos a que transfieran este conocimiento a sus vidas personales.

Al respecto, los entrevistados estimulan la identidad desde diversas posturas, y estas coinciden con lo propuesto por L'Ecuyer (1985), pues refirió que la identidad es todo aquello en lo cual el educando demuestra consciencia de sí y de su existir. Asimismo, otro hecho relevante es el de una entrevistada que promueve la coherencia de pensamientos, sentimientos, actos y deseos de los educandos, pues Rogers (1961), enfatizó que la clave para que una persona sea adaptativa es que tenga coherencia entre su yo real y su yo ideal.

De igual modo, en las respuestas de los entrevistados ante la pregunta de cómo usan los juicios valorativos de los educandos respecto a sus desempeños en el proceso de enseñanza-aprendizaje, entre estas, dos de los entrevistados optan por el pensamiento crítico y el sustento argumentativo, mientras que una entrevistada prefiere apelar al pensamiento analógico y metafórico para corroborar si es que realmente los educandos han reflexionado sobre su proceder. Estas maneras divergentes conectan con lo propuesto por Winne $(2001,2011)$, quien enfatiza la automonitorización como procedimiento cognitivo aledaño de las experiencias de los juicios valorativos de los educandos.

Por otro lado, respecto a la pregunta de cómo los entrevistados utilizan los vínculos con los otros y los vínculos psicosexuales de los educandos en el proceso de enseñanzaaprendizaje, se recopiló que una entrevistada lo promueve a través del uso de estrategias de trabajo colaborativo, cooperativo y un abordaje neutral de los vínculos psicosexuales, con una perspectiva ética y moral del asunto, mientras que otro entrevistado manifestó ser crítico con rigor científico, abordando los vínculos psicosexuales con imparcialidad, no obstante, observa que los educandos se muestran timoratos frente a estas tópicas y 
demanda el uso de las redes sociales a través de internet ya que generan vínculos frugales y superficiales.

Además, revela que la manera tan a la volada de los vínculos de los estudiantes genera "islas" entre ellos, por ende, vínculos desadaptativos, pues al respecto, sugiere que se deben practicar más las habilidades sociales con desconocidos pues estas proveen madurez psicosocial. Finalmente, otra entrevistada apela a la jerarquía vertical y horizontal y promueve el amor, el compromiso y el sexo responsable en los vínculos psicosexuales, así como a la consciencia de sí y del otro, pues esto permite un autoconocimiento de sí y del otro.

A este parecer, es preciso citar a Mead (1934), quien afirmó que la consciencia de sí es posible a través de la adopción de roles de otros vínculos, de este modo, los educandos han ido formando su dimensión psicosocial y psicosexual a través de un proceso de interiorización pasiva del otro generalizado, que vendría a ser el estado actual de la sociedad.

\section{Análisis de la observación a clase de docentes.}

Las seis sesiones de observación semiabierta y no participativa fueron realizadas en los cursos de octavo semestre de Diagnóstico Psicológico y Psicodiagnóstico de Rorschach. Vale añadir que los alumnos observados en su gran mayoría eran los mismos que participaron con el cuestionario para estudiantes, por lo que la fiabilidad incrementa.

En las observaciones, se apreció que, ante la densidad y dificultad de la materia a mediar, la profesora convertía en broma algunos tópicos de la clase, lo cual mantenía a los educandos estimulados entre risas leves y sutiles. Después, cuando la clase se desbordaba entre risas, unos alumnos emitían ademanes de silencio, y el resto acataba el ademán que se esparcía entre todos, originando que el aula se silencie de manera implícita, como si una autorregulación colectiva gobernara la conducta de los educandos en clase.

Ante estos hechos observados, los teóricos Vygotskianos; McCaslin y Hickey (2001), sostuvieron que la autorregulación se da porque el educando desea mejorar su autocontrol en sus interacciones con el entorno y la sociedad, hecho que explica el por qué la clase guardaba silencio inmediatamente después que un compañero realizaba el ademán de silencio.

En otra sesión, hubo un inicio sin recurrir a saberes previos o motivación, además de tener una fuerte característica de clase magistral. Por ende, los alumnos permanecían con ademanes de estar escuchando, sin embargo, se les percibió con posturas de estar absortos e inmersos en una subjetividad sin fronteras, así como entretenidos con sus celulares. 
Al respecto, Kuhl $(1984,1987,2000)$, propugnó la postura volitiva de la autorregulación, hecho que se caracteriza por evocar una autorregulación deliberada y consciente, postura que discrepa con lo observado en clase puesto que los alumnos eran actores pasivos de su aprendizaje y no se evidenciaba indicadores de tener una actitud proactiva en su aprendizaje, por el contrario, la impresión global fue la de un conjunto de alumnos determinados por lo que ocurría en el ambiente tal cual condicionamiento.

Luego, en otra situación, se captó la participación continua de una alumna que emitía comentarios fuera del lugar que a su vez generaban reacciones diversas entre sus compañeros, como risas, miradas despectivas y expresiones de desagrado e ininteligibilidad por no entender esos comentarios con una alogia peculiar.

Al respecto, Combs et al. (1978), manifestó que el ser del educando actúa como filtro selectivo de todo lo que este percibe tendiendo a seleccionar aquello que refuerce sus convicciones ya preexistentes de su ser, infiriendo de esta manera que la alogia particular de la alumna no es más que un mero reflejo de cómo está la configuración de su ser.

En otra observación, la profesora exhortó a los alumnos a que se organicen para poder afrontar una sesión con contenidos conceptuales duros, aparte de que estaban realizando una actividad artística muy cerca al salón y la bulla de la música resonaba con tal fuerza que opacaba lo que la profesora explicaba. Sin embargo, se apreció que casi la mitad del salón pudo contener la exigencia de la profesora y el bullicio de la actividad.

Con respecto a esto, la teoría constructivista plantea que los educandos autorregulan su comportamiento en aras de la adaptación ante el desequilibrio que el entorno les propone, como en este caso era la exhortación de la profesora y el bullicio de la actividad artística. De este modo Paris, Byrnes y Paris (2001), afirmaron que existe una tendencia intrínseca por equilibrar el organismo ante el conflicto cognitivo, situación que atravesaban los educandos. Posteriormente, se observó a un alumno molestando a otro, y repentinamente la víctima se ofuscó y lo amenazó de golpearlo con lisuras hasta que el victimario se quedó en silencio. Después, la profesora realizó una actividad de evaluación en la cámara Gesell, y luego de esta propició la retroalimentación de sus alumnos observadores a los alumnos actores, apareciendo bastantes críticas orientadas a las debilidades más que a las fortalezas.

Para conectar este fenómeno de violencia, González y Tourón (1992), explicaron que Rogers afirmó que cuando un educando ve en sí algo que no le gusta de sí mismo en disonancia con lo que le gusta de sí mismo, automáticamente se elevan sus mecanismos de defensa para salvaguardar a su yo, explicación que aplica al caso de la víctima.

Asimismo, los juicios valorativos emitidos por parte de los alumnos a sus compañeros que realizaron el role playing, reflejaban el ser de los alumnos, apreciándose críticas con tendencias a enfatizar los errores más que los aciertos, y para comprender esto, 
Epstein (1973), afirmó que la autopercepción es una teoría científica sobre sí mismo, además que explica la personalidad del educando, y conforme con esto, se podría inferir que los educandos tienen un estilo cognitivo de percibir con tintes mórbidos.

Finalmente, se observó a alumnos plagiando durante una práctica calificada, y cuando el docente los miraba, ellos dejaban de plagiar, pero cuando el docente volteaba, ellos inmediatamente volvían a plagiar. Sin embargo, llamó la atención el observar que una alumna le pidió al profesor que le dejara plagiar y que le pasara la respuesta a la pregunta 13. Luego, cuando el profesor recogió las prácticas, había dos alumnas que no querían entregarlas, y en frente del profesor, empezaron a realizar un plagio colaborativo hasta terminarlas.

Al analizar la situación desde la teoría de James (1890), quien enfatizó el Mí, y le dio tridimensionalidad, siendo una de estas la conservación del ser, entendida como todas aquellas conductas instintivas que llevan al organismo a la adaptación sobre las demandas del ambiente, se puede inferir que los alumnos plagiaban porque su instinto de conservación estaba en juego a pesar de que el acto de plagiar es estigmatizado.

De manera similar, de acuerdo con la teoría sociocognitiva de la autorregulación, Panadero \& Alonso-Tapia (2014b), indican que el educando tiene la motivación por autorregularse gracias a un objetivo específico que le plantea el ambiente físico o social, que en este caso era aprobar el examen, a pesar de que este objetivo no era ético, la teoría no repara en que el objetivo sea prosocial o antisocial, pues los educandos autorregulaban su comportamiento de plagio colectivo sin considerar la moral y ética.

\section{Resultados de la encuesta aplicada a los estudiantes.}

El cuestionario para estudiantes fue administrado a 28 alumnos que cursaban la asignatura de Diagnóstico Psicológico. Este instrumento constaba con 16 preguntas semiestructuradas para marcar en un formato de escala tipo Likert; en las cuales las alternativas eran casi siempre típico en mí, frecuentemente típico en mí, algunas veces típico en mí, no es muy típico en mí y no es típico en mí en lo absoluto. El objetivo fue constatar la autorregulación y autopercepción de los participantes en el proceso de enseñanza-aprendizaje, y los hallazgos más significativos fueron los siguientes:

En el reactivo de si los educandos utilizan sus posesiones de sí mismos en el proceso de enseñanza aprendizaje, se observa que el 42,9\% manifestaron que es frecuentemente típico en ellos utilizar sus posesiones de sí mismos, lo cual indica que menos de la mitad de los participantes son conscientes de sus objetos, personas y cuerpo físico como herramientas en aras del proceso de enseñanza aprendizaje. No obstante, a pesar de ser una cifra alentadora, se observa que un 7,1\% no es típico en ellos en lo absoluto utilizar sus posesiones, lo cual despierta particular interés ya que esto implicaría 
que no son conscientes sobremanera respecto a su proceso de aprendizaje, como si fuesen objetos autómatas en vez de sujetos conscientes frente al escenario en el cual están inmersos.

Luego, un 35,7\% de los encuestados, afirmaron que frecuentemente es típico en ellos usar juicios valorativos sobre sus experiencias en el proceso de enseñanzaaprendizaje, lo que significa que la tercera parte de los participantes son conscientes de las características de sus juicios valorativos, ya sean para devaluar, sobrevalorar o evaluar subjetiva u objetivamente sus experiencias. En contraparte, se aprecia que el 3,6\% afirma que no es típico en ellos, infiriendo de este modo que su formación para evaluar y diagnosticar sus experiencias con juicios valorativos ha sido poco estimulada.

En el reactivo de los vínculos con los otros en el proceso de enseñanza-aprendizaje, se aprecia que el $42,9 \%$ de los participantes afirman que es frecuentemente típico en ellos utilizarlos, entendiendo esto como un adecuado desarrollo de sus habilidades sociales al poder emplearlas en sus interacciones con sus compañeros. Sin embargo, llama la atención observar que hay un 3,6\% que manifiesta que no es típico en ellos en lo absoluto, interpretando este hallazgo como educandos con vínculos desadaptativos.

Por otro aspecto, un $39,3 \%$ de los participantes expresaron que es algunas veces típico en ellos utilizar como referencia al prójimo para identificarse en el proceso de enseñanza-aprendizaje, entendiendo esto como un dato alentador ya que un poco más de la tercera parte de los encuestados utiliza como referencia directa o indirecta al prójimo para hacer expresión de sus pensamientos, sentimientos, acciones y deseos. A pesar de esto, un $7,1 \%$ afirma que no es típico en ellos en lo absoluto, pudiendo implicar una autoafirmación de su identidad ya que desde primera persona expresan sus pensamientos, sentimientos, acciones y deseos.

En la misma línea, otro dato alentador es el 50,0\% de participantes que expresaron que es frecuentemente típico en ellos controlar la calidad de sus actividades en el proceso de enseñanza-aprendizaje, significando esto la capacidad inherente de integrar sus pensamientos, sentimientos, acciones y deseos en aras de su adaptación al proceso de enseñanza-aprendizaje. No obstante, alarma la cifra de 3,6\% que afirma que no es típico en ellos lo absoluto, implicando esto una forma de llevar su aprendizaje con criterios que están por debajo de los exigidos para un adecuado desenvolvimiento.

\section{Análisis, interpretación, triangulación y discusión de las categorías emergentes} En el presente apartado se presenta un gráfico polarizado con las categorías primaria y secundaria con sus respectivas subcategorías apriorísticas y las categorías emergentes producto del trabajo de campo. 


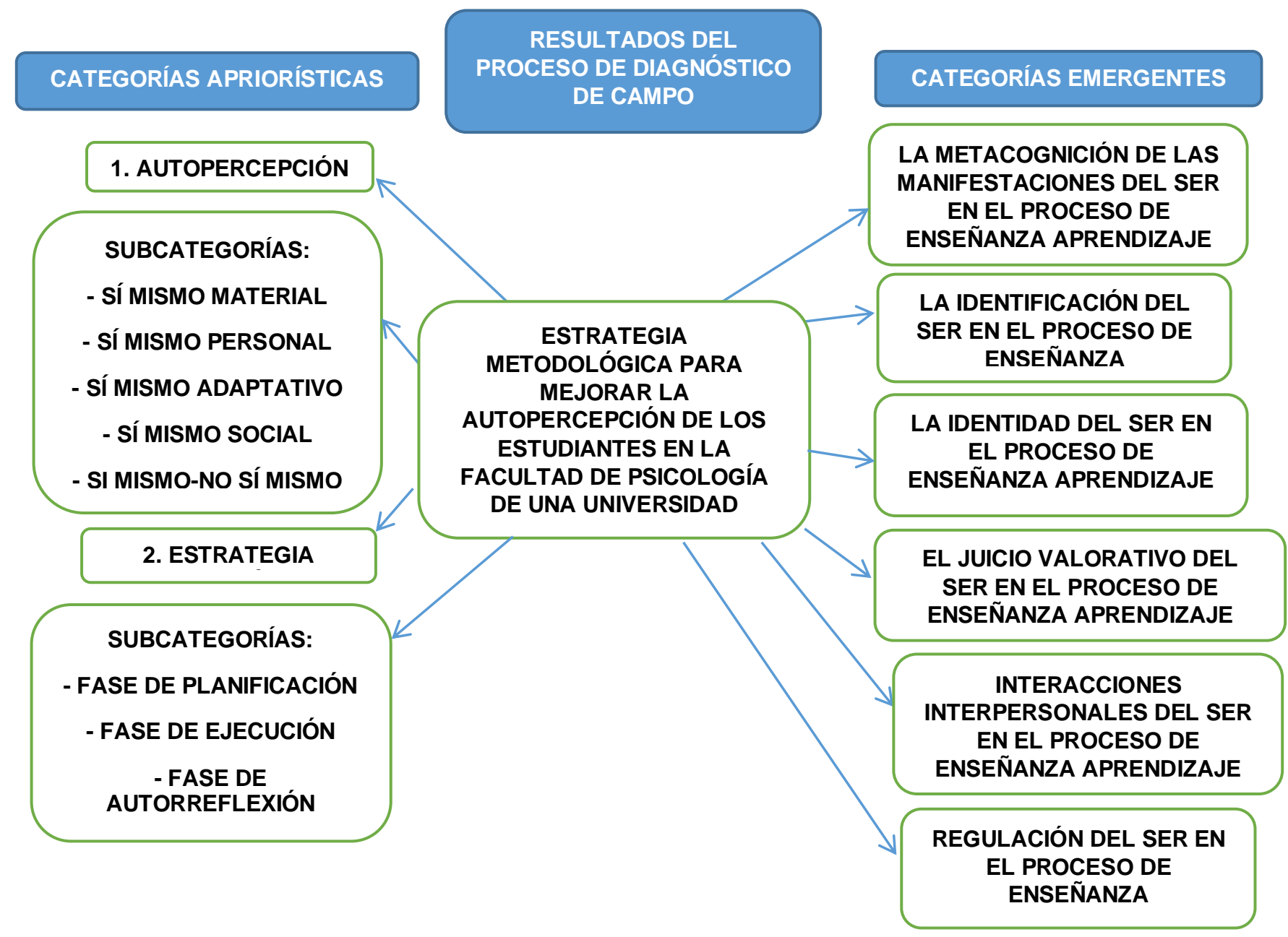

Figura 1. Presentación de las categorías apriorísticas y las emergentes.

Fuente: Elaboración propia, Huertas (2019)

La metacognición de las manifestaciones del ser en el proceso de enseñanza aprendizaje.

Según una entrevistada, se da cuando se enfatiza en los educandos la toma de consciencia de sus posesiones en el proceso de enseñanza aprendizaje y de su vida, ya que solo así podrá tener una autopercepción de sí mismo. De esta manera, el educando podrá entrenar la competencia de la metacognición respecto a sí mismo y sus posesiones. Por esto, su importancia radica en que el educando pueda evitar caer en un automatismo de su ser, soslayando de este modo el automatismo de su aprendizaje.

En la misma senda, la metacognición de los juicios, según los entrevistados, está muy relacionado con la paradoja como evaluación del juicio valorativo del educando, además de que en este se puede evaluar el curso y contenido del pensamiento, así como 
de las emociones. Otra bondad de utilizar los juicios valorativos es que el educando estimula el desarrollo de su sí mismo ya que al ejercitarlo, tiene la posibilidad de conocer aquello que aflora de su ser al emitirlo en su proceso de enseñanza-aprendizaje.

Finalmente, respecto a la consciencia de los juicios valorativos, los entrevistados refieren que se desarrolla a través de autojuicios de diferenciación, incitación al autodidactismo, metacognición durante la elaboración de preguntas y respuestas, promoviendo los juicios personales, apelando al locus de control interno y promoviendo la búsqueda de la causalidad interna de resultados positivos y negativos. Sin embargo, una entrevista recomienda que, frente al fracaso, los educandos han de preguntarse qué pueden hacer para mejorar, cómo involucrarse más y exhortarlos a la autorreflexión, porque la autosuficiencia subjetiva es un riesgo para el proceso de enseñanza-aprendizaje.

\section{La identificación del ser en el proceso de enseñanza aprendizaje.}

Esta categoría elaborada proveniente de los entrevistados, refiere a los objetos de las identificaciones en el proceso de enseñanza aprendizaje, como la identificación con el prójimo teórico y práctico, con las ideas propias, con el aporte intelectual, con el docente, con el desempeño profesional, identificaciones parciales, compromiso personal como indicador de identificación total, etc.

Asimismo, en la observación se apreció que las manifestaciones de la identificación con el prójimo denotan el enfoque teórico del identificado, implican un sentimiento con esa identificación, respeto por la identificación con los otros, entre otros.

A su vez, se promociona la diferenciación de identificaciones, ya que, al tener consciencia de las identificaciones, según un entrevistado, se distingue las ideas de uno de las de los otros, se describe con mayor nivel las identificaciones, implicando todo esto un mayor nivel de diferenciación, ya que el nivel de desarrollo personal está dado por el grado de diferenciación de las identificaciones objetales, personales e interpersonales.

Por esto, los entrevistados demandaron que las identificaciones han de extrapolarse; de personales a académicas, porque entorpecen los vínculos con el prójimo.

Después, de acuerdo a una entrevistada, la conexión con las posesiones corporales en el proceso de enseñanza aprendizaje permite al educando captar el instante en el cual está inmerso durante el estado de identificación, ya que, a mayor sensación corporal, mayor fluidez cognitiva, mayor consciencia de vida, mejor canalización de la atención a algo o alguien, es vivir en la realidad, mientras que la desconexión con las sensaciones corporales desemboca a vivir inmerso en la subjetividad. De esta manera, la atención no anclada en el cuerpo es igual a correr el riesgo de vivir tomado por los estados de identificación. 


\section{La identidad del ser en el proceso de enseñanza aprendizaje.}

Esta elaboración, según un entrevistado, se la entiende como las características de las diferentes esferas de la identidad del ser, como la importancia de la formación de la psicoidentidad que vendría a ser una identidad psicológica formada por la incentivación de los roles de vida y los estatus de sus actividades, para así generar una coherencia entre la identidad aprendida y la esencial.

En este mismo sentido, siguiendo a un entrevistado, la ascensión continua de la identidad del ser se da a través de llamar a los educandos por sus nombres y apellidos, promocionando la autovaloración de recursos personales, reconociendo sus identidades, entrenarse a uno mismo y hacia el otro, autoevaluar su identidad a través de instrumentos, autoadministrarse teorías para autoconocerse, cultivar la identidad con el ejemplo, incentivar la autonomía e interiorizar las teorías para aplicación en la identidad durante la vida.

Además, la identidad se forma con el proceso de socialización, pues apelar a la identidad es estimularla, y al hacer esto, reacciona dándose a conocer ante el entorno. Luego, cuando el educando responde con lo que piensa, ya está estimulando la identidad, accediendo de esta forma a sus pensamientos, sentimientos y conductas.

Sin embargo, de acuerdo con la observación, la identidad de los educandos está muy condicionada por la recompensa, ya que cuando se los descubría plagiando durante un examen, lo dejaban de hacer, pero cuando no los descubrían, continuaban haciéndolo, no obstante, cuando eran redescubiertos plagiando, igual continuaban haciéndolo, mas cuando los educandos descubren que han sido descubiertos plagiando, adoptan una postura de no plagio, y aumentan el sigilo para plagiar con mayor mesura. De esto, se infiere una marcada necesidad de aprobación de sus identidades.

Después, los niveles de autoconocimiento de la identidad del ser, es entendido por una entrevistada a través de una autopercepción integral del ser para que el educando pueda conocer su identidad, de igual modo, sugiere otras vías como la contrastación de la identidad del educando con el otro, la búsqueda de evidencias prácticas de la identidad, la expresión de experiencias de los educandos como reflejo de su identidad y reflejo del contexto ambiental, respuestas proyectivas que dan ante los estímulos semiestructurados e inestructurados como revelador de la autoimagen. Sin embargo, se observó conductas que demuestran el nivel de autoconocimiento de la identidad, como la apelación a la vergüenza para entrar tarde al salón de clase, el apoyo en la autoconfianza para emitir comentarios fuera del contexto y una reticencia al expresar experiencias íntimas de la identidad. 


\section{El juicio valorativo del ser en el proceso de enseñanza aprendizaje.}

De acuerdo con los entrevistados, es una elaboración que se caracteriza por la dimensión dual del juicio valorativo como; su lado racional que es lo cognitivo y su lado emocional que es lo sensitivo. Asimismo, estos se consiguen mediante la interiorización de las experiencias mediadas. Sin embargo, el juicio valorativo tiene un déficit cuando se da por impulso.

Así, según los entrevistados, entre las características se tiene a un juicio valorativo clárido, preciso, exacto, con capacidad prospectiva, con aplicación práctica, con pensamiento crítico de calidad, sopesando las consecuencias para otros y sustentándolos con argumentos.

No obstante, se observó una dificultad en la promoción de los juicios valorativos y esta es el exceso de alumnos, a mayor cantidad de alumnos, mayor obstáculo para la elaboración de estos en clase.

Además, los juicios valorativos tienen diversas expresiones observadas, como emisiones de sonidos como desaprobación ante el bullicio, agradecimiento al prójimo ante la salud por el estornudo, comentarios ininteligibles como reacción ante la respuesta de la profesora, emisión de sonidos como símbolos de juicios y símbolo de entendimiento y risas contrariadas al escuchar respuestas inusitadas.

Por otro lado, los juicios valorativos pueden ser promovidos por acciones que según los entrevistados, pueden ser el uso de reforzadores, castigos, desvaloración para sobrevaloración, incitación a través de preguntas, promesa de recompensa, promoción de resultados buenos, uso del diálogo y de la motivación, entrenamiento a aquellos que no rinden, durante el espacio de dictado de la clase y en el espacio de participación del alumno, uso de reelaboración de preguntas, censurando la búsqueda externa de las consecuencias de sus actos, uso de la retroalimentación positiva, énfasis en no sentirse mal cuando las cosas no salen bien y búsqueda de situaciones específicas para juicios específicos.

Por otra parte, un entrevistado defendió el uso del pensamiento autocrítico como sinónimo del juicio valorativo, ya que el pensamiento crítico, arguyó, es la base de las autoevaluaciones de pensamiento y permite la autorreflexión.

\section{Interacciones interpersonales del ser en el proceso de enseñanza aprendizaje.}

Esta elaboración, conforme a los entrevistados, aborda las dimensiones de los vínculos como la jerarquía vertical y horizontal con el otro, el conocimiento de sí y del otro. Además, refieren que un vínculo útil para uno es útil para el otro y desarrolla más el ser, aparte que el uso de la conciliación es indicado para resolver conflictos entre vínculos y que debe investigarse la aproximación a las creencias de los vínculos, la elaboración de barreras 
entre grupos de vínculos, el tiempo como requisito para el conocimiento de los vínculos y lo determinante de la primera impresión de los vínculos.

Asimismo, se observa el empleo de trabajos grupales por afinidad, de este modo, se retroalimentan y es que trabajar entre vínculos conocidos cuando es labor sostenida y de largo plazo es mejor y da mayor seguridad personal, asimismo, mayor producción cuando se trabaja entre vínculos, alivio cuando se reparte la carga laboral, la determinación de la proximidad de asientos es por afinidad, competencia entre vínculos y se aprecia adaptación entre las interacciones de los vínculos.

Sin embargo, se observó plagio desmesurado en frente del docente, solicitud de ampliación del tiempo para el examen mientras plagian sin mesura, hasta una solicitud al profesor para que revele la respuesta del examen y desobediencia a la orden jerárquica acompañado de resistencia, vínculos en riesgo por diferencia de intereses y tensión en la atmósfera del salón por preguntas abiertas de la profesora.

Por otro lado, siguiendo las sugerencias de los entrevistados, se demandaron una mayor promoción de las habilidades psicosociales, y que estas sean con vínculos desconocidos, también mayor promoción de vínculos académicos, respeto entre los vínculos extraños, por las conductas de los vínculos y la complementación de habilidades entre los vínculos. Asimismo, sugieren que, en vez de vínculos superficiales, se elaboren vínculos académicos fructíferos.

Para esto, se apeló a la consciencia de relaciones de pareja responsables y constructivas considerando las expectativas de la psicosexualidad femenina y masculina y las redes sociales. Las cuales pueden violar la privacidad psicosexual, y generar relaciones de pareja superficiales en contraposición a relaciones de pareja profundas.

\section{Regulación del ser en el proceso de enseñanza aprendizaje.}

Conforme con los entrevistados y observado, esta categoría emergente está compuesta por las estrategias cognitivas que regulan el ser, como el chiste, la disciplina académica, la apelación a la puntualidad por parte del docente, uso de momentos para preguntas, el respeto con silencio de la exposición del profesor, uso de parámetros para la participación del alumno, uso de procedimientos prácticos, uso de preguntas y apelando al encuadre académico.

Estas estrategias son reflejadas a través de las opiniones de los educandos y son estimuladas a través del análisis, del descubrimiento, de la asociación, de la espontaneidad de habilidades cognitivas, de la comprensión de contenidos, de la comprensión de sí mismos, de la codificación de respuestas y de las interpretaciones contextualizadas. Vale añadir que estas pueden tener una activación natural sin que el docente las propicie. 
Por otro lado, según los entrevistados, la regulación del ser es posible porque un objetivo común genera motivación colaborativa, un problema motiva el ego, la motivación tiene una volición de por medio, la apelación a la mejor representación de la calidad promueve la regulación del ser en aras de sus objetivos como el uso de apuntes como control de calidad, sostenimiento de la lectura compartida, uso de la atención sostenida, empleo del silencio, mantenimiento de apuntes ante datos que la profesora brinda y agarre del mentón mientras se da el análisis y que es una falacia el hecho de que la motivación solo se da al inicio de la clase, la motivación ha de ser longitudinal.

Sin embargo, también se observó que la práctica calificada mantiene el interés y la concentración al igual que los instrumentos de estudio aunado al tiempo de duración del examen, la proyección de un video acompañado del silencio respectivo, y para finalizar, vale resaltar lo volitivo del mantenimiento del interés y concentración.

Por otro lado, conforme a los entrevistados, la autorregulación tiene un mantenimiento relativo ya que el riesgo de distracción por parte de los educandos después de trabajar arduo es alto y obstaculiza el interés y la concentración. Además, desaconsejan las clases magistrales puesto que los educandos entran en un estado de ensimismamiento y pasividad.

\section{Categorías influyentes en el problema}

Una de las problemáticas que más influyó sobre el modelamiento y que deviene de la categoría emergente de la identificación del ser en el PEA, es la dificultad por parte de los discentes en diferenciar sus identificaciones personales con las académicas, lo que demuestra un déficit en el nivel de desarrollo del ser, ya que al no poder darse cuenta que sus posturas personales sobre la materia en curso son reflejo de sus concepciones académicas y el desarrollo de estas, generan una desadaptación en sus desempeños al vivir sujetos con aquello que traen a clase y cerrándose a una apertura ante lo nuevo que el docente intenta mediar, entorpeciendo el vínculo con sus compañeros y el docente.

Otra problemática que influyó sobre el modelamiento fueron los juicios valorativos que traen los educandos de su educación particular proveniente de sus familias, vecindarios, culturas y escuelas por las cuales atravesaron, a clase, lo cual generó una diversidad en las expresiones de sus juicios valorativos respecto a sus desempeños en sesión, observándose que para algunos no es un problema hacer bulla en plena sesión de clase con el fin de generar chiste, hasta alumnos que condenan todo acto que genere distracción en el PEA. Asimismo, el obstáculo mayor respecto a la diversidad de juicios valorativos es el hecho de que son muchos los alumnos por salón, impidiendo que el docente pueda elaborar un espacio durante la sesión para abordar los juicios valorativos de cada alumno respecto a su desempeño en clase y hacia la temática mediada. Esto generó 
la categoría emergente de juicios valorativos del ser en el proceso de enseñanzaaprendizaje.

Finalmente, una categoría emergente que influyó sobre el modelamiento es interacciones interpersonales del ser en el proceso de enseñanza-aprendizaje, cuya problemática reside en el mal uso de los vínculos entre pares e impares, de esta manera, se obtuvo impresiones de los alumnos plagiando colaborativamente durante una práctica calificada y burlando la vigilancia del docente para volver a incurrir en el acto de plagiar, como si el hecho de asegurar una nota aprobatoria justificara lo inmoral de sus vínculos en las relaciones interpersonales durante el proceso de enseñanza-aprendizaje.

\section{Conclusiones aproximativas de los análisis realizados}

Se encontró que los educandos consideran de manera preferente sus posesiones materiales académicas para su desempeño en el proceso de enseñanza-aprendizaje. Como segundo lugar, consideran a sus posesiones socioemocionales como factor secundario, por ejemplo, pedir a un compañero algo prestado o preguntar si entendió o no la clase. Como tercer lugar, se halló que consideran su cuerpo como posesión para adaptarse, por ejemplo, prestar atención a sus sensaciones corporales para volver a la realidad y salir de un estado de ensimismamiento.

Luego, se concluye que los participantes se caracterizan por tener rasgos mórbidos en sus juicios valorativos hacia el desempeño del prójimo. Así como recomendaciones para que estos puedan desarrollar un juicio valorativo basado en principios cuantitativos; indicadores de lógica adecuada, prosocial y prospectiva, y cualitativos; valoración positiva del objeto a enjuiciar a pesar de que los indicadores cuantitativos no lo acrediten como tal.

En otra vertiente, se concluye de acuerdo con lo observado, que hay una autorregulación colectiva implícita que gobierna las conductas de los educandos en aras del proceso de enseñanza aprendizaje. Así como sus interacciones psicosexuales, pues los resultados indican que la manera como se nominan, se tratan, consideran sus roles, sugieren que tienen muy bien interiorizado al prójimo y sus propiedades en sí mismos, lo que no excluye que se den interacciones psicopatológicas como se observó en el acto de bullying.

Finalmente, los hallazgos sugieren concluir que los educandos están predispuestos a una autorregulación en el escenario del proceso de enseñanza aprendizaje sui géneris más allá del contexto educativo, como si el hecho de estar en un ambiente que implica determinados pactos sociales preestablecidos e implícitos, originara que su autorregulación se moldee de tal manera que pueda diferir en gran escala a la manera como se autorregulan fuera del proceso de enseñanza-aprendizaje. 


\section{Capítulo III}

\section{Modelación y validación de la propuesta}

\section{Propósito de la investigación}

El presente propósito es plantear la estrategia metodológica para mejorar la autopercepción de los estudiantes de octavo semestre de psicología en base a lo hallado en el diagnóstico producto del trabajo de campo y los fundamentos socioeducativo, pedagógico, psicológico y curricular. Asimismo, es la validación de la estrategia según juicio de expertos.

\section{Justificación.}

La presente propuesta se justifica porque según los hallazgos encontrados en el trabajo de campo, se aprecia una merma en la autopercepción del ser en el sujeto muestral de acuerdo a lo esperado y conforme a lo recopilado en las entrevistas de los docentes, al cuestionario que desarrollaron los sujetos de estudio y la guía de observación.

Además, el para qué de la estrategia metodológica se fundamenta en la mejora de la autopercepción en tanto se entiende esta como un proceso de autoconocimiento y desarrollo del ser para poder proveer al educando de octavo semestre de psicología con las técnicas y procedimientos necesarios que ofrecen la estrategia metodológica en aras de una mayor calidad de sus seres y acorde a las expectativas del contexto educativo.

\section{Fundamentación teórica y científica}

\section{Fundamentación socioeducativa.}

El contexto de fundamentación donde se plantea la propuesta reside en el distrito de Santiago de Surco, ubicado en la parte centro occidental del departamento de Lima y en la zona suroeste de la provincia homónima. La descripción social, según el INEI, al 30 de junio del año 2015, informa que la población total asciende a una cifra ascendente a 499210 habitantes (Municipalidad Santiago de Surco, 2019).

Luego, en lo referido a la descripción económica, se puede apreciar que en Surco habitan personas desde una condición socioeconómica alta, media alta, hasta baja. Esta variación se presenta de acuerdo al sector de residencia. Además, no solo se aprecian surcanos de diferentes clases sociales, sino también de diferentes ocupaciones; desde empresarios, políticos, hasta trabajadoras del hogar.

La propuesta tiene su recinto en la Universidad Ricardo Palma, una universidad particular fundada el 1 de julio de 1969, cuyas 18 carreras se agrupan en ocho facultades y está registrada en derecho privado sin fines de lucro personal en los Registros Públicos de Lima, cuya organización está compuesta por las autoridades de los órganos de Asamblea 
Universitaria, Consejo Universitario, Rectorado y Consejo de Facultad. Asimismo, su campus principal se localiza en la Av. Benavides 5440, Urb. Las Gardenias en el distrito de Surco.

De esta manera, la propuesta radica específicamente en la carrera de Psicología, cuyo inicio se dio con la creación de la URP de acuerdo al Decreto Ley № 17723 del primero de julio de 1969, integrándola al sistema de la Universidad Peruana de acuerdo al procedimiento del Artículo $22^{\circ}$ del Decreto ley № 17437 del 18 de febrero de 1969 . Al promulgarse la Ley Universitaria $N^{\circ} 23733$, del 9 de diciembre de 1983, y de acuerdo al capítulo XVI de las disposiciones transitorias, artículo octavo, se reimplanta el sistema de Facultades, y luego de las gestiones respectivas y en el plazo de ley, se logra la aprobación para constituir la Facultad de Psicología, posibilitando de esta manera constituir el Consejo de Facultad, la cual gestiona hasta la actualidad la formación en la carrera profesional de Psicología.

En lo que concierne a la visión de la Facultad de Psicología, se tiene que es: "Alcanzar el reconocimiento y la excelencia científica y profesional a nivel nacional e internacional en la formación de profesionales promotores del cambio y el desarrollo social sostenible", y lo referido a la misión: "Proporcionar a la comunidad profesionales en Psicología con una formación integral en el contexto multidisciplinar y la investigación científica posibilitando una adecuada inserción laboral acorde a las exigencias regionales, nacionales e internacionales, propiciando actividades asociadas al desarrollo social y cultural del país tendiente al logro del bienestar general de la sociedad".

A su vez, la Facultad de Psicología tiene un modelo pedagógico basado en el enfoque por competencias, mientras que su malla curricular se divide en malla general, cuya aplicación se da desde el primer hasta el séptimo semestre, dentro del marco de estudios profesionales, y mallas internas por especialidad, cuya aplicación se da desde el octavo semestre hasta el término de la carrera. Este diseño curricular de psicología tiene como estructura al enfoque cognitivo conductual, con énfasis en la investigación científica y la proyección social, por tanto, se deja claro las características académicas de los estudiantes.

De esta manera, se ve que la propuesta está inmersa por los principios de excelencia de la Facultad de Psicología que siguen los profesores, alumnos y personal, como; buen trato a las personas, espíritu crítico y racional, integridad y congruencia, puntualidad y orden, proactividad y espíritu de servicio, entre otros.

\section{Fundamentación pedagógica.}

La propuesta tiene como fundamento pedagógico al Modelo Educativo Etievan, en adelante MEE. Este modelo fue concebido en 1972, propuesto por Nathalie de Salzmann de Etievan 
y aplicado por primera vez en 1974 en el colegio "Los Hipocampitos" en Venezuela, además que ha sido extendido a otros países como, Colombia, Chile y Perú. Esta educadora nació en Georgia y se educó en la comunidad Fontainebleau, Francia, bajo las ideas de George Ivánovich Gurdjieff.

EI MEE fue concebido inicialmente para la educación básica regular, no obstante, sus preceptos y principios también se imparten en el Instituto para el Desarrollo Armónico del Hombre, instituto de donde derivan los postulados fundamentales para el MEE. EI IDAH es sin fines de lucro, cuya población objetivo son personas de ambos sexos y, de preferencia, mayores de 18 años en adelante, sin distinción de ocupación alguna, por tanto, aplicable a los estudiantes de octavo semestre de psicología. Las actividades que se imparten en el instituto incluyen el Estudio de las Ideas, el Trabajo de los Movimientos y la Práctica de la Enseñanza, dejados por G. I. Gurdjieff. Asimismo, el IDAH pertenece a la Asociación Internacional de Fundaciones Gurdjieff con filiales en Nueva York, París, Londres y Caracas.

Volviendo al modelo pedagógico, este se caracteriza, según lo escrito en "No saber es Formidable" (De Salzmann, 1989), por no presentar fundamentos teóricos per se, por el contrario, se fundamenta en las experiencias directas de su autora al tener contacto con niños, adolescentes y adultos en un transcurso mayor a 40 años de búsqueda. A su vez, este fundamento tiene valor científico de tipo empírico, porque están basados en la observación prolija de situaciones educativas y su proceso de enseñanza aprendizaje considerando los lineamientos de su maestro G. I. Gurdjieff.

En esta misma línea, el MEE presenta una cosmovisión pedagógica tricéntrica sobre el ser humano, situándolo como un ser cuyas manifestaciones son los pensamientos, sentimientos y actos. Por tal razón, De Salzmann (1989), propuso que "la educación debe ser un proceso mediante el cual se trata de desarrollar, en una forma integral y equilibrada, la mente, el sentimiento y el cuerpo" (p. 14).

La cosmovisión pedagógica tricéntrica que pregona el MEE es el más ideal como fundamento pedagógico para la estrategia metodológica, porque aborda la estructura psíquica del ser a cabalidad; el centro intelectual, el centro emocional y el centro motor instintivo.

Así, contextualizando el MEE a la categoría a mejorar aplicada a la muestra objetivo; se ve que la autopercepción, como se la fundamenta y entiende, conecta con este modelo pedagógico ya que presenta entre sus subcategorías fundamentadas la concepción tricéntrica del ser humano, de este modo; la autoimagen sería el aspecto intelectual de la autopercepción, la autoestima sería el aspecto afectivo de la autopercepción y la preservación de sí sería el aspecto motor instintivo de la autopercepción. 
Por otro lado, el MEE cuenta con 11 principios básicos que la sustentan, cuyos componentes conforman los pilares pedagógicos de este modelo. Estos son: (a) El amor al esfuerzo, el reto. (b) El amor al trabajo. (c) El desarrollo de la atención. (d) La educación no competitiva. (e) La importancia de buscar: no saber es formidable. (f) La necesidad de confianza. (g) El sentido de la responsabilidad. (h) La educación de la voluntad. (i) La necesidad de amor. (j) La exigencia y la libertad. Y (k) Preparación para la vida.

\section{Fundamentación psicológica.}

En lo referido a la fundamentación psicológica de la propuesta a modelar, se adopta el enfoque psicológico de la máquina humana tricéntrica, un enfoque coherente conforme al fundamento pedagógico adoptado (Ouspensky, 2010).

La adopción de este modelo se sustenta en el hecho de que facilita una mejor explicación para el proceso de autopercepción, el cual, a su vez, ayudará a estructurar la fundamentación de la estrategia metodológica a elaborar. De este modo, el proceso de autopercepción, desde una óptica de la dimensión del ser, inicia con un recuerdo de sí; en el cual el estudiante se recuerda, despertando de esta manera en su ser un sujeto perceptor en sí mismo y un objeto percibido en sí mismo. La dinámica binomial generada entre sujeto y objeto de sí, se da gracias a la consciencia, cuyas características, para los fines del presente trabajo, son: extensión, frecuencia, intensidad y tiempo.

Acto seguido, la consciencia del sujeto perceptor va a tener una impresión del objeto percibido de sí mismo, cuyas manifestaciones son las funciones de su tricentrismo, es decir, el pensamiento y sus expresiones intelectuales, el sentimiento y sus expresiones emocionales, y el instinto y/o movimiento junto a sus expresiones instintivas y motoras. Esta impresión genera en el sujeto perceptor un choque o shock, pudiendo suscitar, dependiendo de si es coherente o no con la autoconcepción del sujeto perceptor, un mecanismo de defensa.

Hasta este punto, está casi concluido el proceso de autopercepción de la estrategia metodológica a modelar, sin embargo, suceda o no el mecanismo de defensa, es necesario que el estudiante se ancle a sus sensaciones corporales para volver en sí y estar sintonizado con la realidad objetiva y subjetiva. Entonces, hasta este punto, el estudiante habrá obtenido una percepción de sí pura y objetiva de su realidad tricéntrica del ser.

A continuación, se describe los elementos sustanciales a detalle de este proceso de autopercepción, cuya estructura da fundamento a la estrategia metodológica.

\section{Recuerdo de sí.}

El proceso autoperceptivo inicia con el recuerdo de sí, esta parte medular e inicial del proceso tal como lo entiende Ouspensky (2010), significa que el sujeto se percata de sí 
mismo en el momento de la autopercepción. Abriendo las puertas y obteniendo la oportunidad con este ademán interior a los procesos a posteriori.

Mientras el educando se encuentra en alguna actividad donde el incesante flujo de pensamientos distraen su atención, es necesario, previamente explicado este primer paso, que se llame para sus adentros cada vez que pueda o como diría Ouspensky (2012), cada vez que las situaciones de fuerte estrés emocional lo obliguen a estar presente, para poder estar consciente de sí, y así dirigirla a una de las manifestaciones que pueda percibir de sus funciones psicológicas o alguna que esté muy exacerbada, y sea obvia su manifestación.

\section{Consciencia.}

Luego de iniciar el proceso autoperceptivo con el recuerdo de sí, se da inicio a la consciencia, entendiendo esta como una especie muy particular de darse cuenta (Ouspensky, 2010). Aquí, es necesario enfatizar que la consciencia no es un proceso cognitivo, ya que es independiente a ella, por el contrario, es una actividad psíquica propia del ser humano y que solo este puede percatarse de ella. Es una característica clave que diferencia al humano del resto de animales.

De este modo, el estudiante podrá, gracias al chispazo de consciencia, percatarse de los diferentes estados en que se encuentran sus centros psicológicos. Además, con este chispazo, podrá tener la oportunidad de diferenciar sus manifestaciones y llevarse una impresión experiencial y vivencial de aquello que se manifestó en él o ella.

Asimismo, es válido mencionar que no hay forma de observar la consciencia desde afuera, cuya implicación denota en que solo el sujeto perceptor puede saber qué percibe y cómo lo percibe. Sin embargo, Ouspensky (2010), refirió que hay grados de consciencia; primero está la duración, entendida como ¿cuánto tiempo el sujeto ha estado consciente?, luego está la frecuencia, entendida como ¿cuántas veces el sujeto ha llegado a ser consciente?, después está la extensión, entendida como ¿qué abarca la consciencia del sujeto sobre sí?, y la intensidad, entendida como ¿qué tanto el sujeto ha podido ser consciente de una percepción?

Como se verá, estos indicadores cuantitativos son transversales y observables por todo sujeto, siendo de esta manera compartido por tal para así poder ser comprendido por los demás y en este caso, por el mediador de la estrategia metodológica, retroalimentando de esta forma las características del fenómeno autopercibido para el educando participante.

\section{Funciones de los centros psicológicos.}

En la misma línea, la autopercepción está dirigida a captar las manifestaciones del ser tricéntrico con fines de desarrollar un corpus de autoconocimiento de los estados de sus centros a través de la constatación vivencial y experiencial que otorga la acción de 
autopercibirse, que tiene beneficios como el desarrollo de consciencia y efectos terapéuticos.

Vale añadir que todo aquello que perciban de sí puede suscitar diversas reacciones en cada uno de sus centros, lo cual ha de conservarse para una posterior elaboración de aquello que percibieron. Sin embargo, la manera de cómo han de abordar estas reacciones ha de ser, solo con fines de limitar fronteras y seguir la estructura que la estrategia metodológica provee, la más limpia elaboración del objeto percibido con aceptación incondicional para que esta acción genere su propio efecto en el ser del educando.

Así, se explica de manera general las características particulares de cada centro psíquico, independientemente de su funcionamiento, para posteriormente proceder a fundamentar cada una de sus funciones.

Entre las características de los centros, la primera es que estas pueden solapar sus funciones (Ouspensky, 2010), es decir, el centro intelectual puede ayudar al centro motor a adquirir una competencia específica, el centro emocional puede solaparse con el centro motor, el centro intelectual y emocional pueden solaparse y así sucesivamente.

Por otro lado, una segunda característica de los centros es su velocidad, así, el centro intelectual es más lento que el motor instintivo y emocional, mientras que el motor instintivo es más lento que el emocional (Ouspensky, 2010).

Continuando, una tercera característica de los centros es su memoria funcional que se da gracias a las impresiones que el sujeto desarrolla en su vida y a las cuales se ve expuesto, generando de esa manera los recuerdos y las asociaciones particulares en cada centro que posteriormente se activan conforme el centro se desenvuelve (Ouspensky, 2010). De este modo, el educando al autopercibirse podrá tener la posibilidad de darse cuenta sobre el funcionamiento de sus centros; si trabajan bien o trabajan mal, ahora cual fuere el caso, gracias a una autopercepción según esta propuesta se podrá constatar su funcionamiento a través de la consciencia para una posterior corrección y optimización de sus funciones.

Como cuarta y última característica de los centros, se tiene a la polaridad, en otros términos, alude a los polos opuestos que definen las funciones de los centros psíquicos, de esta manera, el centro intelectual afirma y niega, el centro emocional gusta y disgusta y el centro motor instintivo agrada y desagrada, además de ser activo o pasivo (Ouspensky, 2010).

Asimismo, no solo la división en polos es la característica final de los centros, sino también la subdivisión de cada polo en tres aspectos; la mecánica, la emocional y la intelectual, de esta forma, se tiene que los centros tienen una división polar que a su vez cada polo se subdivide en tres aspectos, como el centro intelectual afirmativo de corte mecánico, emocional o intelectual, el centro emocional que gusta de corte mecánico, 
emocional o intelectual, el centro motor instintivo activo de corte mecánico, emocional o intelectual, y así sucesivamente con el polo opuesto (Ouspensky, 2010).

De esta manera, las características de los centros se resumen en bipolaridad y subdivisiones de tres por cada polo, velocidad, memoria funcional y solapamiento de funciones. Estas características han de tenerse en cuenta a la hora de estructurar la estrategia metodológica ya que intervienen en el proceso de autopercepción de manera esquemática.

Función del pensamiento.

En el instante que el educando de psicología se recuerda a sí mismo, y aparece junto con ella la consciencia, esta es potencial de enfocarse a toda la mescolanza de las funciones de sus centros psicológicos, de esta manera, si la dirige a las manifestaciones del centro intelectual, se topará con los procesos mentales; como la comparación, el raciocinio, el análisis, la síntesis, la afirmación, la negación, la generalización, la elaboración de palabras, de ideas, la imaginación, entre otras (Ouspensky, 2010).

Además, podrá percibir el contenido y curso de sus pensamientos, así como las manifestaciones sublimes del intelecto, como la creatividad intelectual o artística. Cabe mencionar que también podrá percibir absurdos intelectuales, falacias, sofismas, deslices cognitivos y particularidades de su funcionamiento intelectual.

\section{Función del sentimiento.}

Por otro lado, cuando la autopercepción es dirigida a las manifestaciones del centro afectivo, el educando se topará con los procesos afectivos motivacionales; como las emociones en toda su gama de posibles manifestaciones, formas, gustos y disgustos, entre ellas estarían la alegría, la pena, la felicidad, la tristeza, la añoranza, la dicha, etc. (Ouspensky, 2010).

Asimismo, podrá percibir el contenido y curso de sus emociones, así como las manifestaciones sublimes, como la motivación, la bondad, el amor, la esperanza, la caridad, la excitación, no obstante, también es susceptible de percibir remordimientos, odios, tensiones, miedos, y las particularidades afectivas más remotas propias de cada ser.

Función del instinto y movimiento.

En otra vertiente, el educando cuando dirige la autopercepción a los centros instintivo y motor, podrá captar todas aquellas manifestaciones que el organismo cumple sin necesidad de aprenderlo, como la respiración, la función de los sentidos, el apetito, la sed, la eliminación de desechos, el agrado y desagrado ante determinados estímulos motores instintivos, los reflejos como el bostezo, la risa, el movimiento de la pierna cuando la 
golpeas en la rodilla, etcétera. Además, podrá percibir todas las funciones motoras como caminar, comer, hablar, escribir, aguzar un sentido, movimientos reflejos, etcétera (Ouspensky, 2010).

Para resumir, las funciones del centro instintivo son innatas, mientras que las funciones del centro motor son aprendidas. Comprendido esto, la autopercepción dirigida a estas funciones, puede captar el curso y contenido de los procesos motores instintivos, así como sus manifestaciones sublimes, como movimientos guturales en la garganta para emitir canciones de rock pesado o sonidos como de robot o de la naturaleza, movimientos gimnásticos complejos, tipos de respiraciones que practican los yoguis, entre otras.

Por otro lado, también es susceptible de percibir las funciones erráticas del centro motor instintivo, ya sean tics motores, regurgitaciones, movimientos motores involuntarios, hipo, inapetencia, estreñimiento, insomnio, entre otros.

\section{Mecanismo de defensa.}

La última etapa del proceso autoperceptivo viene con los mecanismos de defensa planteados por la hija de Freud, (Freud, 1965), cuya definición alude a los diversos medios psicológicos que el yo emplea ante estímulos que surgen entre las exigencias instintivas de los centros psíquicos y la necesidad de adaptarse al mundo de la realidad para salvaguardarse.

De este modo, el estudiante tiene como reto final en el proceso autoperceptivo el poder darse cuenta de aquello que lo distancia entre el objeto percibido en esencia y el sujeto perceptor, pues entre este binomio está susceptible de aparición algún mecanismo de defensa que obstruya la percepción pura de aquello potencialmente perceptible.

Sin embargo, tanto se perciba el mecanismo de defensa como el objeto perceptible en esencia de las manifestaciones del ser, ambos son aceptables en la medida que la aceptación incondicional sea el acto que defina el final del proceso perceptivo, además de su posterior elaboración. A su vez, en caso de que el sujeto se vea envuelto en los efectos del mecanismo de defensa, se sugiere anclarse a sus sensaciones corporales hasta que el estado haya transcurrido y quedarse con el proceso de la impresión percibida.

Una vez establecido los elementos del proceso autoperceptivo, se tiene claro el conducto estándar por el cual atravesará el sujeto muestral; iniciando con un recuerdo de sí cuya activación posibilitará acceder a un chispazo de consciencia que se podrá dirigir a algunas de las funciones de los centros psicológicos corriendo el riesgo de percibir un mecanismo de defensa en vez de la esencia del objeto potencialmente perceptible, y si el sujeto perceptor se ve envuelto por los efectos del mecanismo de defensa, una vez dado cuenta de esto, ha de recurrir al anclaje con las sensaciones corporales para quedarse con la última impresión percibida para posterior elaboración, y así sucesivamente. 


\section{Fundamentación curricular.}

Los fundamentos curriculares para la presente propuesta se basan en el documento normativo titulado "plan estratégico para la carrera profesional de psicología periodo 2015 2019" de la Facultad de Psicología en la Universidad Ricardo Palma.

Aquí se describe una de las características de la misión de la carrera de psicología, cual es la formación integral del educando, haciendo énfasis en sólidos valores éticos, humanísticos y culturales. Estas características son viables en tanto se promueva una formación dirigida al ser del educando, objetivo posible a través de la estrategia metodológica que se fundamenta porque mejorar la autopercepción genera, entre otros beneficios, posibilidades de autoconocimiento, por tanto, condiciones para interiorizar valores éticos y humanísticos, tal como describe una de las misiones de la carrera de psicología.

Asimismo, entre los valores institucionales de la Facultad de Psicología, asume el humanismo y la ética. Nuevamente, se ve el énfasis en lo axiológico dentro de la gestión curricular. Objetivo que se acomoda con los propósitos de la propuesta a modelar.

Además, el lema institucional de la Universidad Ricardo Palma es "Formamos seres humanos para una cultura de paz". Y con este lema, se afirma el énfasis en promover la dimensión del ser en la malla curricular de las carreras en general a través del humanismo.

Por otro lado, entre los principios de excelencia de la Facultad de Psicología que impregnan el currículo y el clima organizacional, se tiene la integridad y congruencia, la proactividad y espíritu de servicio y la veracidad y autenticidad. Principios acordes con un desarrollo del ser, por tanto, se refuerza y reafirma la idea de que el currículo de la Facultad de Psicología tiene fuertes bases que conectan con la dimensión del ser. Idea que se asocia con los objetivos de la propuesta a modelar.

Finalmente, en lo que refiere a la malla curricular, se aprecia que en el sexto semestre se enseña el curso de Psicología y Ética Profesional, curso que han llevado los sujetos de estudio. Dentro de la sumilla, se resalta el desarrollo de la función reguladora del comportamiento humano y su importancia en el ejercicio del psicólogo profesional. Con esto, se verifica el marcado rasgo tendiente al desarrollo del ser como uno de los objetivos curriculares primarios que promueve la Facultad de Psicología en sus educandos.

Por tanto, los fundamentos curriculares para una propuesta basada en una estrategia metodológica para mejorar la autopercepción de los educandos de psicología quedan sentadas. 


\section{Diseño gráfico funcional de la propuesta}

\section{Esquema teórico funcional.}

A continuación, se presenta el siguiente gráfico como modelado iconográfico de la estrategia metodológica para mejorar la autopercepción de los estudiantes de octavo semestre de psicología: 


\section{Descripción de la propuesta.}

En el modelado iconográfico se puede observar que el circuito empieza a la izquierda con el estado real de las categorías emergentes para luego dirigirse con una flecha a la propuesta en sí como encabezado principal del gráfico. En este encabezado del centro medio superior inicia la intervención con una flecha bidireccional de retroalimentación hacia una llave que delimita las técnicas autorregulatorias y el proceso autoperceptivo.

Vale aclarar que el proceso autoperceptivo y las técnicas autorregulatorias son un binomio, por tanto, se traslapan y juntas forman parte inherente de la autopercepción per se. De este modo, mientras se den las técnicas de lluvia de ideas, asociación libre, técnica de relajación, compartir de experiencias y movimientos en sus respectivas sesiones y con sus respectivos objetivos, la dinámica del proceso autoperceptivo se estará dando.

Así, el ciclo inicia cuando el educando activa el recuerdo de sí, lo cual llama a la consciencia que a su vez trae consigo inmediatamente el riesgo de experimentar un mecanismo de defensa o tope. No obstante, si aquello que ve el educando en sí no es coherente con la forma como se autoconcibe, el mecanismo de defensa lo obnubilará de inmediato, de esta forma, no se podrá llegar a la percepción pura de sí, por esto se insta a mantenerse anclado en sus sensaciones corporales mientras sucede este proceso fugaz y se traspasa el umbral del posible mecanismo de defensa o tope.

Hasta este punto, si el procedimiento es seguido conforme se instruye, se obtendrá irremediablemente una percepción pura de sí en su totalidad o parcial que el educando ha de elaborarla objetivamente para compartirla como experiencia de sí a posteriori con sus compañeros de trabajo y con su respectiva retroalimentación que al mismo tiempo transformará su ser en el sentido de que lo enriquecerá con una impresión de autoconocimiento y la posibilidad de mejorar aquello que sienta hacer.

\section{Implementación de la propuesta}

En este tercer momento de la propuesta se procede a esquematizar la estructura global de la estrategia metodológica para mejorar la autopercepción de los estudiantes de octavo semestre de psicología, de esta manera, se empieza elaborando el plan general, cuyo contenido abarca las sesiones con sus respectivos contenidos, actividades, técnicas e indicadores.

\section{Objetivo general.}

Diseñar la estructura de la estrategia metodológica para mejorar la autopercepción de los estudiantes de octavo semestre de psicología. 


\section{Objetivos específicos.}

\section{Diseñar la estructura del proceso autoperceptivo y las técnicas de la estrategia}

metodológica.

Diseñar la estructura del centro intelectual, sus funciones y sus características.

Diseñar la estructura del centro emocional, sus funciones y sus características.

Diseñar la estructura del centro motor instintivo, sus funciones y sus características.

\section{Organización de contenidos y actividades del diseño de la E. M.}

Tabla 2.

\section{Organización de contenidos y actividades del diseño de la estrategia metodológica}

\begin{tabular}{|c|c|c|c|c|}
\hline Sesión & Contenido & Actividades & Técnicas & Indicadores \\
\hline $\begin{array}{l}\text { Sesión } \\
N^{\circ} 1: \\
\text { "Introduc } \\
\text { ción a la } \\
\text { estrategi } \\
\text { a } \\
\text { metodoló } \\
\text { gica para } \\
\text { mejorar } \\
\text { la } \\
\text { autoperc } \\
\text { epción". }\end{array}$ & $\begin{array}{l}\text { Explicación } \\
\text { de los } \\
\text { centros } \\
\text { psicológicos } \\
\text { y sus } \\
\text { funciones, el } \\
\text { recuerdo de } \\
\text { sí, la } \\
\text { consciencia } \\
\text { durante la } \\
\text { autopercepci } \\
\text { ón y los } \\
\text { mecanismos } \\
\text { de defensa } \\
\text { en la } \\
\text { autopercepci } \\
\text { ón. }\end{array}$ & $\begin{array}{l}\text { Identificar y comunicar el modus } \\
\text { operandi autoperceptivo. } \\
\text { Detectar y comunicar lo percibido } \\
\text { en uno. } \\
\text { Reflexionar sobre el estilo } \\
\text { autoperceptivo y su mejora. } \\
\text { Aprender el proceso } \\
\text { autoperceptivo y la estrategia } \\
\text { metodológica. } \\
\text { Desarrollar una temática grupal } \\
\text { basada en la asociación libre y la } \\
\text { lluvia de ideas. } \\
\text { Autoadministrarse el proceso } \\
\text { autoperceptivo y las técnicas de } \\
\text { la estrategia metodológica. } \\
\text { Comprometerse a la transferencia } \\
\text { de lo aprendido para la vida. } \\
\text { Compartir experiencias de la } \\
\text { sesión. }\end{array}$ & $\begin{array}{l}\text { Observación de } \\
\text { sí. } \\
\text { Anclaje en las } \\
\text { sensaciones } \\
\text { corporales. } \\
\text { Sentir al otro. } \\
\text { Compartir de } \\
\text { experiencias. } \\
\text { Aceptación } \\
\text { incondicional. } \\
\text { Compromiso del } \\
\text { ser. } \\
\text { Elaboración } \\
\text { objetiva de lo } \\
\text { percibido. } \\
\text { Lluvia de ideas. } \\
\text { Asociación libre. } \\
\text { Paros. } \\
\text { Retroalimentaci } \\
\text { ón. }\end{array}$ & $\begin{array}{l}\text { Nomina su estilo } \\
\text { autoperceptivo. } \\
\text { Nombra sus } \\
\text { autopercepciones. } \\
\text { Demuestra señales de } \\
\text { reflexión. } \\
\text { Demuestra dominio sobre } \\
\text { el proceso autoperceptivo y } \\
\text { la estrategia metodológica. } \\
\text { Demuestra señales de } \\
\text { participación usando la } \\
\text { asociación libre y la lluvia } \\
\text { de ideas. } \\
\text { Demuestra señales de } \\
\text { autoadministración de lo } \\
\text { anclado. } \\
\text { Demuestra compromiso } \\
\text { con la transferencia de lo } \\
\text { aprendido. } \\
\text { Comunica sus vivencias de } \\
\text { la sesión. }\end{array}$ \\
\hline $\begin{array}{l}\text { Sesión } \\
N^{\circ} 2 \text { : } \\
\text { "Constat } \\
\text { ación del } \\
\text { curso y } \\
\text { contenid } \\
\text { o de las } \\
\text { funcione } \\
\text { s } \\
\text { intelectu } \\
\text { ales". }\end{array}$ & $\begin{array}{l}\text { Explicación } \\
\text { del centro } \\
\text { intelectual, } \\
\text { sus } \\
\text { funciones y } \\
\text { sus } \\
\text { característic } \\
\text { as. }\end{array}$ & $\begin{array}{l}\text { Identificar y comunicar el modus } \\
\text { operandi autoperceptivo de las } \\
\text { manifestaciones intelectuales. } \\
\text { Detectar y comunicar las } \\
\text { manifestaciones intelectuales. } \\
\text { Reflexionar sobre el estilo } \\
\text { autoperceptivo de las } \\
\text { manifestaciones intelectuales y su } \\
\text { mejora. } \\
\text { Aprender el proceso } \\
\text { autoperceptivo de las } \\
\text { manifestaciones intelectuales y } \\
\text { sus características. } \\
\text { Realizar una técnica de relajación } \\
\text { basada en la observación sin } \\
\text { intervención del intelecto. } \\
\text { Autoadministrarse las técnicas de } \\
\text { la estrategia metodológica. } \\
\text { Comprometerse a la transferencia } \\
\text { de lo aprendido para la vida. } \\
\text { Compartir experiencias de la } \\
\text { sesión. }\end{array}$ & $\begin{array}{l}\text { Retroalimentaci } \\
\text { ón. } \\
\text { Paros. } \\
\text { Relajación. } \\
\text { Sentir al otro. } \\
\text { Observación de } \\
\text { sí. } \\
\text { Anclaje en las } \\
\text { sensaciones } \\
\text { corporales. } \\
\text { Compartir de } \\
\text { experiencias. } \\
\text { Aceptación } \\
\text { incondicional. } \\
\text { Compromiso del } \\
\text { ser. } \\
\text { Elaboración } \\
\text { objetiva de lo } \\
\text { percibido. }\end{array}$ & $\begin{array}{l}\text { Nomina su estilo } \\
\text { autoperceptivo de las } \\
\text { manifestaciones } \\
\text { intelectuales. } \\
\text { Nombra sus } \\
\text { manifestaciones } \\
\text { intelectuales. } \\
\text { Demuestra señales de } \\
\text { reflexión. } \\
\text { Demuestra dominio sobre } \\
\text { el proceso autoperceptivo } \\
\text { de las manifestaciones } \\
\text { intelectuales y sus } \\
\text { características. } \\
\text { Demuestra señales de } \\
\text { participación en la técnica } \\
\text { de relajación. } \\
\text { Demuestra señales de } \\
\text { autoadministración de lo } \\
\text { anclado. } \\
\text { Demuestra compromiso } \\
\text { con la transferencia de lo } \\
\text { aprendido. } \\
\text { Comunica sus vivencias de } \\
\text { la sesión. }\end{array}$ \\
\hline
\end{tabular}




\begin{tabular}{|c|c|c|c|c|}
\hline $\begin{array}{l}\text { Sesión } \\
N^{\circ} 3: \\
\text { "Constat } \\
\text { ación del } \\
\text { curso y } \\
\text { contenid } \\
\text { o de las } \\
\text { funcione } \\
\text { s } \\
\text { emocion } \\
\text { ales". }\end{array}$ & $\begin{array}{l}\text { Explicación } \\
\text { del centro } \\
\text { emocional, } \\
\text { sus } \\
\text { funciones y } \\
\text { sus } \\
\text { característic } \\
\text { as. }\end{array}$ & $\begin{array}{l}\text { Identificar y comunicar el modus } \\
\text { operandi autoperceptivo de las } \\
\text { manifestaciones emocionales. } \\
\text { Detectar y comunicar las } \\
\text { manifestaciones emocionales. } \\
\text { Reflexionar sobre el estilo } \\
\text { autoperceptivo de las } \\
\text { manifestaciones emocionales y su } \\
\text { mejora. } \\
\text { Aprender el proceso } \\
\text { autoperceptivo de las } \\
\text { manifestaciones emocionales y } \\
\text { sus características. } \\
\text { Identificar y compartir una } \\
\text { experiencia de vida mientras el } \\
\text { receptor siente lo narrado. } \\
\text { Autoadministrarse las técnicas de } \\
\text { la estrategia metodológica. } \\
\text { Comprometerse a la transferencia } \\
\text { de lo aprendido para la vida. } \\
\text { Compartir experiencias de la } \\
\text { sesión. }\end{array}$ & $\begin{array}{l}\text { Retroalimentaci } \\
\text { ón. } \\
\text { Paros. } \\
\text { Sentir al otro. } \\
\text { Observación de } \\
\text { sí. } \\
\text { Anclaje en las } \\
\text { sensaciones } \\
\text { corporales. } \\
\text { Compartir de } \\
\text { experiencias. } \\
\text { Aceptación } \\
\text { incondicional. } \\
\text { Compromiso del } \\
\text { ser. } \\
\text { Elaboración } \\
\text { objetiva de lo } \\
\text { percibido. }\end{array}$ & $\begin{array}{l}\text { Nomina su estilo } \\
\text { autoperceptivo de las } \\
\text { manifestaciones } \\
\text { emocionales. } \\
\text { Nombra sus } \\
\text { manifestaciones } \\
\text { emocionales. } \\
\text { Demuestra señales de } \\
\text { reflexión. } \\
\text { Demuestra dominio sobre } \\
\text { el proceso autoperceptivo } \\
\text { de las manifestaciones } \\
\text { emocionales y sus } \\
\text { características. } \\
\text { Demuestra señales de } \\
\text { participación en el } \\
\text { compartir de experiencias. } \\
\text { Demuestra señales de } \\
\text { autoadministración de lo } \\
\text { anclado. } \\
\text { Demuestra compromiso } \\
\text { con la transferencia de lo } \\
\text { aprendido. } \\
\text { Comunica sus vivencias de } \\
\text { la sesión. }\end{array}$ \\
\hline $\begin{array}{l}\text { Sesión } \\
N^{\circ} 4 \text { : } \\
\text { "Constat } \\
\text { ación del } \\
\text { curso y } \\
\text { contenid } \\
\text { o de las } \\
\text { funcione } \\
\text { s } \\
\text { motoras } \\
\text { instintiva } \\
\text { s". }\end{array}$ & $\begin{array}{l}\text { Explicación } \\
\text { del centro } \\
\text { motor } \\
\text { instintivo, } \\
\text { sus } \\
\text { funciones y } \\
\text { sus } \\
\text { característic } \\
\text { as. }\end{array}$ & $\begin{array}{l}\text { Identificar y comunicar el modus } \\
\text { operandi autoperceptivo de las } \\
\text { manifestaciones motoras } \\
\text { instintivas. } \\
\text { Detectar y comunicar las } \\
\text { manifestaciones motoras } \\
\text { instintivas. } \\
\text { Reflexionar sobre el estilo } \\
\text { autoperceptivo de las } \\
\text { manifestaciones motoras } \\
\text { instintivas y su mejora. } \\
\text { Aprender el proceso } \\
\text { autoperceptivo de las } \\
\text { manifestaciones motoras } \\
\text { instintivas y sus características. } \\
\text { Realizar movimientos bajo la } \\
\text { instrucción del mediador según la } \\
\text { técnica del canon. } \\
\text { Autoadministrarse las técnicas de } \\
\text { la estrategia metodológica. } \\
\text { Comprometerse a la transferencia } \\
\text { de lo aprendido para la vida. } \\
\text { Compartir experiencias de la } \\
\text { sesión. }\end{array}$ & $\begin{array}{l}\text { Canon. } \\
\text { Sentir al otro. } \\
\text { Retroalimentaci } \\
\text { ón. } \\
\text { Paros. } \\
\text { Observación de } \\
\text { sí. } \\
\text { Anclaje en las } \\
\text { sensaciones } \\
\text { corporales. } \\
\text { Compartir de } \\
\text { experiencias. } \\
\text { Aceptación } \\
\text { incondicional. } \\
\text { Compromiso del } \\
\text { ser. } \\
\text { Elaboración } \\
\text { objetiva de lo } \\
\text { percibido. }\end{array}$ & $\begin{array}{l}\text { Nomina su estilo } \\
\text { autoperceptivo de las } \\
\text { manifestaciones motoras } \\
\text { instintivas. } \\
\text { Nombra sus } \\
\text { manifestaciones motoras } \\
\text { instintivas. } \\
\text { Demuestra señales de } \\
\text { reflexión. } \\
\text { Demuestra dominio sobre } \\
\text { el proceso autoperceptivo } \\
\text { de las manifestaciones } \\
\text { motoras instintivas y sus } \\
\text { características. } \\
\text { Demuestra participación } \\
\text { sobre los movimientos. } \\
\text { Demuestra señales de } \\
\text { autoadministración de lo } \\
\text { anclado. } \\
\text { Demuestra compromiso } \\
\text { con la transferencia de lo } \\
\text { aprendido. } \\
\text { Comunica sus vivencias de } \\
\text { la sesión. }\end{array}$ \\
\hline
\end{tabular}

Fuente: Elaboración propia (2019)

Organización de las actividades.

A continuación, se procede a organizar la estructura de cada una de las sesiones

programadas. 


\section{Estrategia introductoria a la autorregulación}

\begin{tabular}{|c|c|}
\hline Propósito de la estrategia & $\begin{array}{l}\text { Que el estudiante comprenda desde su } \\
\text { experiencia los centros psicológicos y sus } \\
\text { funciones, el recuerdo de sí, la consciencia } \\
\text { durante la autopercepción y los mecanismos de } \\
\text { defensa en la autopercepción. }\end{array}$ \\
\hline Tiempo & $\begin{array}{l}\text { La duración de la sesión es de un tiempo de } 60 \\
\text { minutos. }\end{array}$ \\
\hline Materiales & $\begin{array}{l}\text { Aula, carpetas, pizarra, plumones, proyector y } \\
\text { computadora. }\end{array}$ \\
\hline $\begin{array}{l}\text { Desarrollo de la actividad: } \\
\text { 1. Se inicia formando parejas de trabajo entre los } \\
\text { participantes para que uno de ellos pregunte al otro ¿cómo te } \\
\text { autopercibes?, y el compañero responda. Luego, se cambia } \\
\text { de roles e inicia de nuevo preguntando y respondiendo, para } \\
\text { una posterior retroalimentación del mediador a todos según } \\
\text { lo recabado. } \\
\text { 2. Posteriormente, una pareja pregunta al otro ¿qué has } \\
\text { percibido de ti?, y el compañero responde. Después, se } \\
\text { cambian de roles e inicia de nuevo preguntando y } \\
\text { respondiendo, para una posterior retroalimentación del } \\
\text { mediador a todos según lo recabado. } \\
\text { 3. Inmediatamente, el mediador les dice a todos: Según lo } \\
\text { vivido hasta el momento ¿cómo deberían percibirse? Y ¿qué } \\
\text { deberían autopercibir?, deja un momento para que } \\
\text { reflexionen mientras vuelven a sus asientos. } \\
\text { 4. El mediador interactuando con los participantes desarrolla } \\
\text { los procesos de la autopercepción; centros psicológicos y sus } \\
\text { funciones, el recuerdo de sí, la consciencia durante la } \\
\text { autopercepción y los mecanismos de defensa en la } \\
\text { autopercepción. Además, comparte técnicas de la estrategia } \\
\text { metodológica para que el proceso autoperceptivo se ejecute } \\
\text { a cabalidad. } \\
5 \text { Se les invita a los participantes a crear una temática } \\
\text { novedosa a través de la asociación libre y la lluvia de ideas, } \\
\text { mientras aplican lo anclado en sí mismos y el mediador } \\
\text { organiza la información en la pizarra. } \\
6 \text {. Después, se les solicita el compromiso por parte de cada } \\
\text { uno para transferir lo aprendido a sus vidas personales hasta } \\
\text { que las sesiones de la estrategia metodológica culminen y se } \\
\text { puedan cumplir los objetivos trazados. } \\
\text { 7. Finalmente, se forma un círculo entre todos para que los } \\
\text { participantes puedan intercambiar sus experiencias de la } \\
\text { sesión, mientras el mediador actúa de moderador y genera } \\
\text { una retroalimentación general. }\end{array}$ & 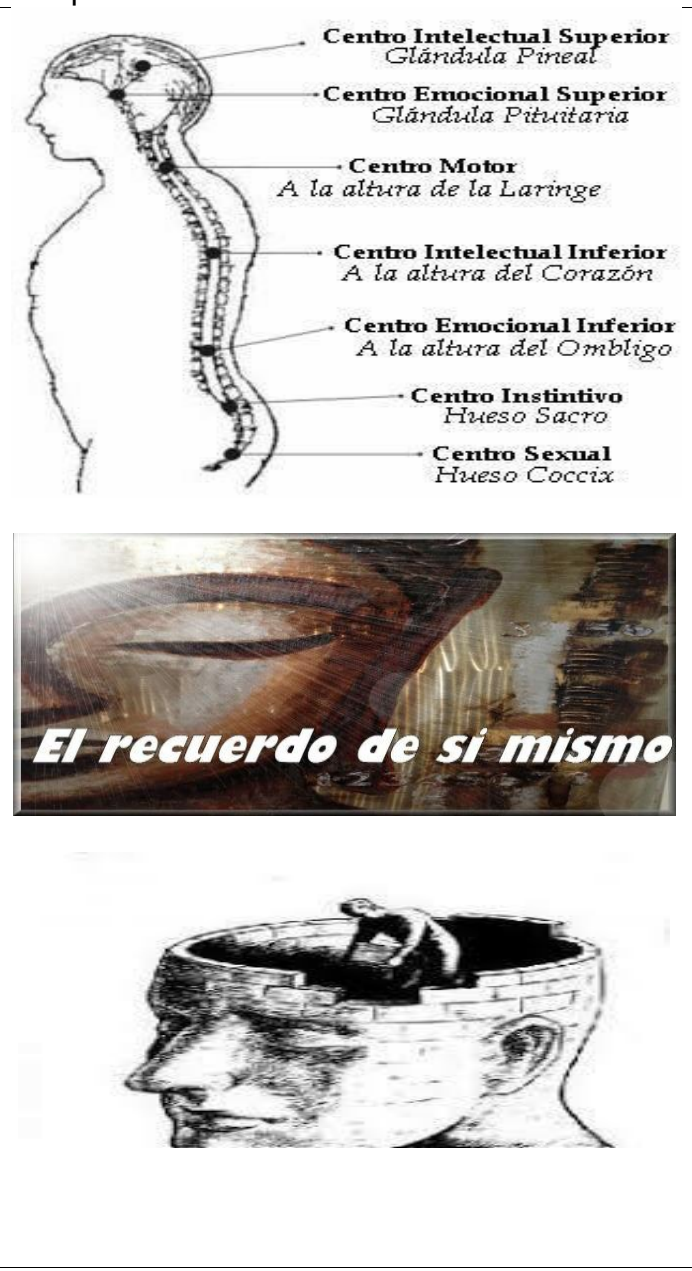 \\
\hline Criterio de evaluación de los aprendizajes & $\begin{array}{l}\text { Constatación del proceso autoperceptivo y las } \\
\text { técnicas de la estrategia metodológica. }\end{array}$ \\
\hline Indicadores de evaluación & $\begin{array}{l}\text { 1. Nomina su estilo autoperceptivo. } \\
\text { 2. Nombra sus autopercepciones. } \\
\text { 3. Demuestra señales de reflexión. } \\
\text { 4. Demuestra dominio sobre el proceso } \\
\text { autoperceptivo y la estrategia metodológica. } \\
\text { 5. Demuestra señales de participación usando la } \\
\text { asociación libre y la lluvia de ideas. } \\
\text { 6. Demuestra señales de autoadministración de } \\
\text { lo anclado. } \\
\text { 7. Demuestra compromiso con la transferencia } \\
\text { de lo aprendido. } \\
\text { 8. Comunica sus vivencias de la sesión. }\end{array}$ \\
\hline
\end{tabular}




\section{Estrategia metodológica para las funciones intelectuales}

\begin{tabular}{|c|c|}
\hline Propósito de la estrategia & $\begin{array}{l}\text { Que el estudiante comprenda desde su } \\
\text { experiencia el centro intelectual, sus funciones y } \\
\text { sus características. }\end{array}$ \\
\hline Tiempo & $\begin{array}{l}\text { La duración de la sesión es de un tiempo de } 60 \\
\text { minutos. }\end{array}$ \\
\hline Materiales & $\begin{array}{l}\text { Aula, carpetas, pizarra, plumones, proyector y } \\
\text { computadora. }\end{array}$ \\
\hline $\begin{array}{l}\text { Desarrollo de la actividad: } \\
\text { 1. Se inicia formando parejas de trab } \\
\text { participantes para que uno de ellos pregunte } \\
\text { autopercibes tus manifestaciones intelec } \\
\text { compañero responda. Luego, se cambia de r } \\
\text { nuevo preguntando y respondiendo, para } \\
\text { retroalimentación del mediador a todos según } \\
\text { 2. Posteriormente, una pareja pregunta al } \\
\text { percibido de tus manifestaciones intelec } \\
\text { compañero responde. Después, se cambian } \\
\text { de nuevo preguntando y respondiendo, para } \\
\text { retroalimentación del mediador a todos según } \\
\text { 3. Inmediatamente, el mediador les dice a t } \\
\text { vivido hasta el momento ¿cómo debería } \\
\text { manifestaciones intelectuales? Y ¿qué deber } \\
\text { de sus manifestaciones intelectuales?, deja un } \\
\text { que reflexionen mientras vuelven a sus asient } \\
\text { 4. El mediador interactuando con los participa } \\
\text { el centro intelectual, sus funciones y sus } \\
\text { Además, comparte técnicas de la estrategi } \\
\text { para que el proceso autoperceptivo de las n } \\
\text { del centro intelectual se ejecute a cabalidad. } \\
5 \text { Se les invita a los participantes a formar un } \\
\text { carpetas en el salón para proceder a sen } \\
\text { postura erguida y a realizar una técnica de re } \\
\text { por el mediador haciendo énfasis en la obse } \\
\text { plena de sus pensamientos sin la intervención } \\
\text { mientras aplican lo anclado en sí mismos. } \\
6 \text {. Después, se les solicita el compromiso po } \\
\text { uno para transferir lo aprendido a sus vidas pe } \\
\text { que las sesiones culminen y se puedan cump } \\
\text { trazados. } \\
\text { 7. Finalmente, se forma un círculo entre todo } \\
\text { participantes puedan intercambiar sus expe } \\
\text { sesión, mientras el mediador actúa de mode } \\
\text { una retroalimentación general. }\end{array}$ & \\
\hline Criterio de evaluación de los aprendizajes & $\begin{array}{l}\text { Constatación del centro intelectual, sus } \\
\text { funciones y sus características. }\end{array}$ \\
\hline Indicadores de evaluación & $\begin{array}{l}\text { 1. Nomina su estilo autoperceptivo de las } \\
\text { manifestaciones intelectuales. } \\
\text { 2. Nombra sus manifestaciones intelectuales. } \\
\text { 3. Demuestra señales de reflexión. } \\
\text { 4. Demuestra dominio sobre el proceso } \\
\text { autoperceptivo de las manifestaciones } \\
\text { intelectuales y sus características. } \\
\text { 5. Demuestra señales de participación en la } \\
\text { técnica de relajación. } \\
\text { 6. Demuestra señales de autoadministración de } \\
\text { lo anclado. } \\
\text { 7. Demuestra compromiso con la transferencia } \\
\text { de lo aprendido. } \\
\text { 8. Comunica sus vivencias de la sesión. }\end{array}$ \\
\hline
\end{tabular}


Estrategia metodológica para las funciones emocionales

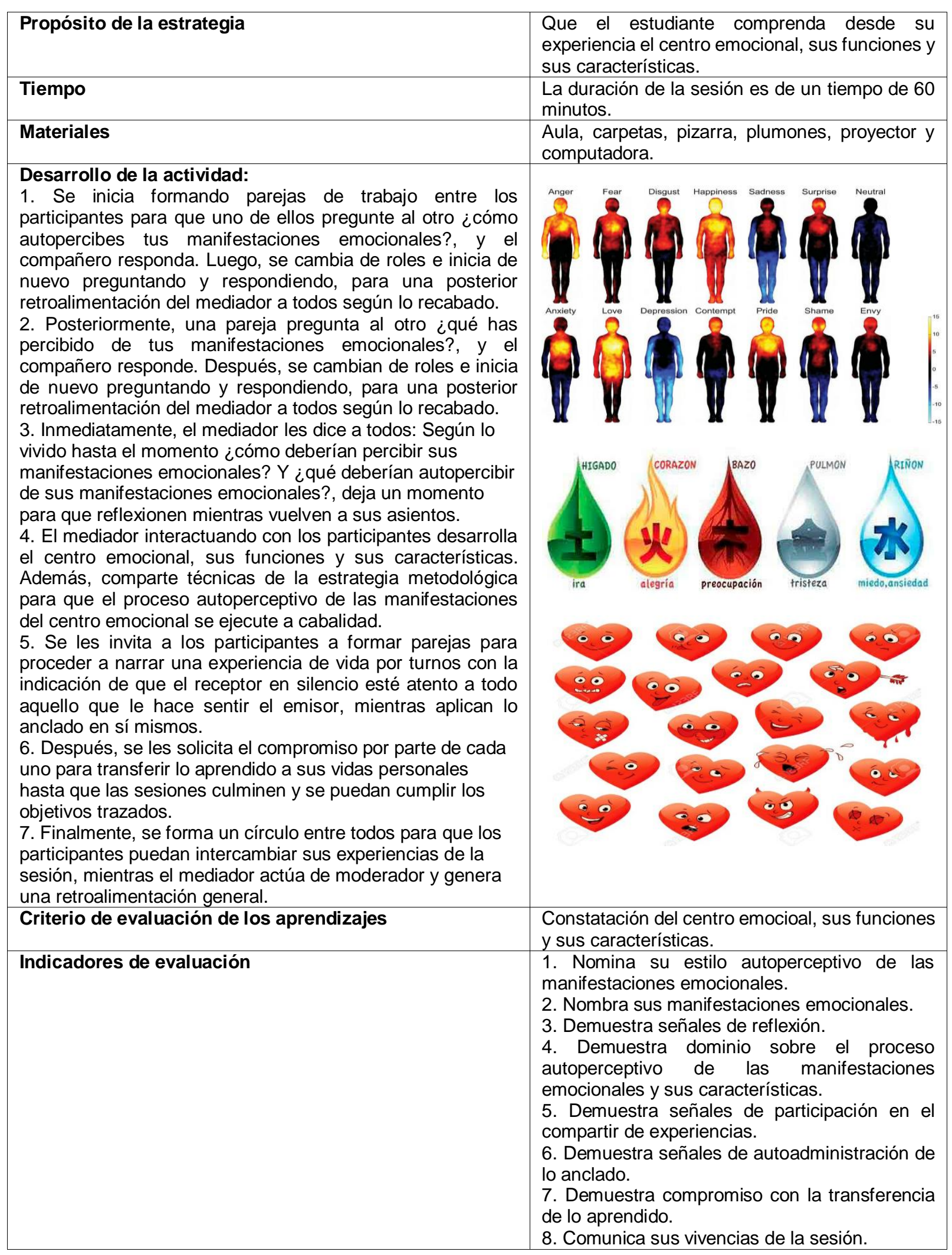




\section{Estrategia metodológica para las funciones motoras instintivas}

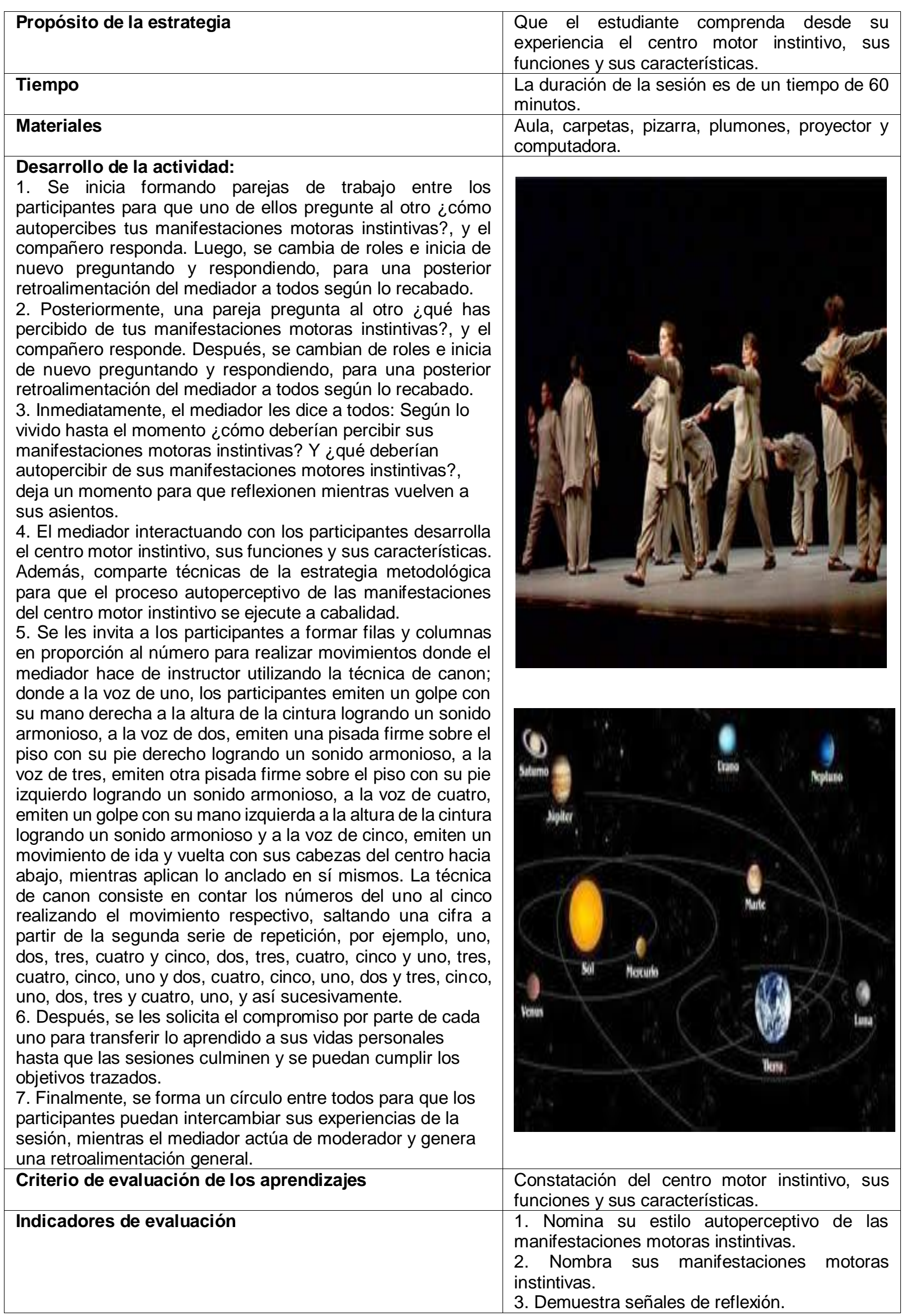




\begin{tabular}{|l|l|}
\hline $\begin{array}{l}\text { 4. Demuestra dominio sobre el proceso } \\
\text { autoperceptivo de las manifestaciones motoras } \\
\text { instintivas y sus características. } \\
5 . \quad \text { Demuestra participación sobre los } \\
\text { movimientos. } \\
\text { 6. Demuestra señales de autoadministración de } \\
\text { lo anclado. } \\
\text { 7. Demuestra compromiso con la transferencia } \\
\text { de lo aprendido. } \\
\text { 8. Comunica sus vivencias de la sesión. }\end{array}$ \\
\hline
\end{tabular}




\section{SESIÓN DE APRENDIZAJE N¹}

\section{DATOS INFORMATIVOS}

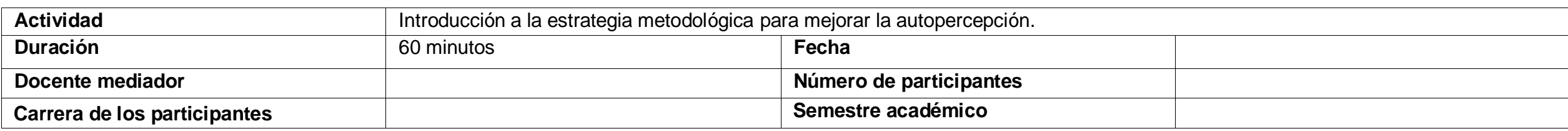

\section{APRENDIZAJE ESPERADO}

Comprende desde su experiencia los centros psicológicos y sus funciones, el recuerdo de sí, la consciencia durante la autopercepción y los mecanismos de defensa en la autopercepción.

\section{DESARROLLO DE LA SESIÓN DE APRENDIZAJE}

\begin{tabular}{|c|c|c|c|c|}
\hline \multicolumn{2}{|c|}{ PROCESOS PEDAGÓGICOS } & ESTRATEGIAS / ACTIVIDADES & TIEMPO & RECURSOS \\
\hline \multirow{2}{*}{$\begin{array}{l}\text { Motivaci } \\
\text { ón, } \\
\text { desarroll } \\
\text { o y } \\
\text { evaluaci } \\
\text { ón } \\
\text { permane } \\
\text { nte de } \\
\text { actitudes }\end{array}$} & $\begin{array}{l}\quad \mathrm{INICIO} \\
\text { 1. Despertar el interés. } \\
\text { 2. Recuperar experiencias } \\
\text { previas. } \\
\text { 3. Estimular el conflicto en el } \\
\text { ser. }\end{array}$ & $\begin{array}{l}\text { 1. Se inicia formando parejas de trabajo entre los participantes para que uno de ellos pregunte al otro } \\
\text { ¿cómo te autopercibes?, y el compañero responda. Luego, se cambia de roles e inicia de nuevo } \\
\text { preguntando y respondiendo, para una posterior retroalimentación del mediador a todos según lo } \\
\text { recabado. } \\
\text { 2. Posteriormente, una pareja pregunta al otro ¿qué has percibido de ti?, y el compañero responde. } \\
\text { Después, se cambian de roles e inicia de nuevo preguntando y respondiendo, para una posterior } \\
\text { retroalimentación del mediador a todos según lo recabado. } \\
\text { 3. Inmediatamente, el mediador les dice a todos: Según lo vivido hasta el momento ¿cómo deberían } \\
\text { percibirse? Y ¿qué deberían autopercibir?, deja un momento para que reflexionen mientras vuelven } \\
\text { a sus asientos. }\end{array}$ & 15 minutos & $\begin{array}{l}\text { Aula, carpetas, } \\
\text { pizarra, } \\
\text { plumones, } \\
\text { proyector y } \\
\text { computadora. }\end{array}$ \\
\hline & $\begin{array}{l}\text { DESARROLLO } \\
\text { 4. Anclar. } \\
\text { 5. Aplicar. } \\
\text { 6. Transferir lo aprendido. }\end{array}$ & $\begin{array}{l}\text { 4. El mediador interactuando con los participantes desarrolla los procesos de la autopercepción; } \\
\text { centros psicológicos y sus funciones, el recuerdo de sí, la consciencia durante la autopercepción y } \\
\text { los mecanismos de defensa en la autopercepción. Además, comparte técnicas de la estrategia } \\
\text { metodológica para que el proceso autoperceptivo se ejecute a cabalidad. } \\
5 \text {. Se les invita a los participantes a crear una temática novedosa a través de la asociación libre y } \\
\text { lluvia de ideas, mientras aplican lo anclado en sí mismos y el mediador organiza la información en la } \\
\text { pizarra. } \\
\text { 6. Después, se les solicita el compromiso por parte de cada uno para transferir lo aprendido a sus } \\
\text { vidas personales hasta que las sesiones de la estrategia metodológica culminen y se puedan cumplir } \\
\text { los objetivos trazados. }\end{array}$ & 30 minutos & $\begin{array}{l}\text { Aula, carpetas, } \\
\text { pizarra, } \\
\text { plumones, } \\
\text { proyector y } \\
\text { computadora. }\end{array}$ \\
\hline
\end{tabular}




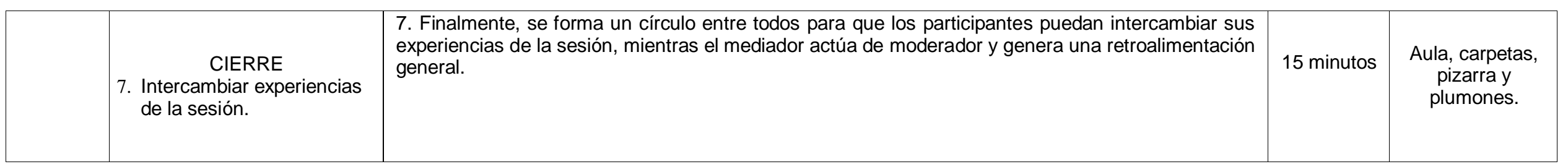

\section{EVALUACIÓN}

\begin{tabular}{|c|c|}
\hline CRITERIO DE EVALUACIÓN DE LOS APRENDIZAJES & INDICADORES DE EVALUACIÓN \\
\hline $\begin{array}{l}\text { Constatación del proceso autoperceptivo y las técnicas de la estrategia } \\
\text { metodológica. }\end{array}$ & $\begin{array}{l}\text { 1. Nomina su estilo autoperceptivo. } \\
\text { 2. Nombra sus autopercepciones. } \\
\text { 3. Demuestra señales de reflexión. } \\
\text { 4. Demuestra dominio sobre el proceso autoperceptivo y la estrategia metodológica. } \\
\text { 5. Demuestra señales de participación usando la asociación libre y la lluvia de ideas. } \\
\text { 6. Demuestra señales de autoadministración de lo anclado. } \\
\text { 7. Demuestra compromiso con la transferencia de lo aprendido. } \\
\text { 8. Comunica sus vivencias de la sesión. }\end{array}$ \\
\hline
\end{tabular}




\section{Validación de la propuesta}

Se apeló a la validación por juicio de expertos, cuyo procedimiento fue entregar una carpeta con los documentos de validación de la propuesta que incluían 10 indicadores de validación interna y 10 externa, cuyos criterios de ponderación abarcan lo cuantitativo a través de puntajes de 1 (deficiente), 2 (bajo), 3 (regular), 4 (buena) y 5 (muy buena), arrojando por cada ficha un puntaje máximo de 50 puntos que sumados equivalen a un total general de 100.

Asimismo, desde lo cualitativo, se valoran a través de apreciaciones críticas de los objetos examinados considerando las dimensiones de positivo, negativo y sugerencias.

\section{Características de los especialistas.}

Los validadores fueron tres especialistas, cuyas trayectorias cumplen las expectativas para validar una propuesta de investigación aplicada educacional. Obsérvese la siguiente tabla: Tabla 3.

Especialistas de la validación

\begin{tabular}{ccccc}
\hline $\begin{array}{c}\text { Apellidos y } \\
\text { nombres }\end{array}$ & $\begin{array}{c}\text { Grado } \\
\text { académico }\end{array}$ & Especialidad/Profesión & Ocupación & $\begin{array}{c}\text { Años de } \\
\text { experienci } \\
\text { a }\end{array}$ \\
\hline $\begin{array}{c}\text { Flores Valdiviezo } \\
\text { Hernán }\end{array}$ & Magíster & Sociólogo & $\begin{array}{c}\text { Docente } \\
\text { investigador }\end{array}$ & 35 años \\
$\begin{array}{c}\text { Montero Doig, Ana } \\
\text { María }\end{array}$ & Doctora & Psicóloga & $\begin{array}{c}\text { Docente } \\
\text { investigador }\end{array}$ & 45 años \\
$\begin{array}{c}\text { Velásquez Tejeda, } \\
\text { Míriam }\end{array}$ & Doctora & Pedagoga & $\begin{array}{c}\text { Docente } \\
\text { investigador }\end{array}$ & 35 años \\
\hline
\end{tabular}

Fuente: Adaptado de los documentos normativos de la USIL (2019)

El maestro Flores Valdiviezo, Hernán, es licenciado en sociología con una amplia trayectoria como docente universitario. Ha laborado por años en diferentes universidades y escuelas de posgrado. Actualmente se desempeña a dedicación exclusiva en la USIL.

La doctora Montero Doig, Ana María, es licenciada en psicología, con el grado de maestra en docencia superior y estudios en el CAEN, así como un doctorado en la UNIFE. Su trayectoria académica es vasta, desempeñándose en la actualidad como docente en la URP.

La doctora Velásquez Tejeda, Miriam, es licenciada en pedagogía, con el grado de maestra en Psicología Educativa y doctora en Educación. Su trayectoria académica deviene desde Cuba, donde ha ocupado cargos importantes en diferentes universidades. En la actualidad se desempeña a dedicación exclusiva en la Escuela de Posgrado de la USIL. 


\section{Valoración interna.}

La ficha de validación interna tiene como objetivo presentar a los especialistas los 10 indicadores susceptibles de juicio respecto al contenido funcional de la propuesta. De este modo, se presenta el promedio de la valoración interna del total de especialistas.

Tabla 4.

Validez interna por juicio de expertos

\begin{tabular}{|c|c|c|c|c|c|c|}
\hline \multirow[t]{2}{*}{ Indicadores } & \multicolumn{2}{|c|}{ Juez 1} & \multicolumn{2}{|c|}{ Juez 2} & \multicolumn{2}{|c|}{ Juez 3} \\
\hline & $\mathbf{n}$ & $\%$ & $\mathbf{n}$ & $\%$ & $\mathbf{n}$ & $\%$ \\
\hline $\begin{array}{l}\text { Factibilidad de aplicación del resultado que se } \\
\text { presenta. }\end{array}$ & 5 & 10 & 5 & 10 & 5 & 10 \\
\hline Claridad de la propuesta para ser aplicado por otros & 5 & 10 & 5 & 10 & 5 & 10 \\
\hline $\begin{array}{l}\text { Posibilidad de la propuesta de extensión a otros } \\
\text { contextos semejantes } \\
\text { Correspondencia con las necesidades sociales e }\end{array}$ & 5 & 10 & 5 & 10 & 5 & 10 \\
\hline $\begin{array}{l}\text { individuales actuales } \\
\text { Congruencia entre el resultado propuesto y el objetivo }\end{array}$ & 5 & 10 & 5 & 10 & 5 & 10 \\
\hline $\begin{array}{l}\text { fijado. } \\
\text { Novedad en el uso de conceptos y procedimientos de }\end{array}$ & 5 & 10 & 5 & 10 & 5 & 10 \\
\hline la propuesta. & 4 & 8 & 5 & 10 & 5 & 10 \\
\hline detallado, preciso y efectivo & 5 & 10 & 5 & 10 & 5 & 10 \\
\hline $\begin{array}{l}\text { Presenta objetivos claros, coherentes y posibles de } \\
\text { Presio. }\end{array}$ & 5 & 10 & 5 & 10 & 5 & 10 \\
\hline $\begin{array}{l}\text { alcanzar. } \\
\text { Contiene un plan de acción de lo general a lo }\end{array}$ & 5 & 10 & 5 & 10 & 5 & 10 \\
\hline particular. & 4 & 8 & 5 & 10 & 5 & 10 \\
\hline Total & 48 & 96 & 50 & 100 & 50 & 100 \\
\hline Promedio Porcentual & & & & $7 \%$ & & \\
\hline
\end{tabular}

Fuente: Adaptado de los documentos normativos de la USIL (2019)

En la tabla 4, se observa que el Juez 1 valoró la ficha de validación interna con un $96 \%$, a diferencia de los Jueces 2 y 3 , quienes valoraron con un $100 \%$, no obstante, a pesar de esta distancia breve, no se aprecia diferencias significativas por pertenecer a un rango de porcentaje en la escala de valoración de Muy Buena, al igual que los rangos de frecuencias. Asimismo, el promedio porcentual total de la valoración es de 98.67\%, lo cual señala que la propuesta tiene una validez interna ubicada en la escala de valoración de Muy Buena.

\section{Valoración externa.}

La ficha de validación externa tiene como objetivo presentar a los especialistas los 10 indicadores susceptibles de juicio respecto al contenido estructural de la propuesta. De este modo, se presenta el promedio de la valoración externa del total de especialistas. 
Tabla 5.

Validez externa por juicio de expertos.

\begin{tabular}{lcccccc}
\hline \multirow{2}{*}{ Indicadores } & \multicolumn{2}{c}{ Juez 1 } & \multicolumn{2}{c}{ Juez 2 } & \multicolumn{2}{c}{ Juez 3 } \\
\hline Claridad & $\mathbf{n}$ & $\%$ & $\mathbf{n}$ & $\%$ & $\mathbf{n}$ & $\%$ \\
\cline { 2 - 7 } Objetividad & 5 & 10 & 5 & 10 & 5 & 10 \\
Actualidad & 5 & 10 & 5 & 10 & 5 & 10 \\
Organización & 4 & 8 & 5 & 10 & 5 & 10 \\
Suficiencia & 5 & 10 & 5 & 10 & 5 & 10 \\
Intencionalidad & 5 & 10 & 5 & 10 & 5 & 10 \\
Consistencia & 4 & 10 & 5 & 10 & 5 & 10 \\
Coherencia & 5 & 10 & 5 & 10 & 5 & 10 \\
Metodología & 5 & 10 & 5 & 10 & 5 & 10 \\
Pertinencia & 4 & 8 & 5 & 10 & 5 & 10 \\
\multicolumn{1}{c}{ Total } & 47 & 94 & 50 & 100 & 50 & 100 \\
\multicolumn{1}{c}{ Promedio porcentual } & \multicolumn{2}{c}{$98.00 \%$} & & \\
\hline
\end{tabular}

Fuente: Adaptado de los documentos normativos de la USIL (2019)

En la tabla 5, se observa que el Juez 1 valoró la ficha de validación externa con un $94 \%$, a diferencia de los Jueces 2 y 3, quienes valoraron con un 100\%, sin embargo, a pesar de esta distancia corta, no se aprecia diferencias significativas por pertenecer a un rango de porcentaje en la escala de valoración de Muy Buena, al igual que los rangos de frecuencias. Asimismo, el promedio porcentual total de la valoración es de $98.00 \%$, lo cual indica que la propuesta tiene una validez externa localizada en la escala de valoración de Muy Buena.

Estos datos se ponderan en la Escala de Valoración de la Tabla 6, donde se presentan los rangos de frecuencias y porcentajes, permitiendo así, ubicar la validez de la propuesta.

Tabla 6.

Escala de Valoración.

\begin{tabular}{lcc}
\hline \multicolumn{1}{c}{ Escala } & Rango frecuencia & Rango porcentaje \\
\hline Deficiente & {$[10-17]$} & {$[20 \%-35 \%]$} \\
Baja & {$[18-25]$} & {$[36 \%-51 \%]$} \\
Regular & {$[26-33]$} & {$[52 \%-67 \%]$} \\
Buena & {$[34-41]$} & {$[68 \%-83 \%]$} \\
Muy buena & {$[42-50]$} & {$[84 \%-100 \%]$} \\
\hline
\end{tabular}

Fuente: Tomado de los documentos normativos de la USIL (2019) 


\section{Resultados de la valoración de los especialistas y conclusiones.}

En el presente apartado se elabora la sistematización de la información proporcionada por los especialistas en relación a la validación interna y externa de la propuesta.

Tabla 7.

Valoración interna y externa por criterio de jueces

\begin{tabular}{lcccc}
\hline & Especialista 1 & Especialista 2 & Especialista 3 & Promedio \\
\hline Validación interna & $96 \%$ & $100 \%$ & $100 \%$ & $99 \%$ \\
Validación externa & $94 \%$ & $100 \%$ & $100 \%$ & $98 \%$ \\
$\begin{array}{l}\text { Promedio por } \\
\text { especialista }\end{array}$ & $95 \%$ & $100 \%$ & $100 \%$ & $98 \%$ \\
$\quad$ Promedio final & \multicolumn{2}{c}{$98 \%$} \\
\hline
\end{tabular}

Fuente: Adaptado de los documentos normativos de la USIL (2019)

En la tabla 7, se observa que el promedio de valoración del Especialista 1 en la ficha de validación interna es de 96\%, a diferencia de los Especialistas 2 y 3, quienes valoraron en promedio con un $100 \%$, arrojando como promedio total un $99 \%$, lo cual implica que la propuesta tiene una validez interna ubicada en la Escala de Valoración de Muy buena por juicio de expertos. Asimismo, el promedio de valoración del Especialista 1 en la ficha de validación externa es de 94\%, a diferencia de los Especialistas 2 y 3, quienes valoraron en promedio con un $100 \%$, arrojando como promedio total un $98 \%$, lo cual implica que la propuesta tiene una validez externa ubicada en la Escala de Valoración de Muy buena por juicio de expertos. Esto implica que el contenido funcional y estructural de la propuesta de estrategia metodológica según el promedio final por especialistas es de $98 \%$, lo cual la ubica como Muy Buena según la Escala de Valoración.

\section{Conclusiones aproximativas de los análisis y resultados de la propuesta y su validación teórica/práctica}

Después de ponderar el promedio final de la validez interna y externa con un 98\%, observar la ausencia de sugerencias por parte de los jueces y apreciar una valoración de positiva en ambas fichas, se tiene como resultado final que la propuesta de estrategia metodológica se ubica en un nivel muy bueno, por tanto, se concluye científicamente que es aplicable y podría ser administrada a otras áreas del diseño curricular considerando las características sociales, psicopedagógicas, culturales y demográficas, donde se pretenda aplicar. 


\section{Conclusiones}

Después de culminar el proceso investigativo a través de los datos aportados por los referentes científicos, el análisis de la información según el diagnóstico del trabajo de campo, la modelación y validación de la estrategia metodológica para mejorar la autopercepción de los estudiantes y el cumplimiento de los objetivos científicos, se concluye lo siguiente:

\section{Conclusión 1}

Se modeló la estrategia metodológica como objetivo general de la investigación, encaminada a la mejora de la autopercepción de los estudiantes de la asignatura de diagnóstico psicológico de octavo semestre de psicología en una universidad privada de Lima. Así, los estudiantes conocen el proceso autoperceptivo y las técnicas de la estrategia metodológica, las funciones y características de los centros intelectual, emocional y motor instintivo conforme a los contenidos, actividades, técnicas e indicadores de las sesiones planteadas según la estructura de la estrategia metodológica.

\section{Conclusión 2}

Se sistematizaron las teorías, los modelos y enfoques de las categorías apriorísticas de autopercepción y estrategia metodológica según James (1890), Cooley (1902), Mead (1934), Combs (1981), Rogers (1973), Epstein (1973), Bandura (1977), Zimmerman (2001), Panadero \& Alonso-Tapia (2014a, 2014b), Homme (1965), Maslow (1943), Johnson-Laird (1988), Kuhl $(1984,1987,2000)$, Vygotsky $(1962,1978)$ y Piaget $(1926,1932,1952)$; quienes describieron, explicaron y sentaron las bases del proceso autoperceptivo y la estrategia metodológica, cuyas operaciones en el alumno generan un autoconocimiento real, fidedigno y las capacidades para sobrellevar y afrontar los obstáculos que desvían o alejan de la esencia del estudiante en su labor académica para con la vida.

\section{Conclusión 3}

Se diagnosticó el estado actual de la autopercepción de los estudiantes según el trabajo de campo, obteniéndose los siguientes hallazgos más relevantes; dificultad de los alumnos para diferenciar sus identificaciones personales de las académicas, generando una contaminación en sus posturas académicas, lo cual dificulta la apertura ante lo nuevo que el docente intenta mediar. Asimismo, otra problemática develada fue la cantidad de alumnos por salón, ya que al haber muchos, impide que el docente puede generar un espacio de retroalimentación personalizada para que los alumnos emitan juicios valorativos respecto a su desempeño en clase con la materia mediada y sobre sí mismos. Finalmente, se encontró que los educandos hacen mal uso de sus vínculos interpersonales ya que se observó plagio colaborativo entre ellos a pesar de que el docente se percató de la acción. 


\section{Conclusión 4}

Se diseñó la estrategia metodológica, cuyo fin es mejorar la autopercepción de los estudiantes para que puedan atravesar el proceso autoperceptivo conociendo las particularidades de los centros intelectual, emocional y motor instintivo, conforme a sus influencias y determinaciones a través de las actividades de asociación libre, lluvia de ideas, compartir de experiencias, técnica de relajación y movimientos, así como la estructura con sus contenidos, técnicas, actividades e indicadores a modelar.

\section{Conclusión 5}

Se validó la propuesta de estrategia metodológica para mejorar la autopercepción de los estudiantes por unanimidad mediante la validación interna y externa de tres especialistas por criterio de jueces. El calificativo se sitúa en la escala de valoración de muy bueno. Asimismo, los especialistas sugieren que la estructura y funcionalidad de la propuesta garantiza la administración práctica en el proceso de enseñanza-aprendizaje, enfatizando la preparación del mediador y la total entrega de los participantes. 


\section{Recomendaciones}

\section{Recomendación 1}

Compartir y exponer la estrategia metodológica a los coordinadores de psicología de diferentes universidades de Lima con el objetivo de sustentar y plantear su administración como técnica psicopedagógica garantizadora de un correcto desarrollo del ser del alumno de octavo semestre de psicología en aras de los propósitos y deberes bioéticos que ha de cumplimentar según las demandas del entorno para su desempeño académico y laboral.

\section{Recomendación 2}

Fundamentar los referentes teóricos de la estrategia metodológica a los mediadores de la propuesta e interesados a través de un taller práctico y vivencial, cuyo fin sea la constatación empírica de las bases teóricas que dan respaldo a la propuesta a través de un enfoque holístico y ecléctico del conocimiento psicopedagógico requerido.

\section{Recomendación 3}

Comunicar los hallazgos que los mediadores encuentren al administrar la estrategia metodológica en bases de datos científicas con el objetivo de informar acerca del estado anterior y posterior de los participantes, así como los efectos generados.

\section{Recomendación 4}

Adaptar la estrategia metodológica en los diferentes contextos de administración por parte de los mediadores considerando la recopilación de evidencias de su uso, así como de información afín que ayude a enriquecer su formato.

\section{Recomendación 5}

Reforzar la propuesta añadiéndole confiabilidad estadística, así como baremos para poder cotejar los resultados de la administración con unas normas. 


\section{Referencias}

Abu-Hilal, M., Abdelfattah, F., Alshumrani, S., Abduljabbar, A. \& Marsh, H. (2013). Construct validity of self-concepto in TIMSS's student background questionnaire: a test of separation and conflation of cognitive and affective dimensions of self-concept among Saudi eighth graders. European Journal of Psychology of Education, 28(4), 1201-1220. doi: 10.1007/s10212-012-0162-1

Arguello, B. y Sequeira, M. (2016). Estrategias Metodológicas Relacionadas a la Enseñanza - Aprendizaje de la Geografía e Historia en la Educación Secundaria Básica (Tesis de Licenciatura, Universidad Nacional Autónoma de Nicaragua, Managua, Nicaragua). Recuperado de http://repositorio.unan.edu.ni/1638/1/10564.pdf

Bandura, A. (1977). Self-efficacy: Toward a Unifying Theory of Behavioral Change. Psychological Review, 84(2), 191-215.

Bandura, A. (1986). Social foundations of thought and action: A social cognitive theory. Englewood Cliffs, NJ: Prentice-Hall.

Bandura, A. (1997). Self-efficacy: The exercise of control. New York: W. H. Freeman and Company.

Barros, A. \& Duarte, A. (2016). Self-worth, scholastic competence and approaches to learning in university students. Journal of Psychological and Educational Research, 24(2), 37-57. Recuperado de https://www.researchgate.net/publication/311495692_Selfworth_scholastic_competence_and_approaches_to_learning_in_university_students

Boekaerts, M., \& Niemivirta, M. (2000). Self-regulated learning: Finding a balance between learning goals and ego-protective goals. En M. Boekaerts, P. R. Pintrich \& M. Zeidner (Eds.), Handbook of self-regulation (pp. 417-451). San Diego, CA: Academic Press.

Campusano, K. (2017). Manual de Estrategias Didácticas: Orientaciones para su elección. Santiago: Ediciones INACAP.

Castro, J. (2013). Claridad del Autoconcepto y Autoestima en Relación a la Exploración y Compromiso Vocacional en Adolescentes (Tesis de Licenciatura). Recuperada de http://tesis.pucp.edu.pe/repositorio/bitstream/handle/123456789/5221/CASTRO_VAL DEZ_JOAQUIN_CLARIDAD_AUTOCONCEPTO.pdf?sequence=1\&isAllowed=y

Cerezal, J. \& Fiallo, J. (2002). Los Métodos Científicos en las Investigaciones Pedagógicas. La Habana: Pueblo y Educación.

Combs, A. (1981). Some Observations of Selfconcept research and theory. Cambridge: Ballinger. 
Combs, A., Avila, D. \& Purkey, W. (1978). Helping Relationships: Basic Concepts for the Helping Professions ( $2^{\mathrm{a}}$ ed.). Boston: Allyn and Bacon.

Combs, A., Blume, R., Newman, A. \& Wass, H. (1979). Claves para la Formación de Profesores. Un Enfoque Humanístico. Madrid: E. M. E. S. A.

Conde, L. (2015). Claridad del Autoconcepto, Inclusión del Otro en el Self y Ajuste Diádico en Adultos de Lima Metropolitana (Tesis de Licenciatura). Recuperada de http://tesis.pucp.edu.pe/repositorio/bitstream/handle/123456789/6100/CONDE_ZUNI GA_LOURDES_AJUSTE_DIADICO.pdf?sequence=1\&isAllowed=y

Contreras, V. (2010). Autoconcepto y Rendimiento Matemático en Estudiantes de $4^{\underline{a}}$ y $5^{\underline{a}}$ Grado de Secundaria de una Institución Educativa de Ventanilla (Tesis de maestría). Recuperada de http://repositorio.usil.edu.pe/bitstream/123456789/1111/1/2010_Contreras_Autoconc epto\%20y\%20rendimiento\%20matemático\%20en\%20estudiantes\%20de\%204\%20y \%205\%20grado\%20de\%20secundaria\%20de\%20una\%20institución\%20educativa $\% 20 d e \% 20$ Ventanilla.pdf

Cooley, C. (1902). Human Nature and the Social Order. New York: Charles Scibner's Sons. Corno, L. (2001). Volicional aspects of self-regulated learning. En B. J. Zimmerman y D. H. Schunk (Eds.), Self-regulated learning and academic achievement (segunda ed., pp. 191-226). New York: Lawrence Erlbaum Associates.

Delors, J. (1996). La Educación Encierra un Tesoro. Madrid: UNESCO.

De Salzmann, N. (1989). ¡No saber es formidable!. Colombia: Ganesha.

Epstein, S. (1973). The Selfconcept Revisited: Or a Theory of a Theory. American Psychologist, 28, 403-416.

Fareo, D. (2011). A study of self perception and academic performance of students with special needs into mainstreamed public secondary schools in Nigeria. Ife PsychologIA, 19(1), 495-506. http://dx.doi.org/10.4314/ifep.v19i1.64617

Fenning, B. \& May, L. (2013). "Where there is a will, there is an A": examining the roles of self-efficacy and self-concept in college students' current educational attainment and career planning. Social Psychology of Education, 16(4), 635-650. doi: 10.1007/s11218-013-9228-4

Fernández, C., Baptista, P. \& Hernández, R. (2014). Metodología de la Investigación. (6a ed.). México: McGraw-Hill.

Freud, A. (1965). El Yo y Los Mecanismos de Defensa. (4ta ed.). Buenos Aires: Editorial Paidos.

González-Pienda, J., Núñez, J., González-Pumariega, S. \& García, M. (1997). Autoconcepto, autoestima y aprendizaje escolar. Psicothema, 9(2), 271-289. 
González, M. \& Tourón, J. (1992). Autoconcepto y Rendimiento Académico. Sus implicaciones en la motivación y en la autorregulación del aprendizaje. España: EUNSA.

Gonzálvez, C., Inglés, C., Vicent, M., Lagos-San Martín, N., Sanmartín, R. \& GarcíaFernández J. (2016). Diferencias en ansiedad escolar y autoconcepto en adolescentes chilenos. Acta de Investigación Psicológica, 6, 2509-2515.

Goñi, E. (2009). El autoconcepto personal: estructura interna, medida y variabilidad (Tesis doctoral, Universidad del País Vasco, País Vasco, España). Recuperada de http://hdl.handle.net/10810/12241

Hadwin, A., Järvelä, S. \& Miller, M. (2011). Self-regulated, co-regulated, and socially shared regulation of learning. En B. J. Zimmerman y D. H. Schunk (Eds.), Handbook of selfregulation of learning and performance (pp. 65-84). New York: Routledge.

Homme, L. (1965). Perspectives in Psychology. Control of coverants, the operants of the mind. Psychological Record, 15, 501-511.

House, J. (1977). The Three Faces of Social Psychology. Sociometry, 40 (2), 161-177. James, W. (1890). Principles of Psychology. New York: Holt.

Johnson-Laird, P. (1988). The computer and the mind. Cambridge, MA: Harvard University Press.

Kanfer, F. H. (1977). The many faces of self-control, or behavior modification changes its focus. En R. B. Stuart (Ed.), Behavioral self-management: Strategies, techniques, and outcomes (pp. 1-48). New York: Brunner/Mazel.

Kelly, G. (1955). The Psychology of Personal Constructs. New York: Norton.

Kuhl, J. (1984). Volitional aspects of achievement motivation and learned helplessness: Toward a comprehensive theory of action-control. En B. A. Maher (Ed.), Progress in experimental personality research (Vol. 13, pp. 99-171). New York: Academic Press.

Kuhl, J. (1987). Feeling versus being helpless: Metacognitive mediation of failure induced performance deficits. En F. Weinert y R. H. Kluwe (Eds.), Metacognition, motivation and understanding (pp. 217-235). Hillsdale, NJ: Lawerence Erlbaum.

Kuhl, J. (2000). A functional-design approach to motivation and self-regulation. En M.

Boekaerts, P. R. Pintrich y M. Zeidner (Eds.), Handbook of self-regulation (pp. 111169). San Diego, CA: Academic Press.

L’Ecuyer, R. (1985). El Concepto de Sí Mismo. Madrid: Oikos-Tau.

Lachowicz-Tabaczek, K. \& Sniecinska, J. (2011). Self-concept and self-esteem: How the content of the self-concept reveals sources and functions of self-esteem. Polish Psychological Bulletin, 42(1), 24-35. doi: 10.2478/v10059-011-0005-y

Lecky, P. (1945). Self-Consistency. A Theory of Personality. Connecticut: The Shoe String Press. 
Lepkowski, J. (2008). Population. Encyclopedia of Survey Research Methods [SAGE Publications]. Recuperado de http://www.sageereference.com/survey/Article_n383.html

Mace, F. C., Belfiore, P. J. \& Hutchinson, J. M. (2001). Reflections on theories of selfregulated learning and academic achievement. En B. J. Zimmerman y D. H. Schunk (Eds.), Self-regulated learning and academic achievement (pp. 39-66). New York: Lawrence Erlbaum Associates.

Marsh, H. \& Shavelson, R. (1985). Self-concept: Its multifaceted, hierarchical structure. Educational Psychologist, 20, 107-123.

Maslow, A. (1943). A theory of human motivation. Psychological Review, 50, 370-396.

McCaslin, M. \& Hickey, D. (2001). Self-regulated learning and academic achievement: A Vygotskian view. En B. J. Zimmerman y D. H. Schunk (Eds.), Self-regulated learning and academic achievement (pp. 227-252). New York: Lawrence Erlbaum Associates.

McCaslin, M. \& Murdock, T. (1991). The emergent interaction of home and school in the development of students adaptive learning. En M. L. Maehr y P. R. Pintrich (Eds.), Advances in motivation and achievement. Greenwich, CT: JAI Press.

McCombs, B. (2001). Self-regulated learning and academic achievement: A phenomenological view. En B. J. Zimmerman y D. H. Schunk (Eds.), Self-regulated learning and academic achievement (pp. 67-124). New York: Lawrence Erlbaum.

Mead, G. (1934). Mind, Self and Society. Chicago: University of Chicago Press.

Morales, F. (2017). Relaciones entre afrontamiento del estrés cotidiano, autoconcepto, habilidades sociales e inteligencia emocional. Europeran Journal of Education and Psychology, 10, 41-48.

Mosteiro, M. y Porto, A. (2017). La investigación en educación. Notas teórico-metodológicas de pesquisas em educação. Recuperado de http://books.scielo.org/id/yjxdq/pdf/mororo-9788574554938-01.pdf

Moya, A. (2017). Las Estrategias Metodológicas y la Actitud Crítica en los Estudiantes Ingresantes a los Institutos Superiores (Tesis de Doctorado). Recuperado de http://repositorio.ucv.edu.pe/bitstream/handle/UCV/4892/Moya_EAE.pdf?sequence= 1\&isAllowed=y

Municipalidad Santiago de Surco. (2019). Munisurco.gob.pe. Recuperado 11 February 2019, from

http://www.munisurco.gob.pe/municipio/surcoSeguro/planDistritalSeguridadCiudadan a/plan_distrital_seguridad_ciudadana_2018.pdf

Núñez, J. \& González-Pumariega, S. (1996). Procesos motivacionales y aprendizaje. En J.

A. González-Pienda, J. Escoriza, R. González Cabanach y A. Barca (Eds.), 
Psicología de la Instrucción. Vol. 2: Componentes cognitivos y afectivos del aprendizaje escolar. Barcelona: EUB.

Núñez, J., González-Pienda, J., García, M., González-Pumariega, S., Roces, C., Álvarez, L. \& González, M. (1998). Estrategias de aprendizaje, autoconcepto y rendimiento académico. Psicothema, 10, 97-109.

Ouspensky, P. (2010). Psicología de la Posible Evolución del Hombre. México: Gaia Ediciones.

Ouspensky, P. (2012). Un Nuevo Documento. Barcelona: La Teca Ediciones.

Panadero, E. \& Alonso-Tapia, J. (2013). Self- assessment: theoretical and practical connotations. When it happens, how is it acquired and what to do to develop it in our students. Electronic Journal of Research in Educational Psychology, 11, 551-576.

Panadero, E., \& Alonso-Tapia, J. (2014a). ¿Cómo autorregulan nuestros alumnos? Revisión del modelo cíclico de Zimmerman sobre autorregulación del aprendizaje. Anales de Psicología, 30(2), 450-462.

Panadero, E., \& Alonso-Tapia, J. (2014b). Teorías de autorregulación educativa: una comparación y reflexión teórica. Psicología Educativa, 20(1), 11-22.

Paris, S., Byrnes, J. \& Paris, A. (2001). Constructing theories, identities, and actions of selfregulated learners. En B. J. Zimmerman y D. H. Schunk (Eds.), Self- regulated learning and academic achievement (pp. 253-288). New York: Lawrence Erlbaum Associates.

Paris, S. \& Newman, R. (1990). Developmental aspects of self-regulated learning, Educational Psychologist, 25, 87-102.

Paris, S. \& Paris, A. (2001). Classroom applications of research on self-regulated learning, Educational Psychologist, 36, 89-101.

Paredes, C. (1972). Aprender a ser. La educación del futuro. Madrid: Alianza Editorial.

Penado, M. \& Rodicio-García (2017). Análisis del autoconcepto en las víctimas de violencia de género entre adolescentes. Suma Psicológica, 24, 107-114.

Peralta, F., \& Sánchez, M. (2003). Relaciones entre el autoconcepto y el rendimiento académico, en alumnos de Educación Primaria. Electronic Journal of Research in Educational Psychology, 1(1), 95-120.

Piaget, J. (1926). Language and thought of the child. London: Routledge y Kegan Paul.

Piaget, J. (1932). The moral judgement of the child. New York: Harcourt.

Piaget, J. (1952). The origins of intelligence in children. New York: International Universities Press.

Pintrich, P. (2000). The role of goal orientation in self-regulated learning. En M. Boekaerts, P. R. Pintrich, \& M. Zeidner (Eds.), Handbook of self-regulation (pp. 451-502). San Diego, CA: Academic. 
Quintero, Y. (2011). La Importancia de las Estrategias en el Ámbito Educativo. Cuadernos de Educación y Desarrollo, 3(27), 19. Recuperado de http://www.eumed.net/rev/ced/27/yjqc.htm

Ramos-Díaz, E., Rodríguez-Fernández, A. \& Antonio-Agirre, I. (2017). El autoconcepto y el bienestar subjetivo en función del sexo y del nivel educativo en la adolescencia. Psicología Educativa, 23, 89-94.

Restrepo, B. (2002). Investigación en Educación. Colombia: ARFO Editores e Impresores Ltda.

Reyes, Y. (2003). Relación entre el Rendimiento Académico, la Ansiedad ante los Exámenes, los Rasgos de Personalidad, el Autoconcepto y la Asertividad en Estudiantes del Primer Año de Psicología de la UNMSM (Tesis de Licenciatura). Recuperada de http://sisbib.unmsm.edu.pe/bibvirtualdata/Tesis/Salud/Reyes_T_Y/T_completo.pdf

Robertson, J. (2013). Self-concept, school satisfaction, and other selected correlates of subjective well-being for advanced high school learners enrolled in two challenging academic settings. Journal for the Education of the Gifted, 36(4), 461-486. doi: $10.1177 / 0162353213506068$

Rogers, C. (1951). Client-Centered Therapy: its Current Practice, Implications and Theory. Boston: Houghton Mifflin.

Rogers, C. (1961). On Becoming a Person: A therapist's view of psychotherapy. Boston: Houghton Mifflin.

Rogers, C. (1973). My philosophy of interpersonal relationships and how it grew. Journal of Humanistic Psychology, 13, 3-16.

Salazar, M. (2016). Claridad del Autoconcepto, Autoestima y Calidad de la Relación de Pareja en Adultos de Lima Metropolitana (Tesis de Licenciatura). Recuperada de http://tesis.pucp.edu.pe/repositorio/bitstream/handle/123456789/7705/SALAZAR_BE NITES_MARIA_CLARIDAD_AUTOCONCEPTO.pdf?sequence=1\&isAllowed=y

Sánchez, H. \& Reyes C. (2015). Metodología y Diseños en la Investigación Científica. (5a ed.). Lima: Business Support Aneth.

Satici, S. \& Deniz, M. (2019). Adolescents' Self-Perception and School Satisfaction: Assessing the Mediating Role of Subjective Vitality. Education and Science, 44(197), 367-381. doi: 10.15390/EB.2019.7289

Schuster, A., Puente, M., Andrada, O. y Maiza, M. (2013). La Metodología Cualitativa, Herramienta para Investigar los Fenómenos que Ocurren en el Aula. La Investigación Educativa. Revista Electrónica Iberoamericana de Educación en Ciencias y Tecnología, 4(2), 109-139. 
Sendín, M. (2007). Manual de Interpretación del Rorschach para el Sistema Comprehensivo. (3a ed.). Madrid: Psimática.

Valderrama, S. (2013). Pasos para Elaborar Proyectos de Investigación Científica. (2a ed.). Perú: Editorial San Marcos.

Vargas, Z. (2009). La Investigación Aplicada: Una Forma de Conocer las Realidades con Evidencia Científica. Revista Educación, 33(1), 155-165.

Vygotsky, L. (1962). Thought and language (E. Hanfman y G. Vakar ed.). Cambridge, MA: MIT Press.

Vygotsky, L. (1978). Mind in society: The development of higher psychological processes. Cambridge, MA: Harvard University Press.

Weiner, B. (1986). An attributional theory of motivation and emotion. New York: SpringerVerlag.

Winne, P. (1997). Experimenting to bootstrap self-regulated learning. Journal of Educational Psychology, 89(3), 397-410.

Winne, P. (2001). Self-regulated learning viewed from models of information processing. En B. J. Zimmerman y D. H. Schunk (Eds.), Self-regulated learning and academic achievement (pp. 153-190). New York: Lawrence Erlbaum Associates.

Winne, P. (2011). A cognitive and metacognitive analysis of self-regulated learning. En B. J. Zimmerman y D. H. Schunk (Eds.), Handbook of self-regulation of learning and performance (pp. 15-32). New York: Routledge.

Winne, P. \& Hadwin, A. (1998). Studying as self-regulated engagement in learning. En D. Hacker, J. Dunlosky \& A. Graesser (Eds.), Metacognition in educational theory and practice (pp. 277-304). Hillsdale, NJ: Erlbaum.

Wolters, C. (2003). Regulation of motivation: Evaluating an underemphasized aspect of selfregulated learning, Educational Psychologist, 38, 189-205.

Zimmerman, B. (2000). Attaining self-regulation: A social cognitive perspective. En M. Boekaerts, P. R. Pintrich \& M. Zeidner (Eds.), Handbook of self-regulation (pp. 1340). San Diego, California: Academic Press.

Zimmerman, B. (2001). Theories of self-regulated learning and academic achievement: An overview and analysis. En B. J. Zimmerman y D. H. Schunk (Eds.), Self-regulated learning and academic achievement (Second ed., pp. 1-37). New York: Lawrence Elrbaum Associates.

Zimmerman, B. \& Campillo, M. (2003). Motivating self-regulated problem solvers. En J. E. Davidson \& R. J. Sternberg (Eds.), The nature of problem solving (pp. 233-262). New York: Cambridge University Press. 
Zimmerman, B. \& Kitsantas, A. (2005). The hidden dimension of personal competence: SelfRegulated learning and practice. En A. J. Elliot y C. S. Dweck (Eds.), Handbook of competence and motivation (pp. 509-526). New York: Guilford Press.

Zimmerman, B. \& Moylan, A. (2009). Self-regulation: Where metacognition and motivation intersect. En D. J. Hacker, J. Dunlosky \& A. C. Graesser (Eds.), Handbook of Metacognition in Education (pp. 299-315). New York: Routledge. 


\section{Anexos}

Anexo 1: Matriz metodológica y la matriz de categorización

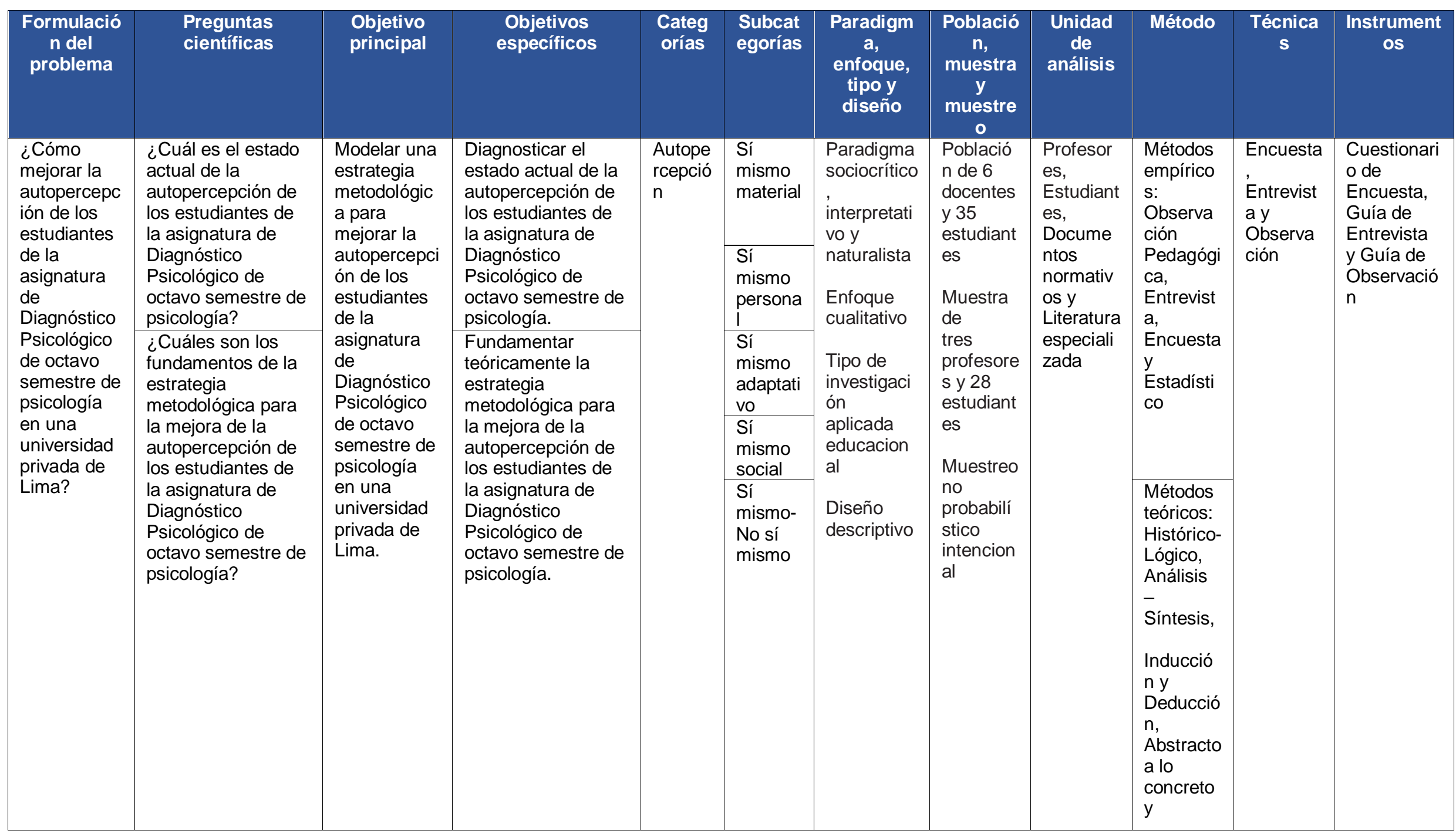




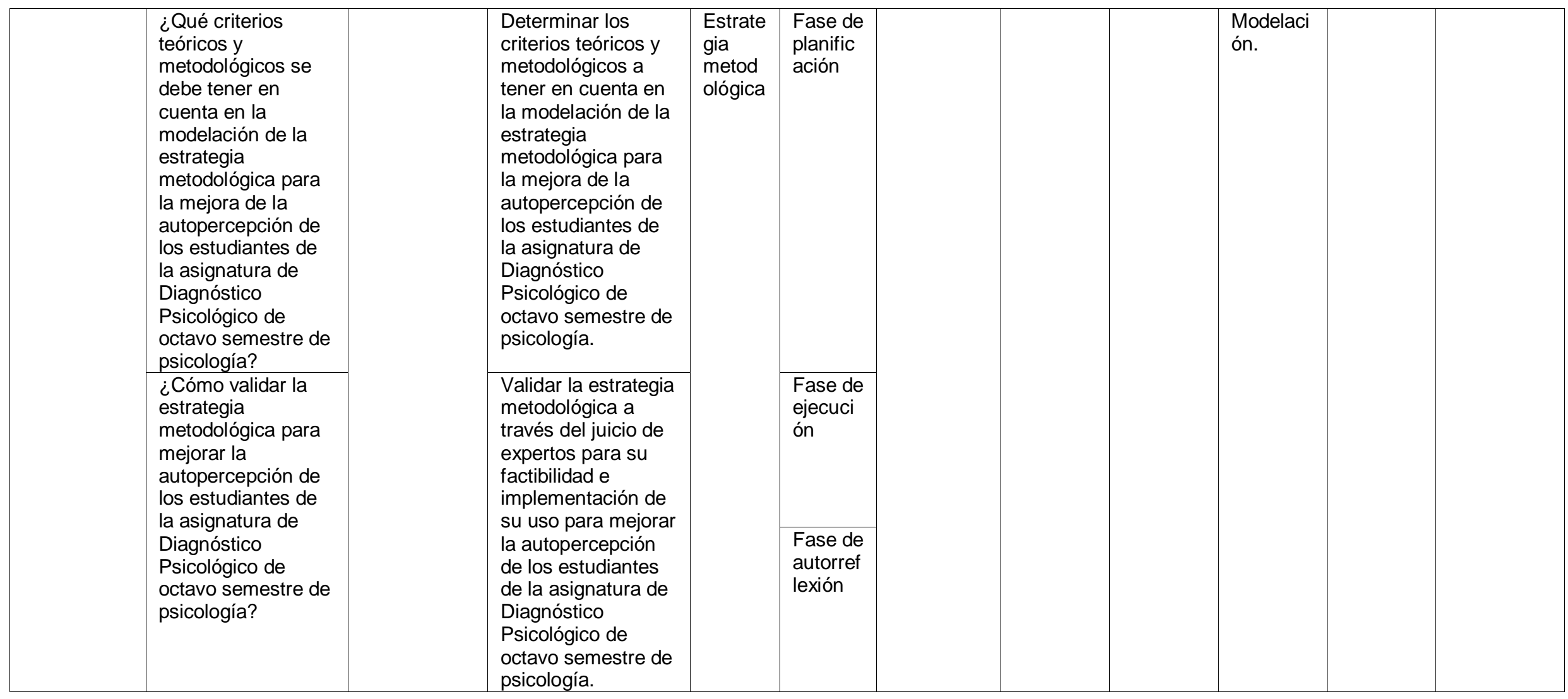




\begin{tabular}{|c|c|c|c|c|c|c|c|}
\hline $\begin{array}{l}\text { Formulación del } \\
\text { problema }\end{array}$ & $\begin{array}{l}\text { Objetivo } \\
\text { principal }\end{array}$ & Categorias & Subcategorías & Indicadores & $\begin{array}{l}\text { Item de la } \\
\text { guía de } \\
\text { entrevista }\end{array}$ & $\begin{array}{l}\text { Item del } \\
\text { cuestion } \\
\text { ario }\end{array}$ & $\begin{array}{l}\text { Item de } \\
\text { la guia } \\
\text { de } \\
\text { observa } \\
\text { ciòn }\end{array}$ \\
\hline \multirow[b]{2}{*}{$\begin{array}{l}\text { ¿Cómo mejorar la } \\
\text { autopercepción de los } \\
\text { estudiantes de la } \\
\text { asignatura de } \\
\text { Diagnóstico Psicológico } \\
\text { de octavo semestre de } \\
\text { psicología en una } \\
\text { universidad privada de } \\
\text { Lima? } \\
\text { Específicos: }\end{array}$} & \multirow[b]{2}{*}{$\begin{array}{l}\text { Modelar una } \\
\text { estrategia } \\
\text { metodológica } \\
\text { para mejorar la } \\
\text { autopercepción } \\
\text { de los estudiantes } \\
\text { de la asignatura } \\
\text { de Diagnóstico } \\
\text { Psicológico de } \\
\text { octavo semestre } \\
\text { de psicología en } \\
\text { una universidad } \\
\text { privada de Lima. } \\
\text { Específicos: }\end{array}$} & \multirow{8}{*}{$\begin{array}{l}\text { Autopercepci } \\
\text { ón. } \\
\text { Es el conjunto } \\
\text { de } \\
\text { constructos, } \\
\text { valoraciones y } \\
\text { actitudes } \\
\text { hacia sí mismo } \\
\text { en las áreas } \\
\text { material, } \\
\text { personal, } \\
\text { adaptativa, } \\
\text { social } \\
\text { identificativa } \\
\text { con el otro que } \\
\text { cada individuo } \\
\text { ha ido } \\
\text { construyendo } \\
\text { sobre su ser } \\
\text { para conseguir } \\
\text { un } \\
\text { autoconocimie } \\
\text { nto de sí de } \\
\text { acuerdo a la } \\
\text { realidad. } \\
\text { (Sendín, } \\
\text { 2007). }\end{array}$} & \multirow{2}{*}{$\begin{array}{l}\text { Sí mismo material. } \\
\text { Dimensión que hace } \\
\text { referencia a todos } \\
\text { aquellos enunciados en } \\
\text { los cuales el educando } \\
\text { identifica su cuerpo y } \\
\text { posesiones (L'Ecuyer, } \\
\text { 1985). }\end{array}$} & $\begin{array}{l}\text { Utiliza su cuerpo en el proceso de } \\
\text { aprendizaje enseñanza }\end{array}$ & \multirow[t]{2}{*}{1} & \multirow[t]{2}{*}{1} & \multirow[t]{2}{*}{7} \\
\hline & & & & $\begin{array}{l}\text { Utiliza sus objetos } \\
\text { y personas } \\
\text { significativas en el proceso de } \\
\text { aprendizaje enseñanza }\end{array}$ & & & \\
\hline \multirow{2}{*}{$\begin{array}{l}\text { ¿Cuál es el estado actual } \\
\text { de la autopercepción de } \\
\text { los estudiantes de la } \\
\text { asignatura de } \\
\text { Diagnóstico Psicológico } \\
\text { de octavo semestre de } \\
\text { psicología? }\end{array}$} & \multirow{2}{*}{$\begin{array}{l}\text { Diagnosticar el } \\
\text { estado actual de } \\
\text { la autopercepción } \\
\text { de los estudiantes } \\
\text { de la asignatura } \\
\text { de Diagnóstico } \\
\text { Psicológico de } \\
\text { octavo semestre } \\
\text { de psicología. }\end{array}$} & & \multirow{2}{*}{$\begin{array}{l}\text { Sí mismo personal. } \\
\text { Dimensión que alude a } \\
\text { todas aquellas } \\
\text { formulaciones que } \\
\text { hace el educando de } \\
\text { sus características } \\
\text { psíquicas (L'Ecuyer, } \\
\text { 1985). }\end{array}$} & $\begin{array}{l}\text { Utiliza sus experiencias de sí mismo en el } \\
\text { proceso de aprendizaje enseñanza }\end{array}$ & \multirow[t]{2}{*}{2} & \multirow[t]{2}{*}{$2,3,4$} & \multirow[t]{2}{*}{$8,9,10$} \\
\hline & & & & $\begin{array}{l}\text { Utiliza su consciencia de existir y ser en el } \\
\text { proceso de aprendizaje enseñanza }\end{array}$ & & & \\
\hline \multirow{4}{*}{$\begin{array}{l}\text { ¿Cuáles son los } \\
\text { fundamentos de la } \\
\text { estrategia metodológica } \\
\text { para la mejora de la } \\
\text { autopercepción de los } \\
\text { estudiantes de la } \\
\text { asignatura de } \\
\text { Diagnóstico Psicológico } \\
\text { de octavo semestre de } \\
\text { psicología? }\end{array}$} & \multirow{4}{*}{$\begin{array}{l}\text { Fundamentar } \\
\text { teóricamente la } \\
\text { estrategia } \\
\text { metodológica } \\
\text { para la mejora de } \\
\text { la autopercepción } \\
\text { de los estudiantes } \\
\text { de la asignatura } \\
\text { de Diagnóstico } \\
\text { Psicológico de } \\
\text { octavo semestre } \\
\text { de psicología. }\end{array}$} & & \multirow{2}{*}{$\begin{array}{l}\text { Sí mismo adaptativo. } \\
\text { Dimensión que engloba } \\
\text { todas aquellas } \\
\text { reacciones por parte del } \\
\text { educandor como } \\
\begin{array}{ll}\text { producto de sus } \\
\text { percepciones } \\
\text { (L'Ecuyer, 1985). }\end{array}\end{array}$} & $\begin{array}{l}\text { Utiliza juicios negativos o positivos hacia } \\
\text { sí mismo en el proceso de aprendizaje } \\
\text { enseñanza }\end{array}$ & \multirow[t]{2}{*}{3} & \multirow[t]{2}{*}{5,6} & \multirow[t]{2}{*}{15,16} \\
\hline & & & & $\begin{array}{l}\text { Utiliza sus acciones y reacciones ante sus } \\
\text { percepciones de sí mismo y frente a la } \\
\text { realidad en el proceso de aprendizaje } \\
\text { enseñanza }\end{array}$ & & & \\
\hline & & & \multirow{2}{*}{$\begin{array}{l}\text { Sí mismo social. } \\
\text { Dimensión que indica } \\
\text { todas aquellas } \\
\text { interacciones entre el } \\
\text { sí mismo del educando } \\
\text { con los otros (L'Ecuyer, } \\
\text { 1985). }\end{array}$} & $\begin{array}{l}\text { Utiliza sus interacciones con los otros en } \\
\text { actividades del proceso de aprendizaje } \\
\text { enseñanza }\end{array}$ & \multirow[t]{2}{*}{4,5} & \multirow[t]{2}{*}{7,8} & \multirow[t]{2}{*}{11,12} \\
\hline & & & & $\begin{array}{l}\text { Utiliza sus interacciones con los otros } \\
\text { integrando la dimensión sexual en el } \\
\text { proceso de aprendizaje enseñanza }\end{array}$ & & & \\
\hline
\end{tabular}




\begin{tabular}{|c|c|c|c|c|c|c|c|}
\hline \multirow{3}{*}{$\begin{array}{l}\text { ¿Qué criterios teóricos y } \\
\text { metodológicos se debe } \\
\text { tener en cuenta en la } \\
\text { modelación de la } \\
\text { estrategia metodológica } \\
\text { para la mejora de la } \\
\text { autopercepción de los } \\
\text { estudiantes de la } \\
\text { asignatura de } \\
\text { Diagnóstico Psicológico } \\
\text { de octavo semestre de } \\
\text { psicología? }\end{array}$} & \multirow{3}{*}{$\begin{array}{l}\text { Determinar los } \\
\text { criterios teóricos y } \\
\text { metodológicos a } \\
\text { tener en cuenta } \\
\text { en la modelación } \\
\text { de la estrategia } \\
\text { metodológica } \\
\text { para la mejora de } \\
\text { la autopercepción } \\
\text { de los estudiantes } \\
\text { de la asignatura } \\
\text { de Diagnóstico } \\
\text { Psicológico de } \\
\text { octavo semestre } \\
\text { de psicología. }\end{array}$} & & $\begin{array}{l}\text { Sí mismo-No sí } \\
\text { mismo. Dimensión en } \\
\text { la cual el educando se } \\
\text { identifica por contraste } \\
\text { interpersonal } \\
\text { (L'Ecuyer, 1985). }\end{array}$ & $\begin{array}{l}\text { Utiliza a otros para identificarse a sí } \\
\text { mismo en el proceso de aprendizaje } \\
\text { enseñanza } \\
\text { Utiliza la opinión de los otros para } \\
\text { identificarse a sí mismo en el proceso de } \\
\text { aprendizaje enseñanza }\end{array}$ & 6 & 9,10 & 13,14 \\
\hline & & \multirow{4}{*}{$\begin{array}{l}\text { Estrategia } \\
\text { metodológica } \\
\text { Es el proceso } \\
\text { formado por } \\
\text { pensamientos, } \\
\text { emociones y } \\
\text { acciones } \\
\text { autogenerada } \\
\text { s que están } \\
\text { organizadas } \\
\text { en fases de } \\
\text { planificación, } \\
\text { ejecución y } \\
\text { autorreflexión } \\
\text { para alcanzar } \\
\text { las metas } \\
\text { propuestas } \\
\text { (Zimmerman, } \\
\text { 2000). }\end{array}$} & $\begin{array}{l}\text { Fase de planificación. } \\
\text { Fase inicial en la cual el } \\
\text { educando se enfrenta a }\end{array}$ & $\begin{array}{l}\text { la tarea, y establece una estrategia } \\
\text { personal para su ejecución }\end{array}$ & \multirow[t]{2}{*}{7,8} & \multirow[t]{2}{*}{11,12} & \multirow[t]{2}{*}{1,2} \\
\hline & & & $\begin{array}{l}\text { la tarea analizándola, } \\
\text { valorando su capacidad } \\
\text { para realizarla con } \\
\text { éxito, estableciendo } \\
\text { metas y planificándolas } \\
\text { (Panadero \& Alonso- } \\
\text { Tapia, 2014a). }\end{array}$ & $\begin{array}{l}\text { sus recursos personales para iniciar y } \\
\text { mantener el nivel y tipo de motivación de } \\
\text { su ejecución }\end{array}$ & & & \\
\hline \multirow{2}{*}{$\begin{array}{l}\text { ¿Cómo validar la } \\
\text { estrategia metodológica } \\
\text { para mejorar la } \\
\text { autopercepción de los } \\
\text { estudiantes de la } \\
\text { asignatura de } \\
\text { Diagnóstico Psicológico } \\
\text { de octavo semestre de } \\
\text { psicología? }\end{array}$} & \multirow{2}{*}{$\begin{array}{l}\text { Validar la } \\
\text { estrategia } \\
\text { metodológica a } \\
\text { través del juicio } \\
\text { de expertos para } \\
\text { su factibilidad e } \\
\text { implementación } \\
\text { de su uso para } \\
\text { mejorar la } \\
\text { autopercepción } \\
\text { de los estudiantes } \\
\text { de la asignatura } \\
\text { de Diagnóstico } \\
\text { Psicológico de } \\
\text { octavo semestre } \\
\text { de psicología. }\end{array}$} & & $\begin{array}{l}\text { Fase de ejecución. } \\
\text { Fase intermedia en la } \\
\text { cual el educando } \\
\text { desempeña la actividad } \\
\text { en sí (Panadero \& } \\
\text { Alonso-Tapia, 2014a). }\end{array}$ & $\begin{array}{l}\text { a el desarrollo y calidad de su actividad } \\
\text { ie el interés y concentración usando } \\
\text { estrategias durante la actividad }\end{array}$ & 9,10 & 13,14 & 3,4 \\
\hline & & & $\begin{array}{l}\text { Fase de } \\
\text { autorreflexión. } \\
\text { Fase final cuya } \\
\text { característica es que el } \\
\text { educando valore su } \\
\text { desempeño y trate de } \\
\text { explicarse el porqué de } \\
\text { sus resultados } \\
\text { conseguidos } \\
\text { (Panadero \& Alonso- } \\
\text { Tapia, 2014a). }\end{array}$ & \begin{tabular}{|l|} 
u proceso de desempeño realizado \\
fracaso o éxito a su desempeño
\end{tabular} & 11,12 & 15,16 & 5,6 \\
\hline
\end{tabular}




\section{Anexo 2. Instrumentos de recolección de datos ENTREVISTA SEMIESTRUCTURADA A LOS DOCENTES}

Datos informativos:

Entrevistador:

Lugar y Fecha:

Duración:

Objetivo: Conocer la preparación profesional que poseen los docentes sobre la autopercepción y autorregulación de los estudiantes de octavo semestre en la Facultad de Psicología de una universidad privada de Lima.

\begin{tabular}{|c|c|}
\hline $\mathbf{N}^{\circ}$ & Preguntas \\
\hline 1 & ¿Cómo utiliza las posesiones objetales de los educandos en el proceso de enseñanza aprendizaje? \\
\hline 2 & ¿Cómo utiliza la identidad de los educandos en el proceso de enseñanza aprendizaje? \\
\hline 3 & $\begin{array}{l}\text { ¿Cómo utiliza los juicios valorativos sobre las experiencias de los educandos en el proceso de enseñanza } \\
\text { aprendizaje? }\end{array}$ \\
\hline 4 & ¿Cómo utiliza los vínculos con los otros de los educandos en el proceso de enseñanza aprendizaje? \\
\hline 5 & $\begin{array}{l}\text { ¿Cómo utiliza las experiencias psicosexuales de los educandos en el proceso de enseñanza } \\
\text { aprendizaje? }\end{array}$ \\
\hline 6 & $\begin{array}{l}\text { ¿Cómo utiliza las experiencias de identificación con el prójimo de los educandos en el proceso de } \\
\text { enseñanza aprendizaje? }\end{array}$ \\
\hline 7 & $\begin{array}{l}\text { ¿Cómo promueve el establecimiento de estrategias cognitivas en los educandos al inicio del proceso de } \\
\text { enseñanza aprendizaje? }\end{array}$ \\
\hline 8 & $\begin{array}{l}\text { ¿Cómo promueve el uso de recursos personales en los educandos para estimular su motivación al inicio } \\
\text { del proceso de enseñanza aprendizaje? }\end{array}$ \\
\hline 9 & $\begin{array}{l}\text { ¿Cómo promueve la calidad del desarrollo de las actividades en los educandos durante el proceso de } \\
\text { enseñanza aprendizaje? }\end{array}$ \\
\hline 10 & $\begin{array}{l}\text { ¿Cómo promueve el mantenimiento del interés y la concentración en los educandos durante el proceso } \\
\text { de enseñanza aprendizaje? }\end{array}$ \\
\hline 11 & $\begin{array}{l}\text { ¿Cómo promueve el juicio valorativo del proceso de desempeño realizado en los educandos al final del } \\
\text { proceso de enseñanza aprendizaje? }\end{array}$ \\
\hline 12 & $\begin{array}{l}\text { ¿Cómo promueve la atribución de fracaso o éxito del desempeño realizado en los educandos al final del } \\
\text { proceso de enseñanza aprendizaje? }\end{array}$ \\
\hline
\end{tabular}

\section{CUESTIONARIO A LOS ESTUDIANTES}

Datos Generales:

Carrera: Ciclo:

Edad: Sexo: Femenino ( ) Masculino ( ) Fecha:

Objetivo: Constatar la autorregulación de los estudiantes de octavo semestre en la Facultad de Psicología de una universidad privada de Lima con la manera en que la docente de la asignatura Diagnóstico Psicológico dirige el proceso de enseñanza aprendizaje para contribuir a la mejora de su autopercepción. 


\section{Instrucciones:}

Estimado estudiante, por favor lee cada enunciado y posteriormente encierra en un círculo tu respuesta de acuerdo a las siguientes claves:

$$
\begin{aligned}
& a=\text { Casi siempre típico en mí } \\
& b=\text { Frecuentemente típico en mí } \\
& c=\text { Algunas veces típico en mí } \\
& d=\text { No es muy típico en mí } \\
& \text { e }=\text { No es típico en mí en lo absoluto }
\end{aligned}
$$

Responde sinceramente seleccionando las respuestas que mejor describan tus comportamientos más comunes

\begin{tabular}{|c|c|c|c|c|c|c|}
\hline $\mathbf{N}^{\circ}$ & Reactivos & $\mathbf{a}$ & b & C & d & e \\
\hline 1 & $\begin{array}{l}\text { ¿Utiliza sus posesiones objetales de sí mismo en el proceso de enseñanza } \\
\text { aprendizaje? }\end{array}$ & & & & & \\
\hline 2 & ¿Utiliza su imagen de sí mismo en el proceso de enseñanza aprendizaje? & & & & & \\
\hline 3 & ¿Utiliza su estima de sí mismo en el proceso de enseñanza aprendizaje? & & & & & \\
\hline 4 & ¿Utiliza su identidad de sí mismo en el proceso de enseñanza aprendizaje? & & & & & \\
\hline 5 & $\begin{array}{l}\text { ¿Utiliza juicios valorativos sobre sus experiencias de sí mismo en el proceso } \\
\text { de enseñanza aprendizaje? }\end{array}$ & & & & & \\
\hline 6 & $\begin{array}{l}\text { ¿Utiliza sus acciones y reacciones de sí mismo producidas en el proceso de } \\
\text { enseñanza aprendizaje? }\end{array}$ & & & & & \\
\hline 7 & ¿Utiliza sus vínculos con los otros en el proceso enseñanza de aprendizaje? & & & & & \\
\hline 8 & $\begin{array}{l}\text { ¿Utiliza sus experiencias psicosexuales en el proceso de enseñanza } \\
\text { aprendizaje? }\end{array}$ & & & & & \\
\hline 9 & $\begin{array}{l}\text { ¿Utiliza como referencia al prójimo para identificarse en el proceso de } \\
\text { enseñanza aprendizaje? }\end{array}$ & & & & & \\
\hline 10 & $\begin{array}{l}\text { ¿Utiliza la opinión del prójimo sobre sí mismo en el proceso de enseñanza } \\
\text { aprendizaje? }\end{array}$ & & & & & \\
\hline 11 & $\begin{array}{l}\text { ¿Establece estrategias cognitivas al inicio del proceso de enseñanza } \\
\text { aprendizaje? }\end{array}$ & & & & & \\
\hline 12 & $\begin{array}{l}\text { ¿Utiliza sus recursos personales para estimular su motivación al inicio del } \\
\text { proceso de enseñanza aprendizaje? }\end{array}$ & & & & & \\
\hline 13 & $\begin{array}{l}\text { ¿Controla la calidad del desarrollo de su actividad durante el proceso de } \\
\text { enseñanza aprendizaje? }\end{array}$ & & & & & \\
\hline 14 & $\begin{array}{l}\text { ¿Mantiene el interés y la concentración durante el proceso de enseñanza } \\
\text { aprendizaje? }\end{array}$ & & & & & \\
\hline 15 & $\begin{array}{l}\text { ¿Juzga su proceso de desempeño realizado al final del proceso de enseñanza } \\
\text { aprendizaje? }\end{array}$ & & & & & \\
\hline 16 & $\begin{array}{l}\text { ¿Atribuye fracaso o éxito a su desempeño realizado al final del proceso de } \\
\text { enseñanza aprendizaje? }\end{array}$ & & & & & \\
\hline
\end{tabular}
hacia tus actividades académicas. Trata de hacer una estimación de ti mismo de cómo el enunciado te describe a ti; no en términos de cómo piensas que debería ser, o de lo que otros piensan de ti. No hay respuestas correctas o incorrectas. Tus respuestas serán absolutamente confidenciales y únicamente serán empleadas para propósitos de investigación. Por favor contesta todos los enunciados, respetando el orden numérico del cuestionario.

GUÍA DE OBSERVACIÓN DE LA AUTOPERCEPCIÓN Y AUTORREGULACIÓN EN CLASE

Observador:

Carrera: Ciclo:

Asignatura:

Tema de la sesión de clase: 
Fecha:

Horario:

Objetivo: Constatar los indicadores de la autopercepción y autorregulación que poseen los educandos de octavo semestre en la Facultad de Psicología de una universidad privada de Lima en el proceso de enseñanza aprendizaje.

\begin{tabular}{|l|l|}
\hline $\mathbf{N}^{\circ}$ & \multicolumn{1}{c|}{ INDICADORES A EVALUAR } \\
\hline & Al Inicio del Proceso de Enseñanza Aprendizaje \\
\hline 1 & Establece estrategias cognitivas para su ejecución \\
\hline 2 & Utiliza sus recursos personales para estimular su motivación de su ejecución \\
\hline & Durante el Proceso de Enseñanza Aprendizaje \\
\hline 3 & Controla la calidad del desarrollo de su actividad \\
\hline 4 & Mantiene el interés y la concentración \\
\hline & Al Final del Proceso de Enseñanza Aprendizaje \\
\hline 5 & Juzga su proceso de desempeño realizado \\
\hline 6 & Atribuye fracaso o éxito a su desempeño realizado \\
\hline & En el Proceso de Enseñanza Aprendizaje \\
\hline 7 & Utiliza sus posesiones objetales de sí mismo \\
\hline 8 & Utiliza su imagen de sí mismo \\
\hline 9 & Utiliza su estima de sí mismo \\
\hline 10 & Utiliza su identidad de sí mismo \\
\hline 11 & Utiliza sus vínculos con los otros \\
\hline 12 & Utiliza sus experiencias psicosexuales \\
\hline 13 & Utiliza como referencia al prójimo para identificarse \\
\hline 14 & Utiliza la opinión del prójimo sobre sí mismo \\
\hline 15 & Utiliza juicios valorativos sobre sus experiencias de sí mismo \\
\hline 16 & Utiliza sus acciones y reacciones de sí mismo \\
\hline
\end{tabular}

\section{Anexo 3. Validación de instrumentos de recolección de la información}




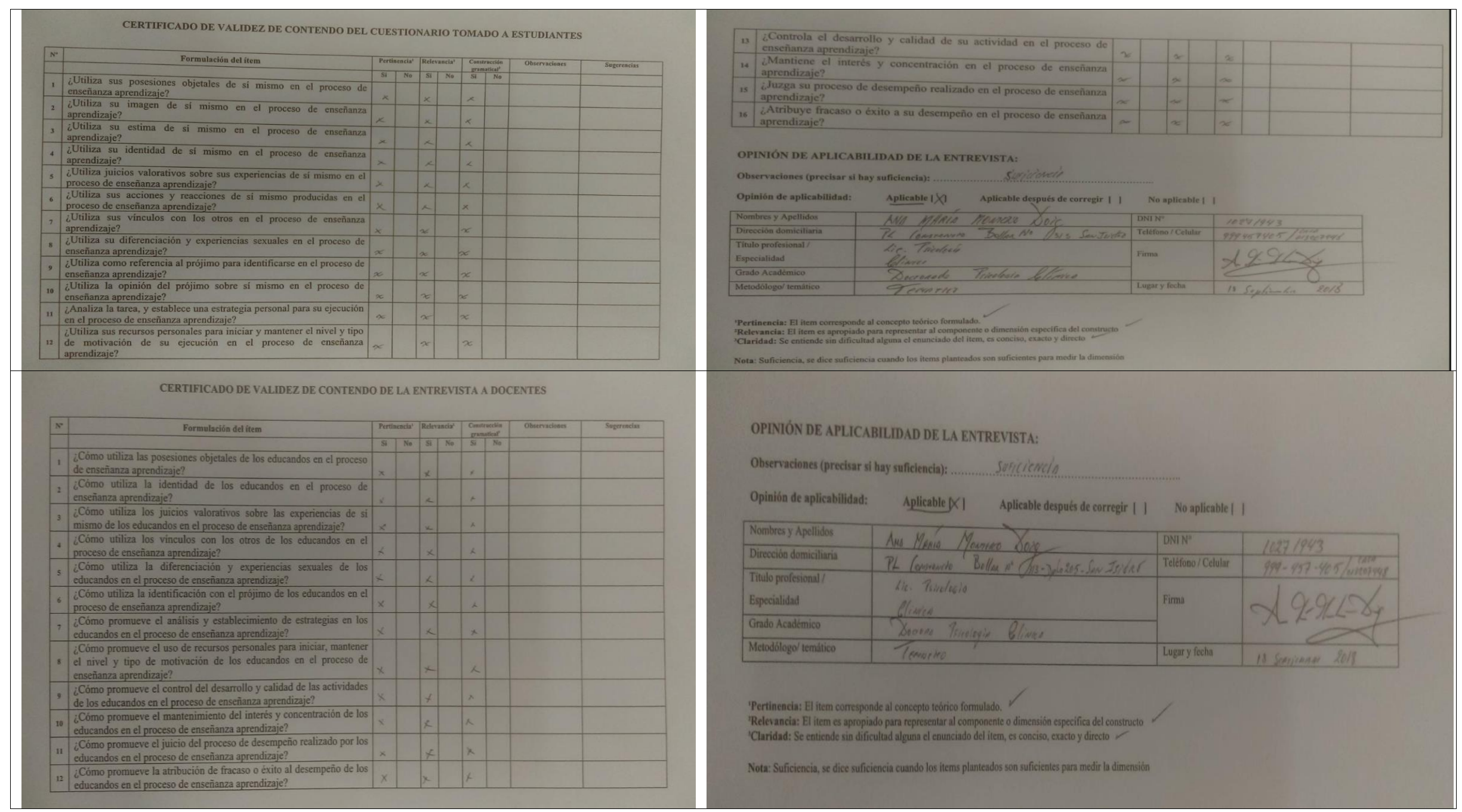




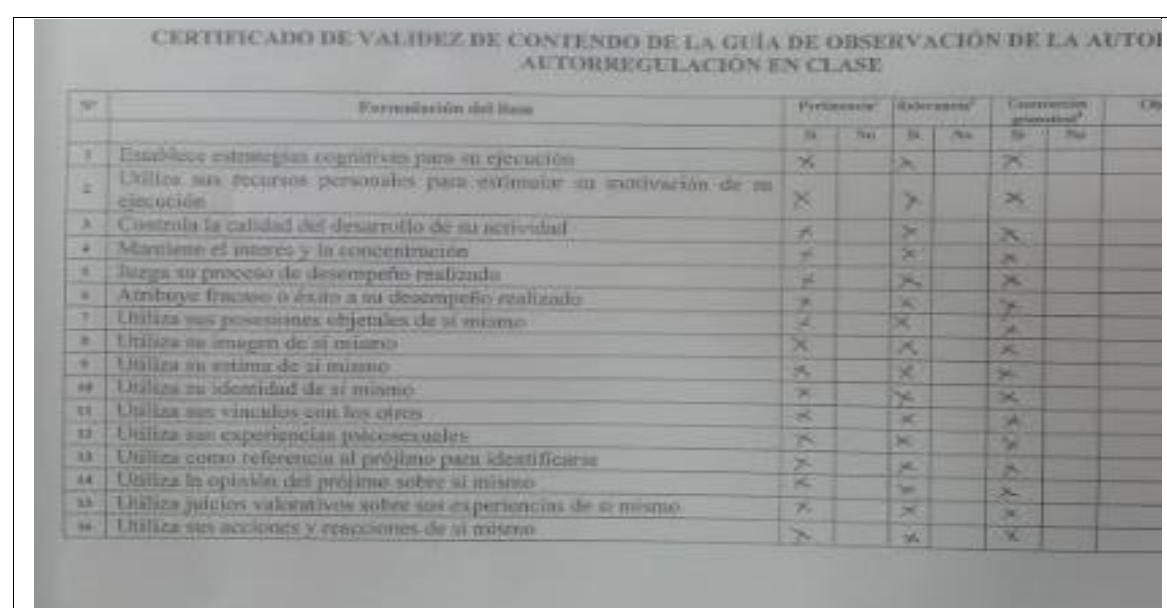

CERTIFICADO DE VALIDEZ DE CONTENDO DE LA ENTREVISTA A DOCENTES

\begin{tabular}{|c|c|c|c|c|c|}
\hline${ }^{*}$ & Formulación del item & \begin{tabular}{|l|l} 
Pertinencin' \\
\end{tabular} & $\begin{array}{l}\text { Releyancia } \\
\end{array}$ & & \\
\hline & & & & & \\
\hline 1 & $\begin{array}{l}\text { ¿Como utiliza las posesiones objetales de los educandos en el proceso } \\
\text { de enseñanza aprendizaje? }\end{array}$ & $\gamma$ & y & J & \\
\hline 2 & $\begin{array}{l}\text { ¿Cómo utiliza la identidad de los educandos en el proceso de } \\
\text { enseñanza aprendizaje? }\end{array}$ & $\checkmark$ & 1 & $J$ & \\
\hline 3 & $\begin{array}{l}\text { ¿Cómo utiliza los juicios valorativos sobre las experiencias de sí } \\
\text { mismo de los educandos en el proceso de enseñanza aprendizaje? }\end{array}$ & $r$ & 0 & $J$ & \\
\hline 4 & $\begin{array}{l}\text { ¿Cómo utiliza los vinculos con los otros de los educandos en el } \\
\text { proceso de enseñanza aprendizaje? }\end{array}$ & $\checkmark$ & $\checkmark$ & J & \\
\hline 5 & $\begin{array}{l}\text { ¿Cómo utiliza la diferenciación y experiencias sexuales de los } \\
\text { educandos en el proceso de enseñanza aprendizaje? }\end{array}$ & $\checkmark$ & $\checkmark$ & $J$ & \\
\hline 6 & $\begin{array}{l}\text { ¿Cómo utiliza la identificación con el prójimo de los educandos en el } \\
\text { proceso de enseñanza aprendizaje? }\end{array}$ & $\checkmark$ & .. & $J$ & \\
\hline 7 & $\begin{array}{l}\text { ¿Cómo promueve el análisis y establecimiento de estrategias en los } \\
\text { educandos en el procesoso de enseñanza aprendizaje? }\end{array}$ & 2 & $J$ & $\sqrt{2}$ & \\
\hline 8 & $\begin{array}{l}\text { ¿Cómo promueve el uso de recursos personales para iniciar, mantener } \\
\text { el nivel y tipo de motivación de los educandos en el proceso de } \\
\text { enseñanza aprendizaje? }\end{array}$ & 2 & $\checkmark$ & V & \\
\hline , & $\begin{array}{l}\text { ¿Como promueve el control del desarrollo y calidad de las actividades } \\
\text { de los educandos en el proceso de enseñanza aprendizaje? }\end{array}$ & $\gamma$ & $J$ & $\gamma$ & \\
\hline 10 & $\begin{array}{l}\text { ¿Cómo promueve el mantenimiento del interés y concentración de los } \\
\text { educandos en el proceso de enseñanza aprendizaje? }\end{array}$ & $\nu$ & $\checkmark$ & $\sqrt{ }$ & \\
\hline " & $\begin{array}{l}\text { ¿Cómo promueve el juicio del proceso de desempeño realizado por los } \\
\text { educandos en el proceso de enseñanza aprendizaje? }\end{array}$ & $\gamma$ & $J$ & J & \\
\hline 12 & $\begin{array}{l}\text { ¿Cómo promueve la atribución de fracasoo o éxito al desempeño de los } \\
\text { educandos en el proceso de enseñanza aprendizaje? }\end{array}$ & $\gamma$ & $\sqrt{7}$ & $\mathrm{~V}$ & \\
\hline
\end{tabular}

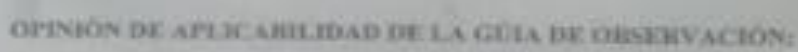

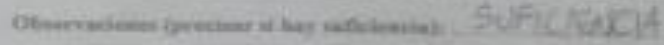

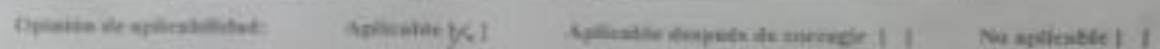

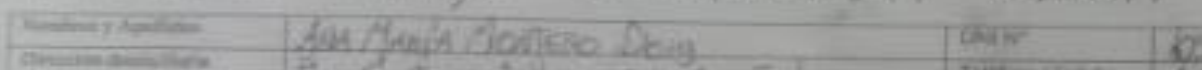

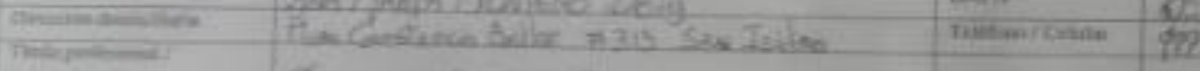

Protion

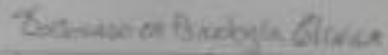

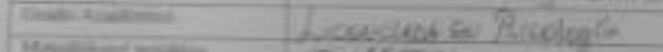

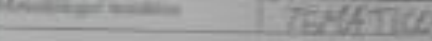

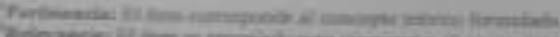

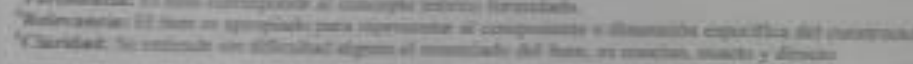

-

OPINIÓN DE APLICABILIDAD DE LA ENTREVISTA:

Observaciones (precisar si hay suficiencia): .....................

Opinión de aplicabilidad: Aplicable |X|X_Aplicable después de corregir | | No aplicable | |

\begin{tabular}{|c|c|c|c|}
\hline Nombres y Apellidos & Tose Miñat SALAZAx & $\mathrm{DNIN}^{\circ}$ & 09536793 \\
\hline Dirección domiciliaria & & Teléfono / Celular & \\
\hline \begin{tabular}{|l|} 
Titulo profesional/ \\
Especialidad
\end{tabular} & InEentaro & Fima & \\
\hline \begin{tabular}{|l} 
Grado Académico \\
\end{tabular} & OOCTOR an Crencid De lI EDUCAOOON & & \\
\hline Metodólogo/ temático & Metodólago & Lugary fecha & USI- 22109118 \\
\hline
\end{tabular}

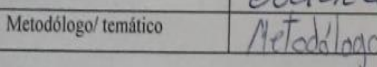

Lugar y fecha 1 USZZ- 22/091/8

'Pertinencia: El item corresponde al conceppto térico formulado

'Relevancia: El item es apropiado para representar al componente o dimensión especifica del constructo 'Claridad: Se entiende sin dificultad alguna el enunciado del item, es conciso, exacto y directo

Nota: Suficiencia, se dice suficiencia cuando los items planteados son suficientes para medir la dimensión 

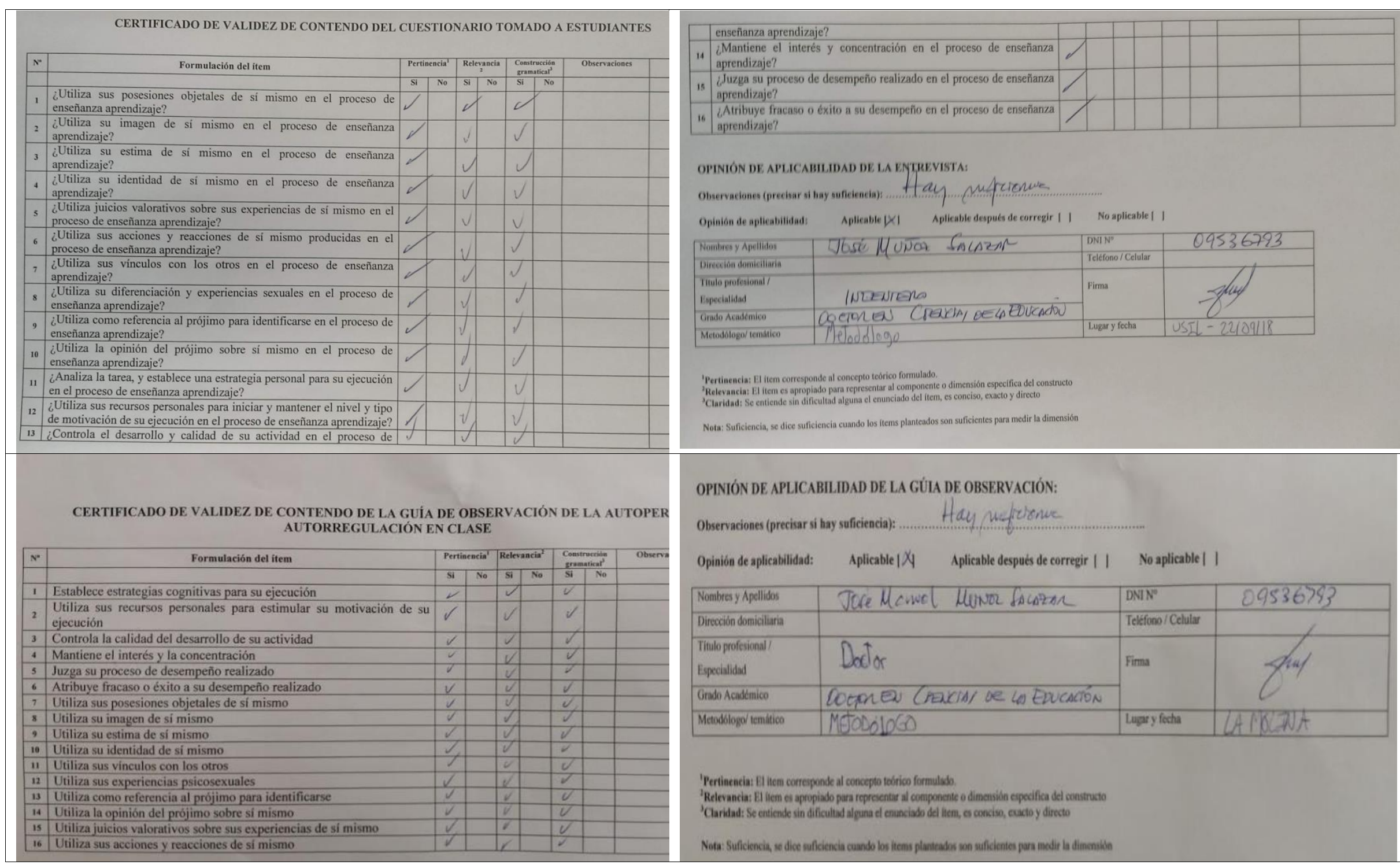

OPINIÓN DE APLICABILIDAD DE LA GÚIA DE OBSERVACIÓN:

Obsernaciones (preciars i hay suficiencia): ......... Hay weficienve

Opinión de aplicabilidad: Aplicable | $x_{\mid} \quad$ Aplicable después de corregir | | No aplicable | |

\begin{tabular}{|c|c|c|c|}
\hline Nombres y Apellidos & Jore Mawol Mlenar facazar & DNIN & 09536743 \\
\hline Dirección domicliaria & & Tekfono / Celular & \\
\hline $\begin{array}{l}\text { Titulo profesional/ } \\
\text { Especialidad }\end{array}$ & Dotor & Fima & \\
\hline Grado Academico & Cotanea (rancia) de la ENCACTON & & \\
\hline Metodologol temiticico & MEODOLDG0 & Lugary factha & CACDAT \\
\hline
\end{tabular}

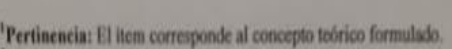

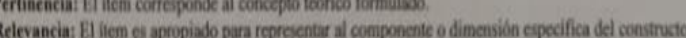

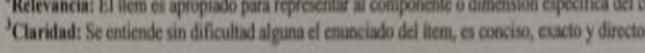

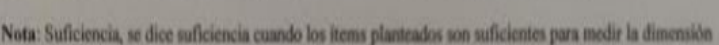




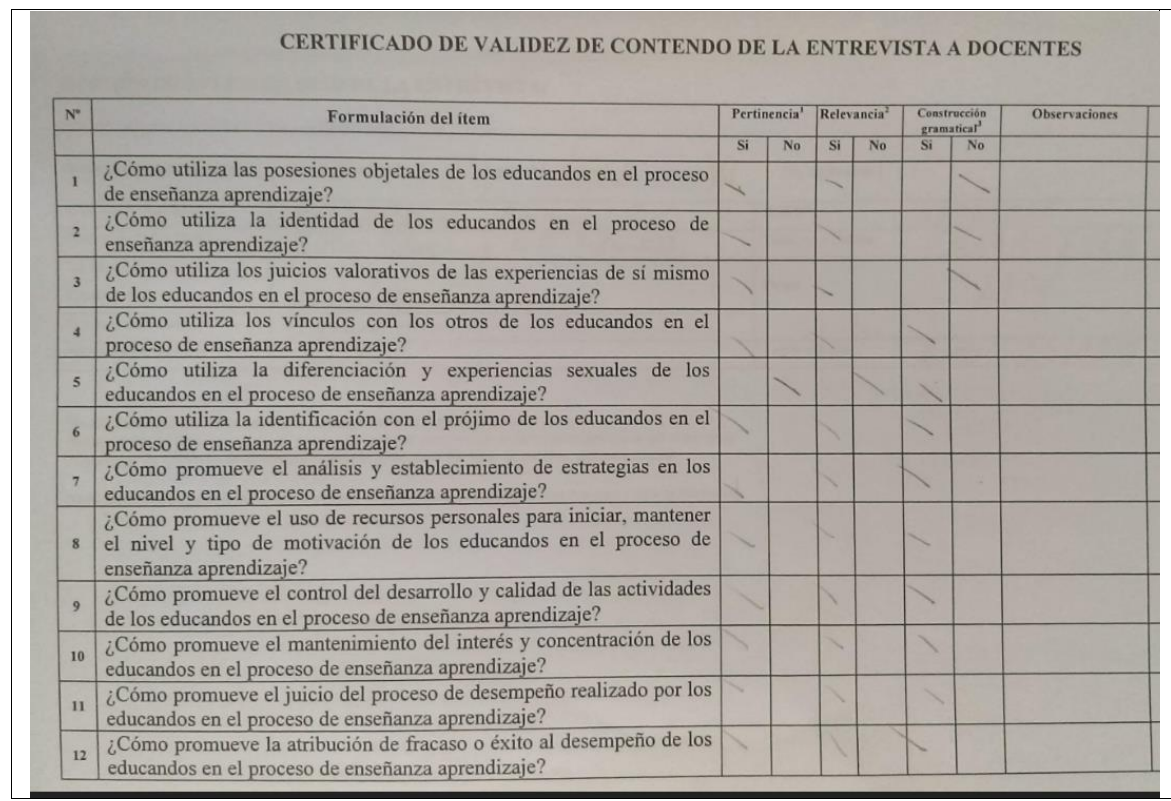

OPINIÓN DE APLICABILIDAD DE LA ENTREVISTA:

Observaciones (precisar si hay suficiencia):

Opinión de aplicabilidad: $\quad$ Aplicable | । Aplicable después de corregir $\mid\langle| \quad$ № aplicable | I

\begin{tabular}{|c|c|c|c|}
\hline Nombres y Apeclidos & Ma delcruen twiner $R$ & DNI N ${ }^{\circ}$ & 21465218 \\
\hline Direceión domicliaria & locar chreme 4s surco & 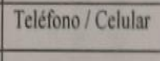 & 99996848 \\
\hline $\begin{array}{l}\text { Titulo profesional / } \\
\text { Especialidad }\end{array}$ & Phoilog & Firma & \\
\hline Grado Académico & $D \mathrm{PN}^{\mathrm{t}}$ & & \\
\hline Metodólogo / temático & Metrdologe & Lugar $y$ fecha & nuros $2 6 \longdiv { 9 }$ \\
\hline
\end{tabular}

'Pertinencia: El item comesponde al concepto teórico formulado.

"Relevancia: El item es apropiado para representar al componente o dimensión especifica del constructo

'Claridad: Se entiende sin dificultad alguna el enunciado del item, es conciso, exacto y directo

Nota: Sufficiencia, se dice suficiencia cuando los items planteados son suficientes para medir la dimensión 


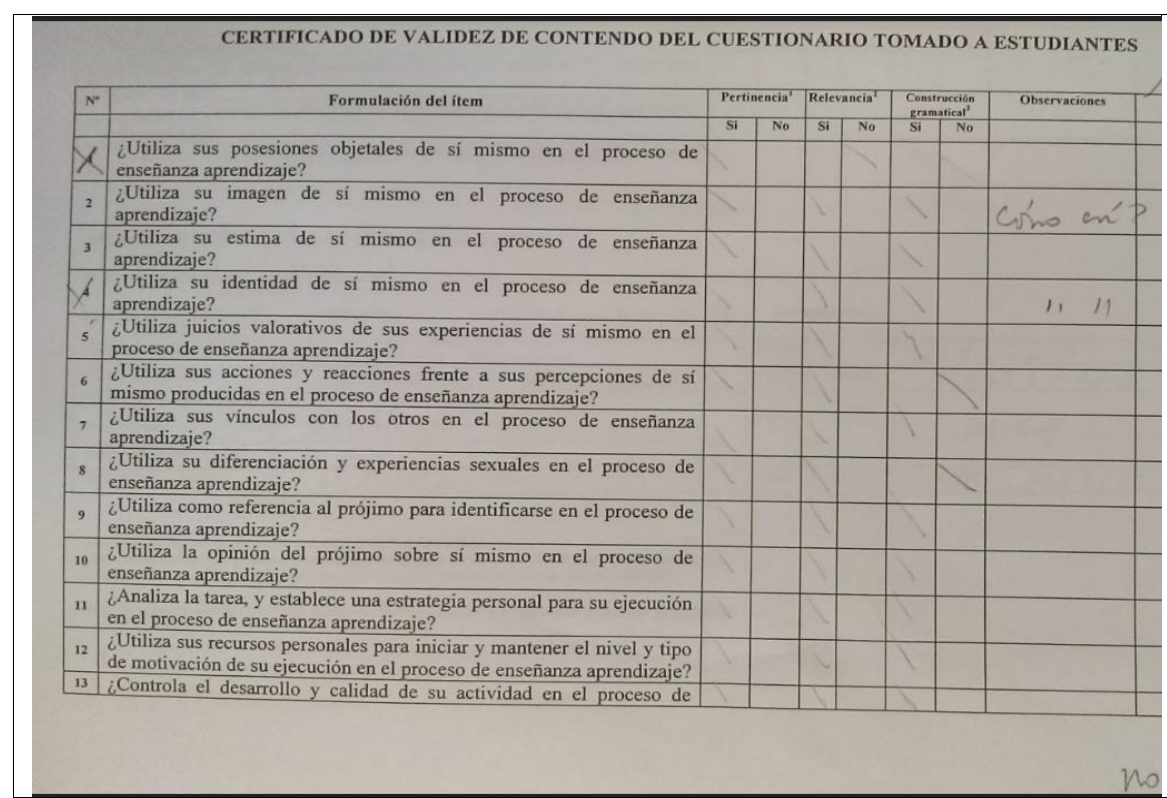

CERTIFICADO DE VALIDEZ DE CONTENDO DE LA GUIA DE OBSERYACIÓN DE LA AUTOPERCEPCIÓN AUTORREGULACION EN CL.ASE

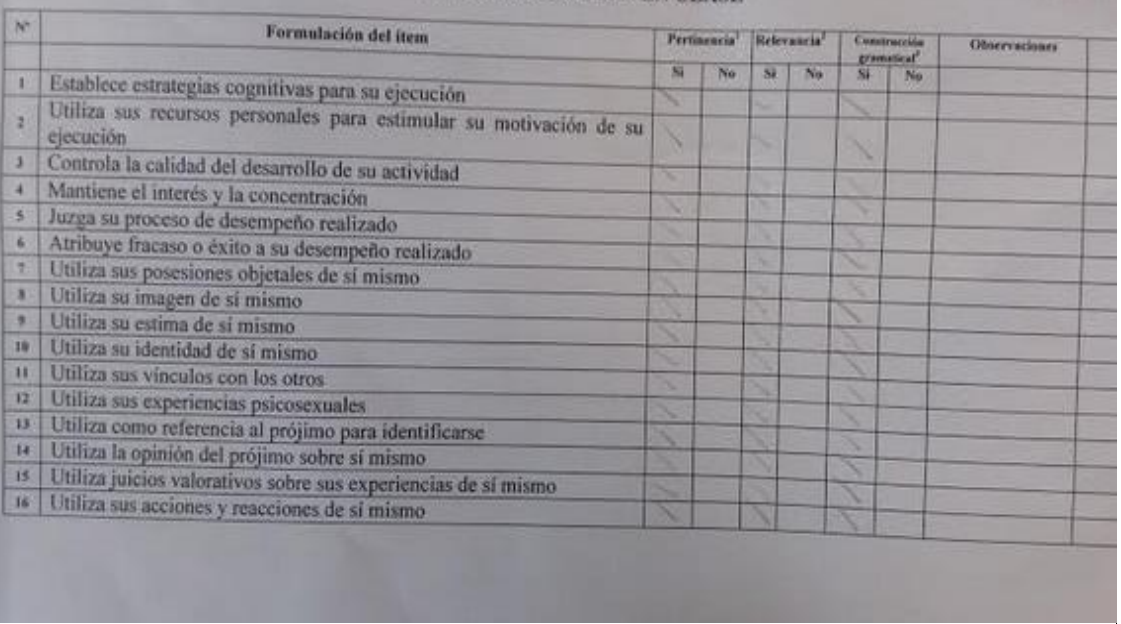

\begin{tabular}{|l|l|l}
\hline enseñanza aprendizaje \\
\hline Mantiene el interís \\
\hline
\end{tabular}

14 ¿Mantiene el interés y concentración en el proceso de enseñanza

15 iJuzza su processo de desempeño realizado en el proceso de enseñanza

16 ¿Atribuye fracaso o éxito a su desempeño en el proceso de enseñanza
aprendizaje?

OPINIÓN DE APLICABILIDAD DE LA ENTREVISTA:

Obsernaciones (precisar si hay sufficencia)

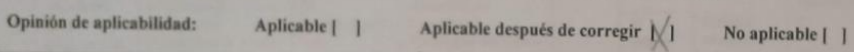

\begin{tabular}{|c|c|c|c|}
\hline Nombres y Apeclididos & Ho blgran ting & DNII N & 21463108 \\
\hline $\begin{array}{l}\text { Dirección domiciliaria } \\
\text { Titulo poftesional/ }\end{array}$ & Oxer concuse & \begin{tabular}{|l} 
Teléfono / Ceculatar \\
\end{tabular} & $949468 \times 80$ \\
\hline $\begin{array}{l}\text { Especialidad } \\
\text { Grido Acallenico }\end{array}$ & Irologe & Firma & $m$ \\
\hline $\begin{array}{l}\text { Grado Acaudemico } \\
\text { Mecosologo temitico }\end{array}$ & drotor & & \\
\hline & Mentoges & Lugary $y$ fecha & tura \\
\hline
\end{tabular}

Melosolologo temiticico Metiolas

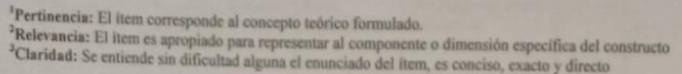

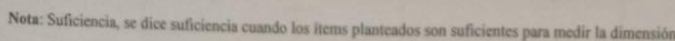

\section{OPINIÓN DE APLICABILIDAD DE LA GÚIA DE OBSERVACIÓN:}

Observaciones (precisar si hay suficiencia):

Aplicable XI Aplicable después de corregir [ ] № aplicable | I

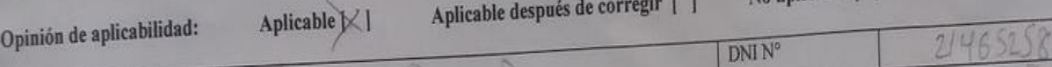

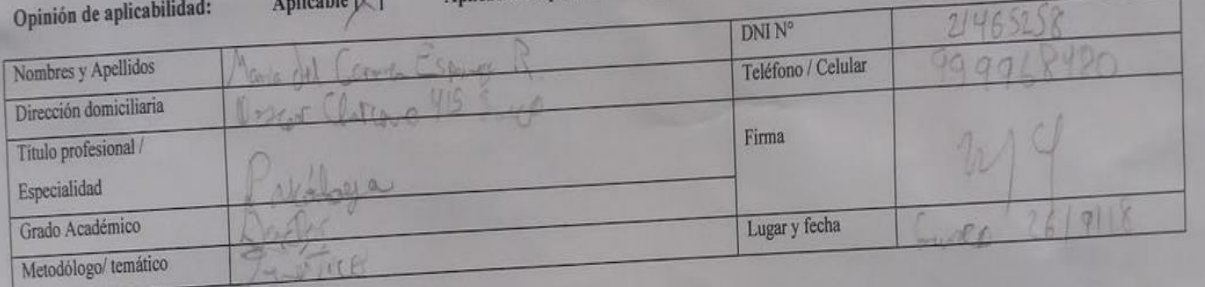

Metodologo/ temático

'Pertinencia: El item conresponde a c conceppoto térico formulado. ${ }^{2}$ Reelevancia: El it item es appopiado para representar al componente o dimension cspect y directo

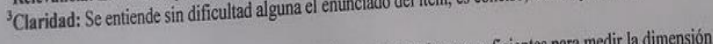

Vor-Suficiencia se dice sufficiencia cuando los fitems planteados son sufficientes para medir la dimensión 


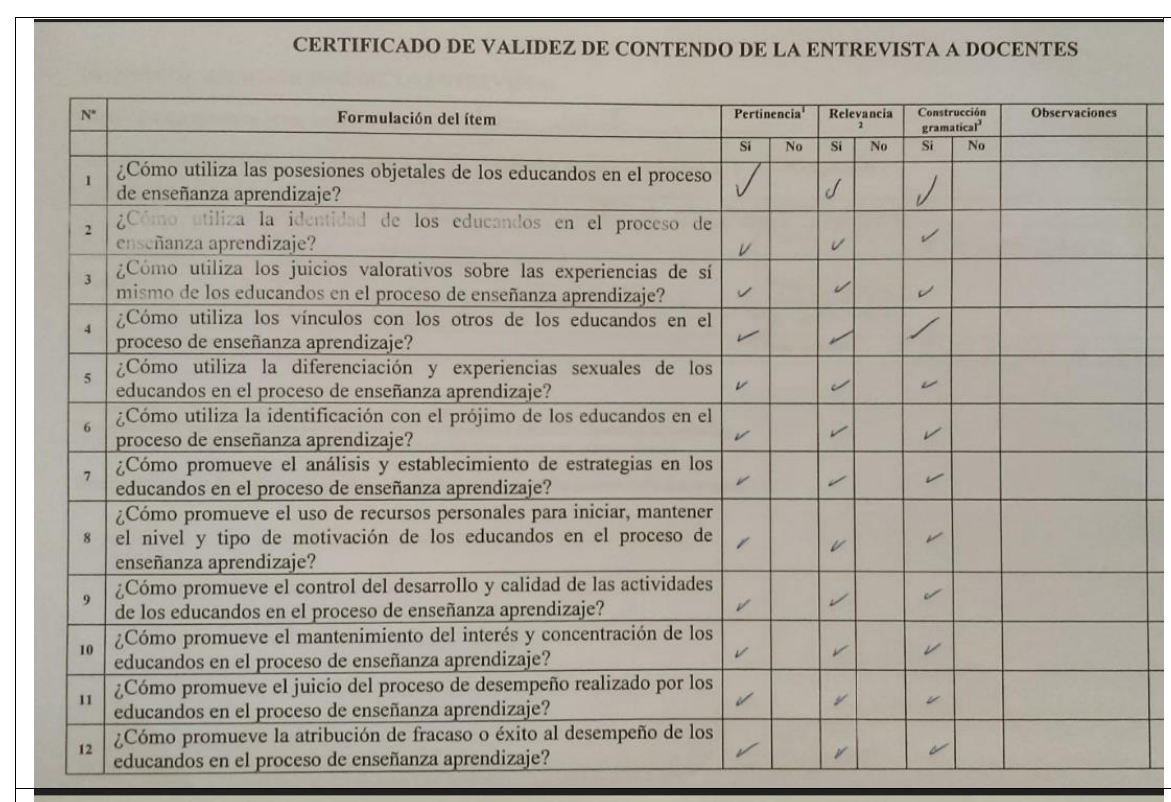

CERTIFICADO DE VALIDEZ DE CONTENDO DEL CUESTIONARIO TOMADO A ESTUDIANT

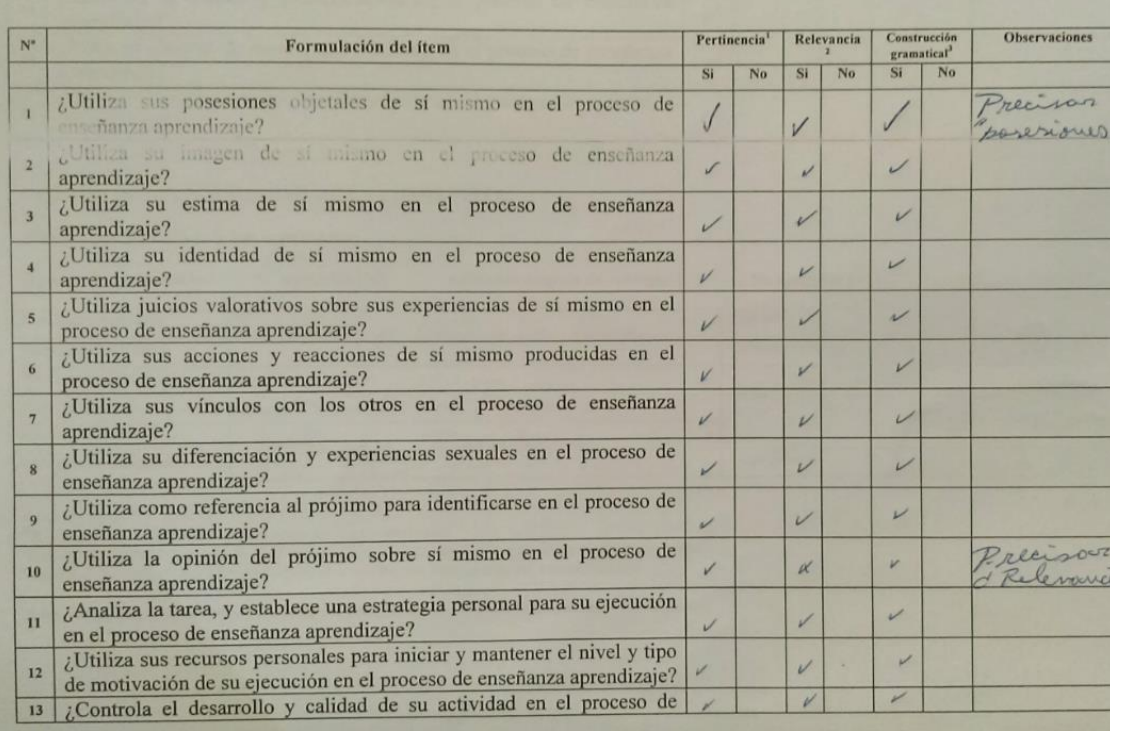

\section{OPINIÓN DE APLICABILIDAD DE LA ENTREVISTA:}

Observaciones (precisar si hay suficiencia): ...................existe

Opinión de aplicabilidad: $\quad$ Aplicable | $\quad$ Aplicable después de corregir | | No aplicable | ।

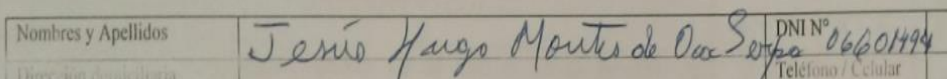

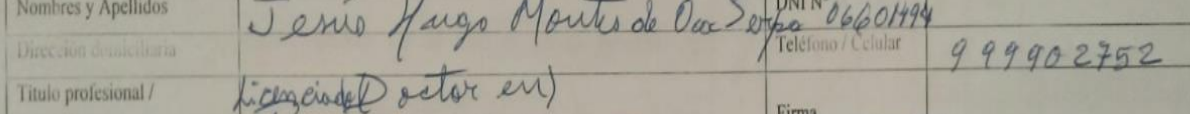

Especialidad

Grado Académico

Pricolosiá Ed

Metodologo/ Lemátic Destri

'Pertinencia: El item corresponde al concepto térico formulado.

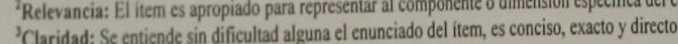

Nota: Suficiencia, se dice suficiencia cuando los items planteados son suficientes para medir la dimensión

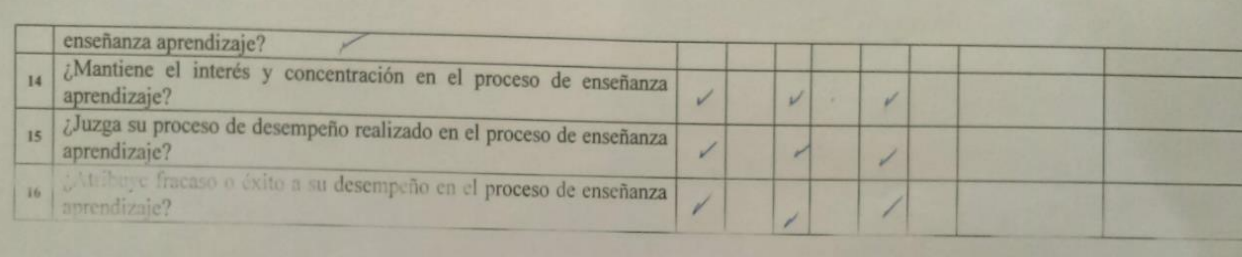

OPINIÓN DE APLICABILIDAD DE LA ENTREVISTA:

Observaciones (precisar si hay suficiencia):

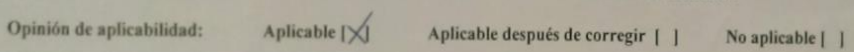

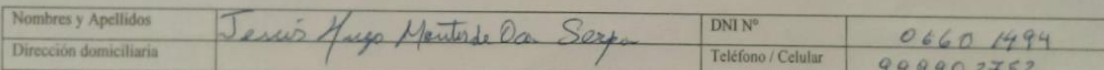

Titulo profecsional t/

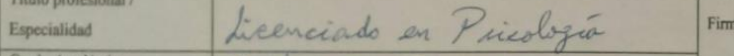

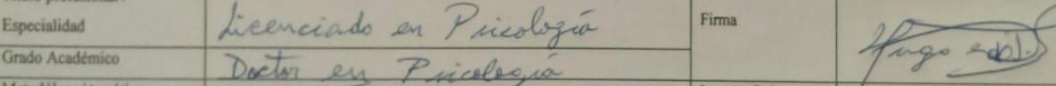

Temantios Lugary fecha Lima 28 de setander 2 on

'Pertinencia: El ilicem cenresponde al conscepto téricico formulado.

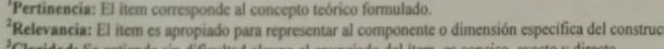

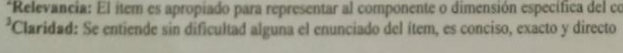

Nota: Surficencia, se dice suficicencia cuando los items planteados son suficientes para medir la dimensión 


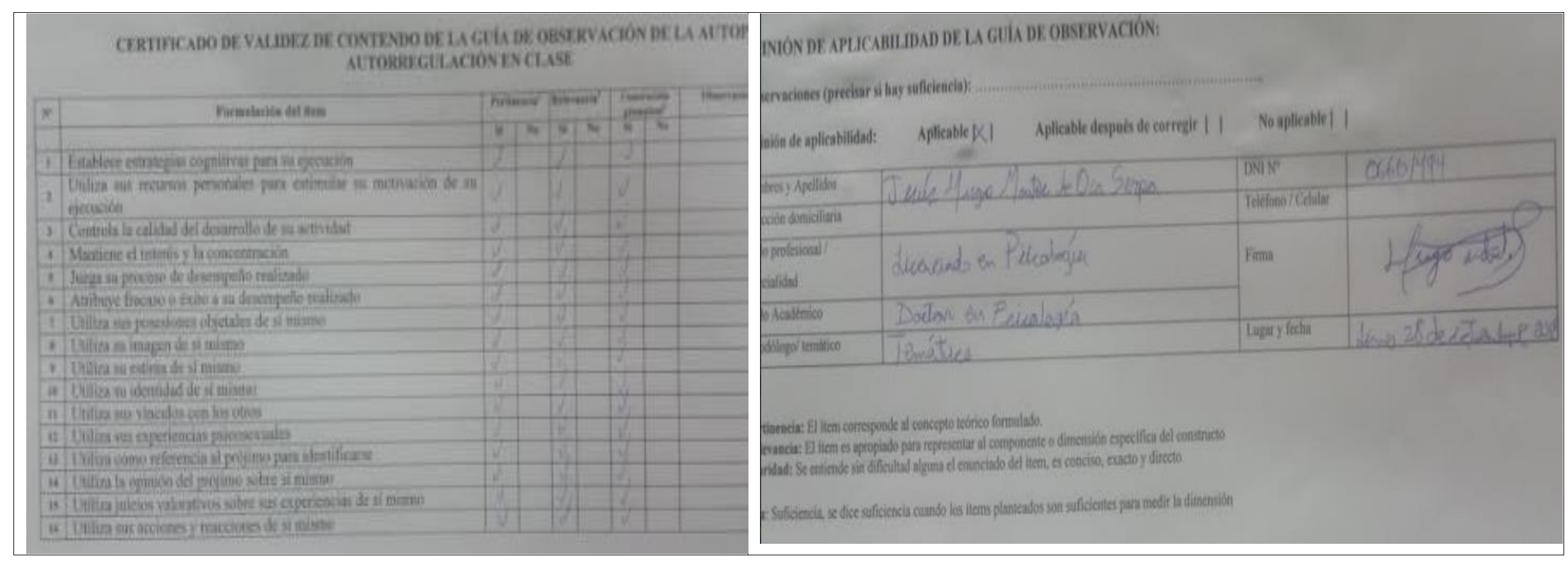

Anexo 4. Validación de la propuesta 


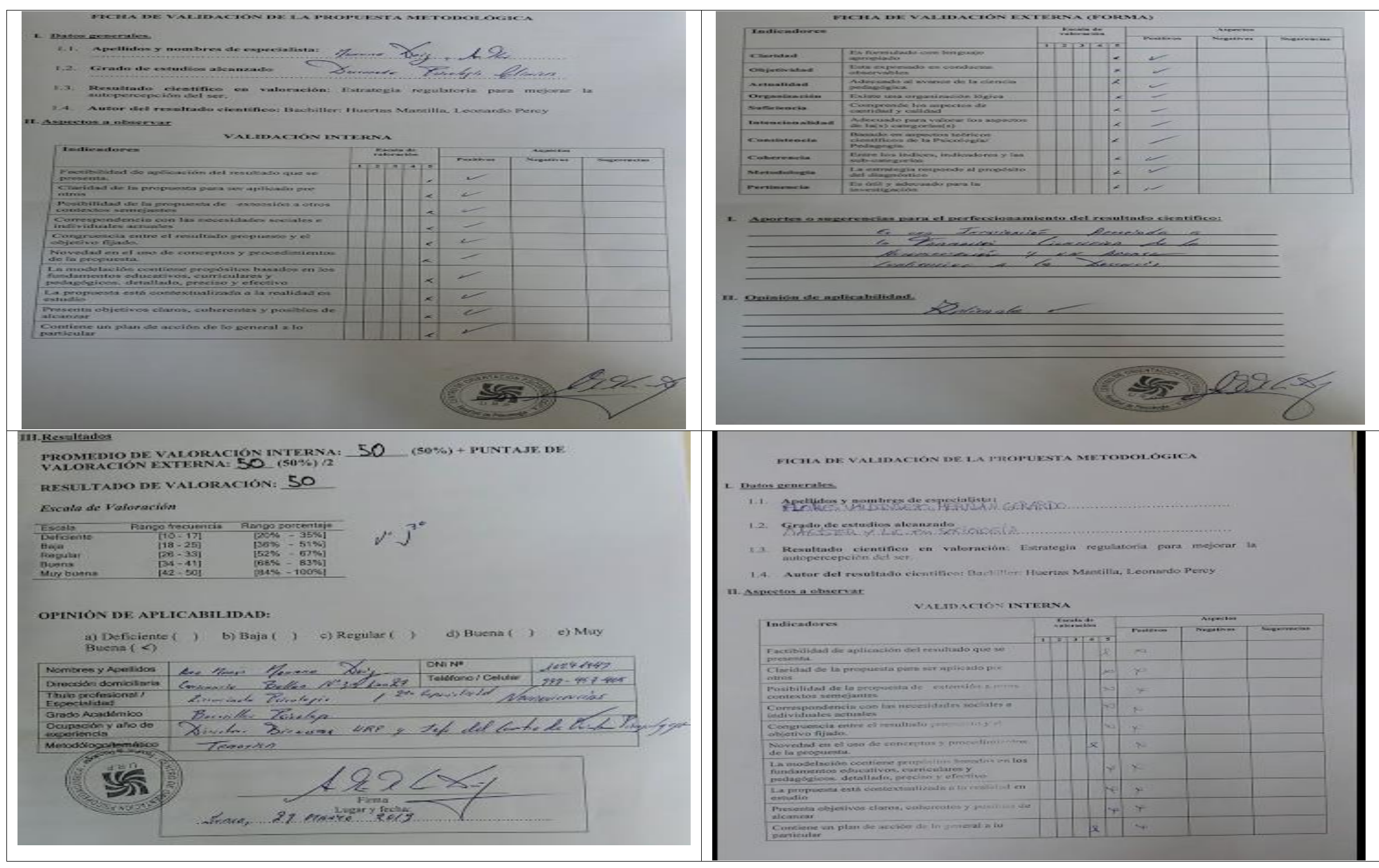



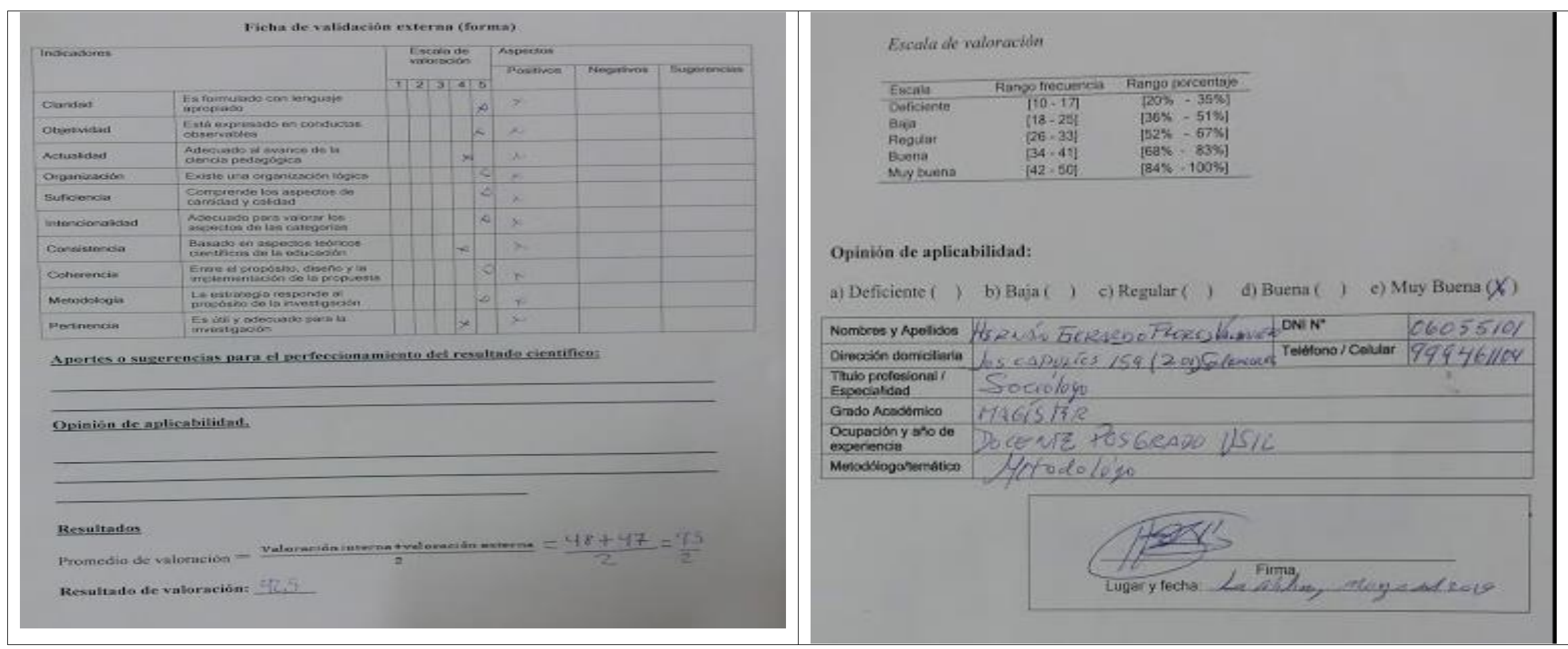

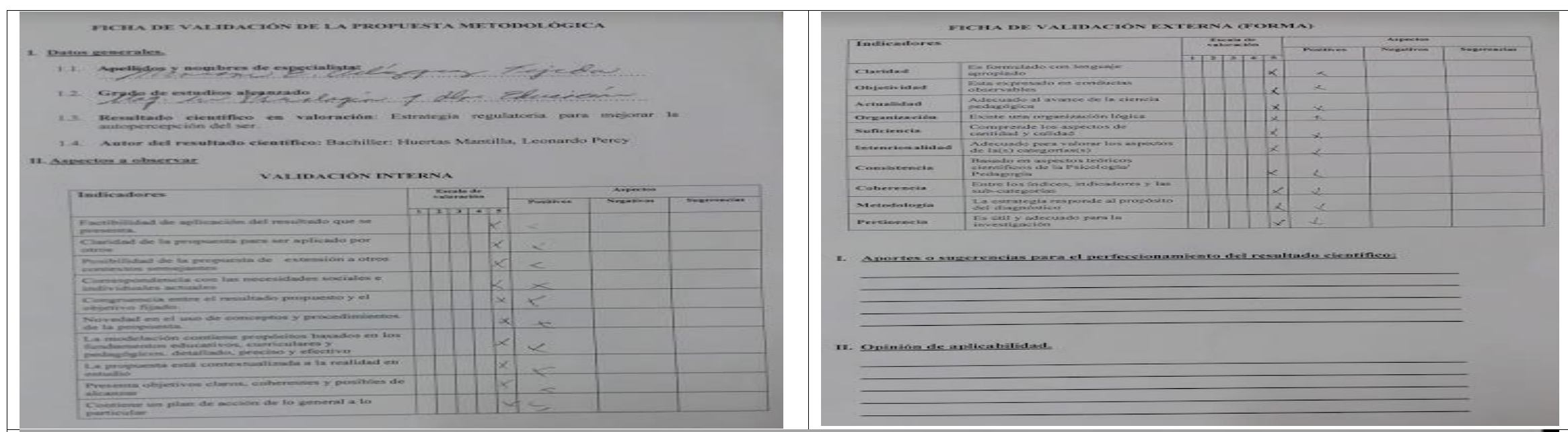

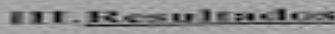

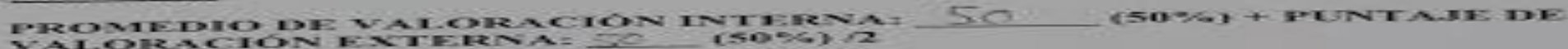

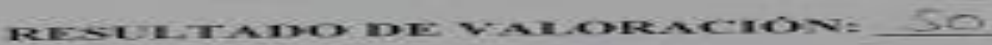

Escrene we vatmonction

Deasion

sein

gumpers

Herego tracuench

$\lim _{120}-281$

Rearga pereorztsos

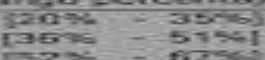

BPENTON DE ATIITCAREMMAD=

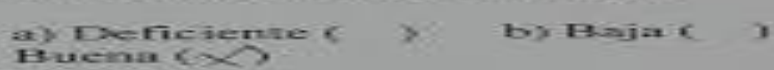

C) Feesulare,

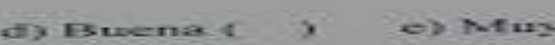

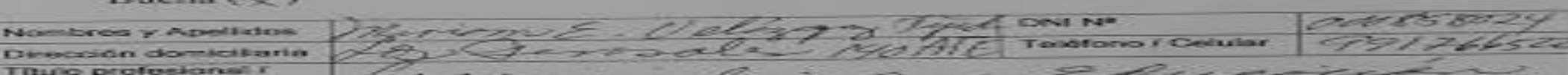

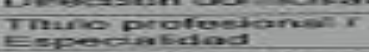

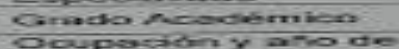

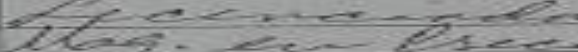

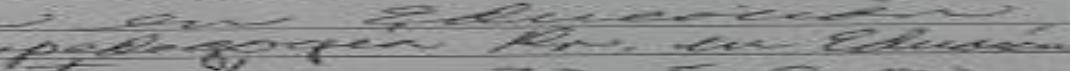

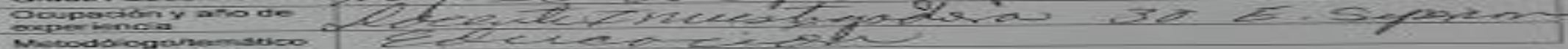

